\section{Journal of Home}

Economics

http://homeEcon.menofia.edu.eg

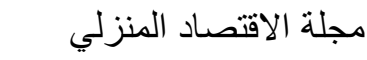

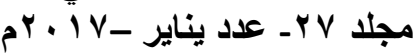

ISSN 1110-2578

أثر مستويات الدعم في التعلم الإكتروني المنتشر على تتمية التحصيل والأداء المهارى لتنفيذ البنطلون لدى طلاب الاقتصاد المنزلي

مدرس بقسم الاقتصلد المنزلي فكلية التربية الثناعية ـ جامعة المنوفية.

مستخلص البحث :

يهذف البحث الحالي إلي الكثف عن أثر مستويات الدعم في التعلم الإلكتروني

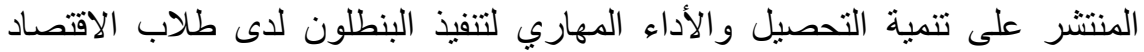

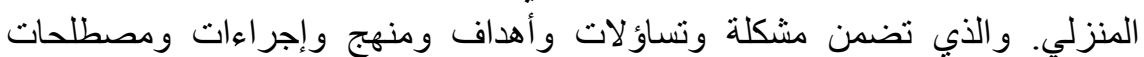

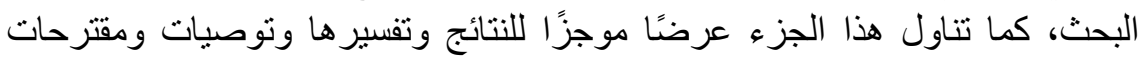

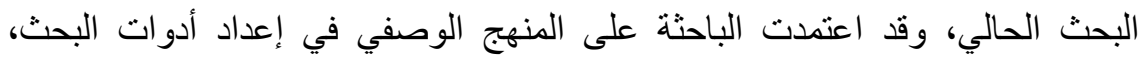

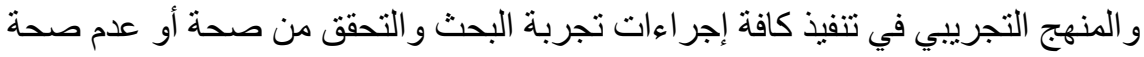

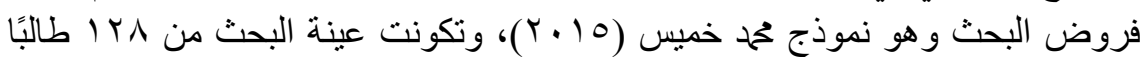

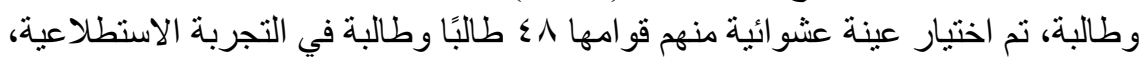

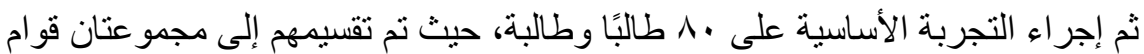

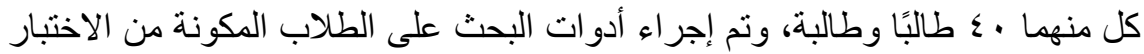

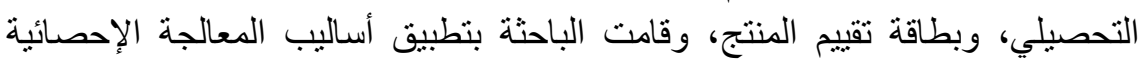

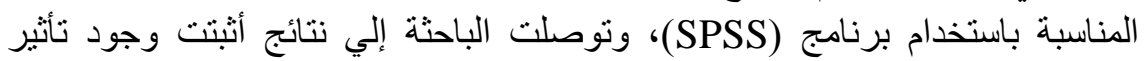

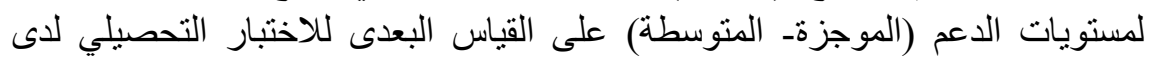

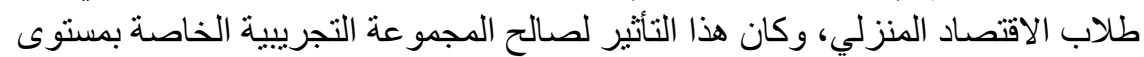

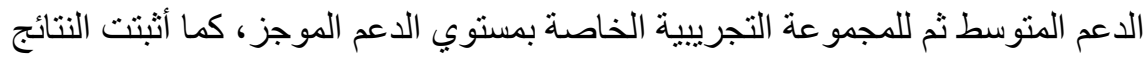

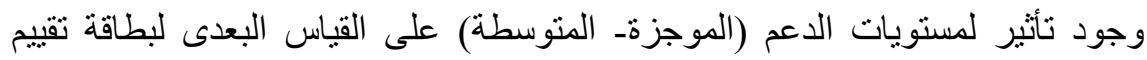

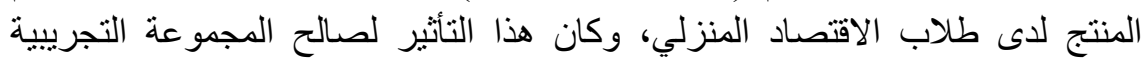

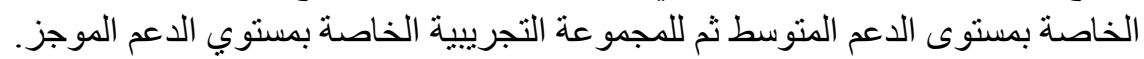

الكلمات الرئيسية: التعلم الإكتروني المنتشر، الدعم، التحصيل، بطاقة تقييم المنتج. 


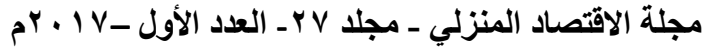

تكنولوجيا التعليم علم دائم وسريع التطور، حيث انتقل سريعًا من تكنولوجيا التعلم

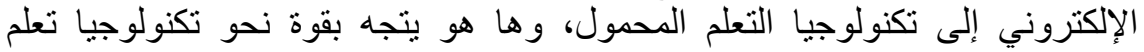

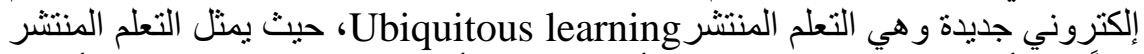

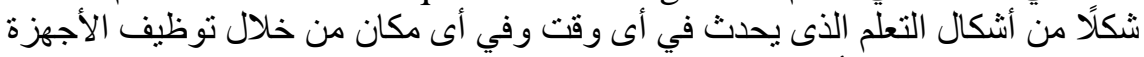
اللاسلكية و النقالة، كما أنه يعمل على نقل التى عملية التعلم خار ج بيئة التعلم التقليدية.

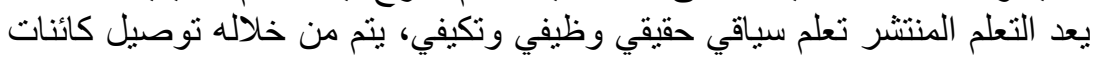

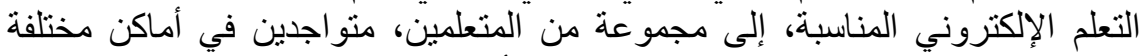

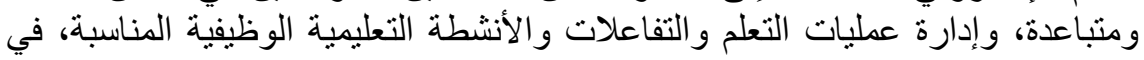

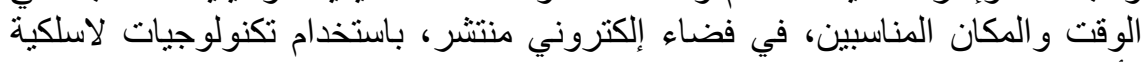

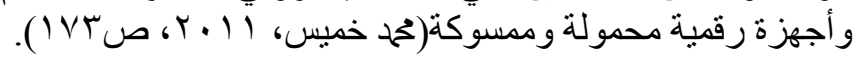

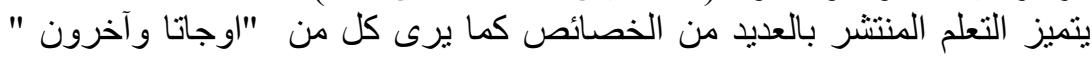
Ogata, Yin, Yano, 2004, p. 27; Yahya, et al., 2010, p. 121) )

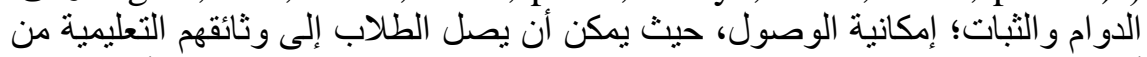

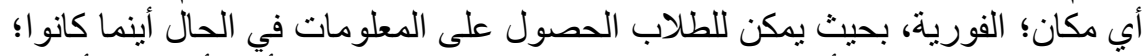

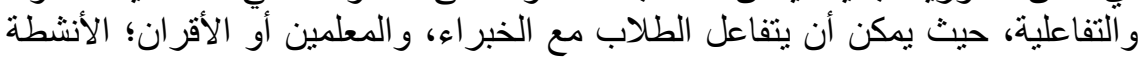

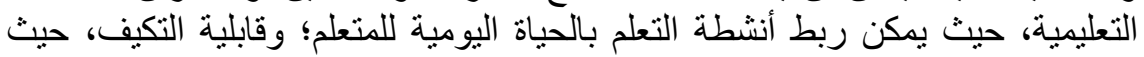

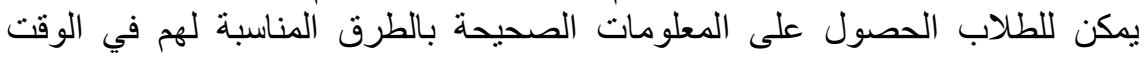

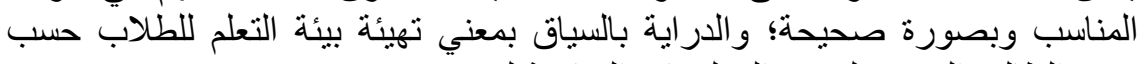

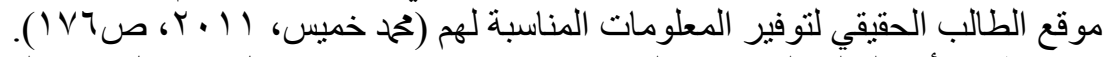

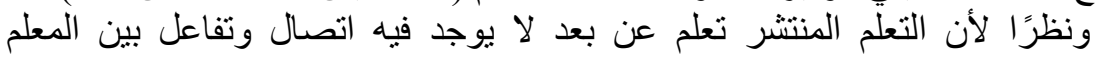

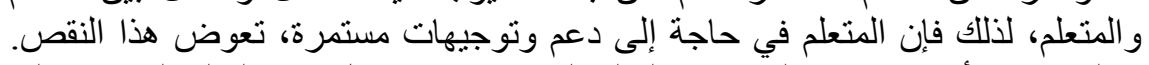

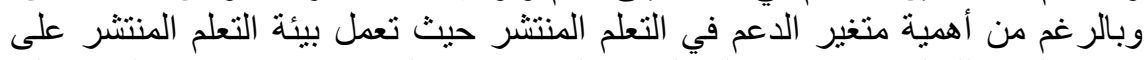

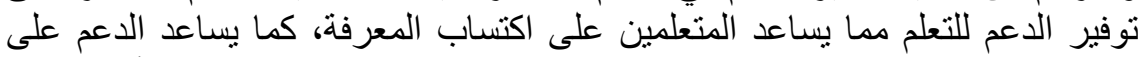

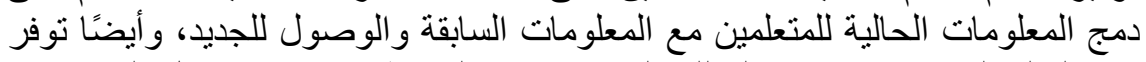

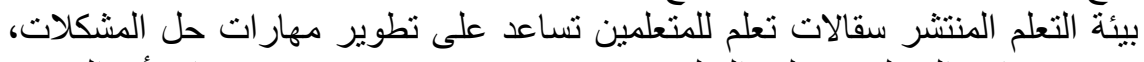

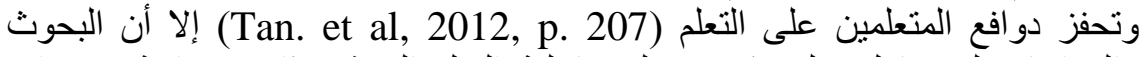

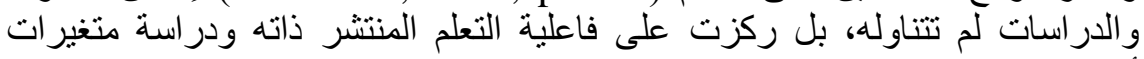

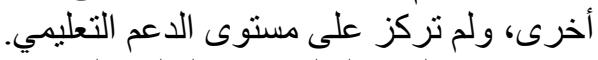

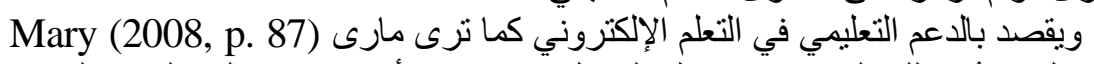

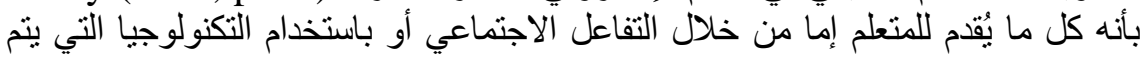

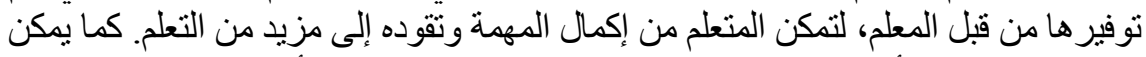

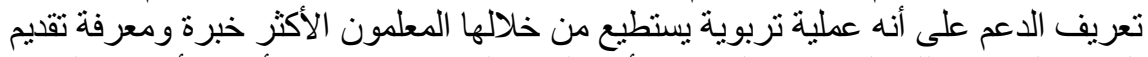

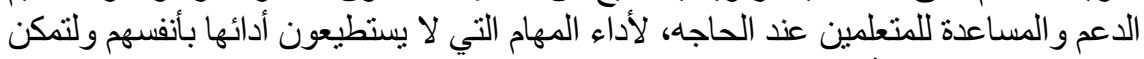

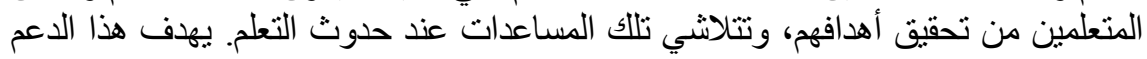
في التعلم المنتشر إلى مساعدة الطلاب في في إكمال المهمات التهات التعليمية.

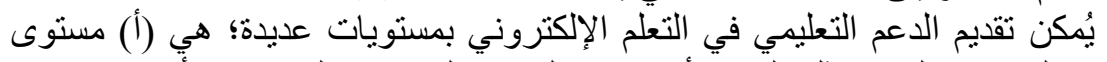

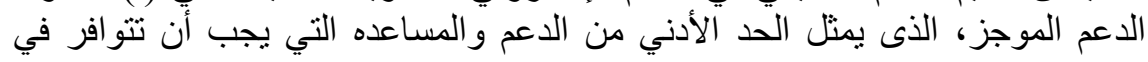




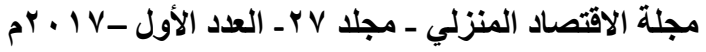

المحتوى الإلكتروني و لا يمكن الاستغناء عنها، وتتمثل في تقديم المساعدات و التوجيهات

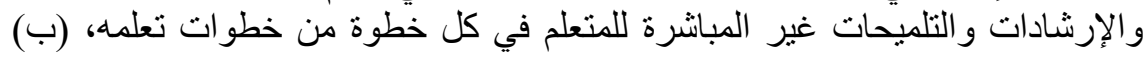

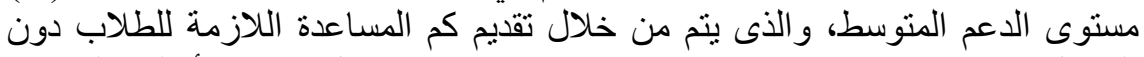
الاخول في تفصيلات واستبعاد ما هو غير ضرو ضوري، من خن خلال استخدام أمثلة وتلميحات

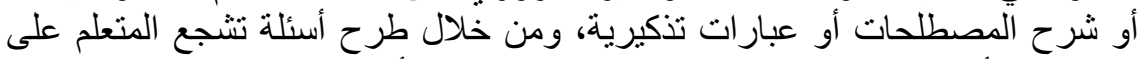

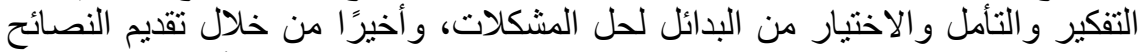

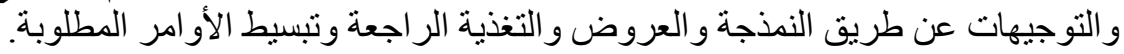

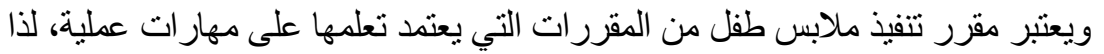

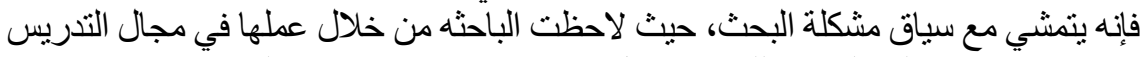

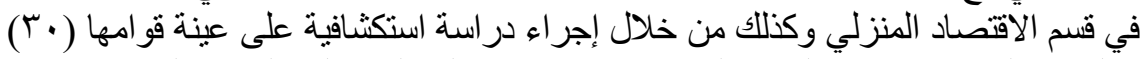

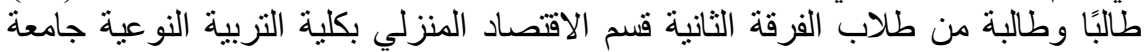

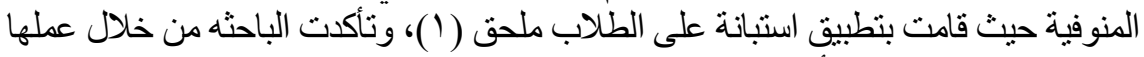

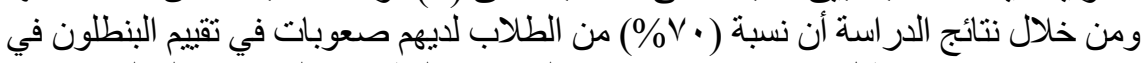

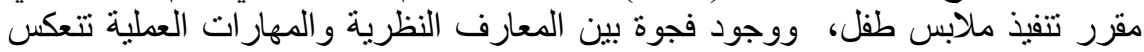

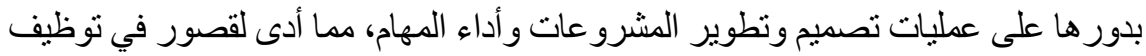
الطلاب لمهار ات تتفيذ البنطلون.

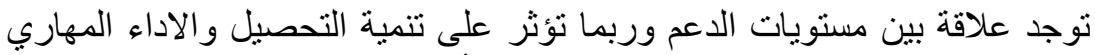

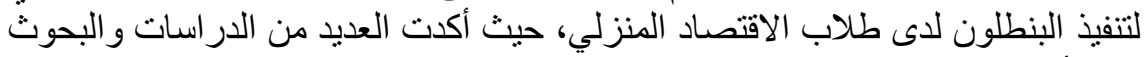

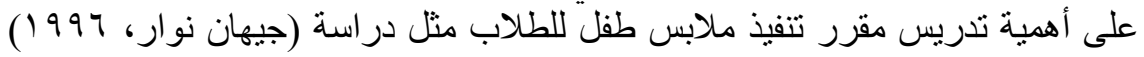

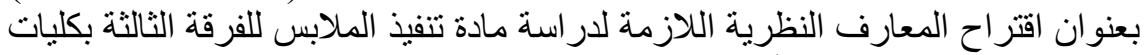

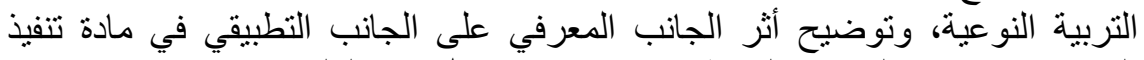

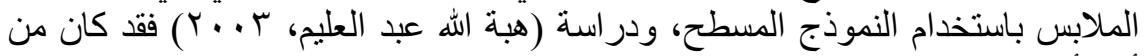

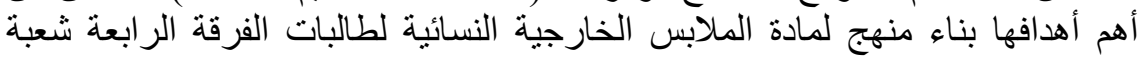

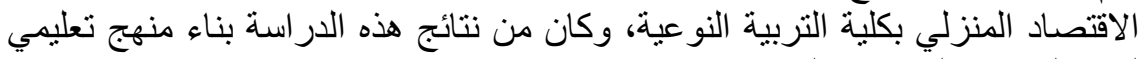
لماده الملابس الخار جية النسائية.

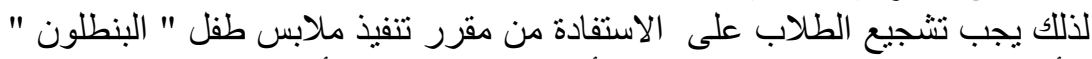

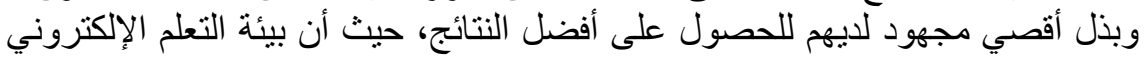

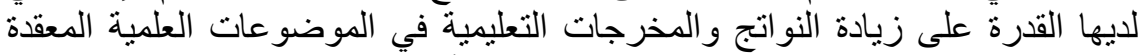

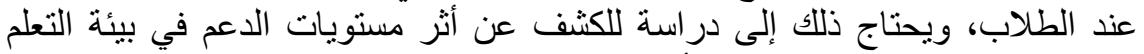

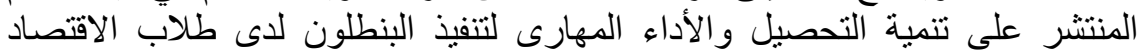

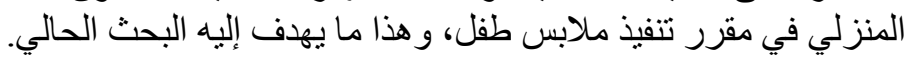

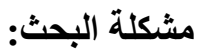

تمكنت الباحثه من بلورة مشكلة البحث، وتحديدها، وصياغتها من خلال المحاور

ا. 'أثبتت البحوث و الدر اسات فاعلية التعلم النقال و التعلم المنتشر مثل (Yang, 2006؛ Norman, Din \& Nordin, ؛Zaho \& Okamoto, 2011 ؛Sung, 2009

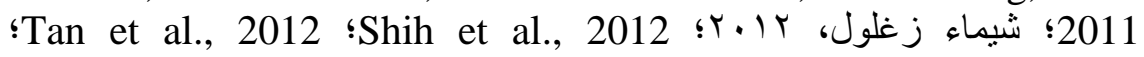




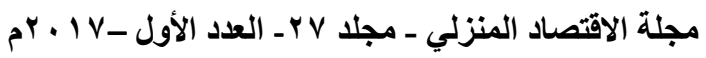

Chen, Chin, 2013 ؛ Chang\& Lui, 2013

r. أثنتت البحوث والدراسات فاعلية الدعم في مساعدة الطلاب في إكمال المهمات

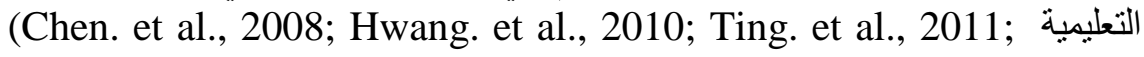
Phumeechanya \& Wannapiroon,2013; Jeong et al., 2014; Phumeechanya \& Wannapiroon, 2015)

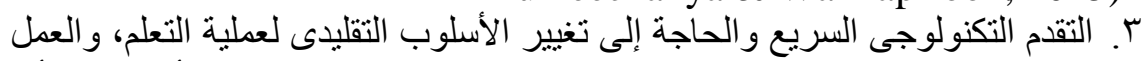

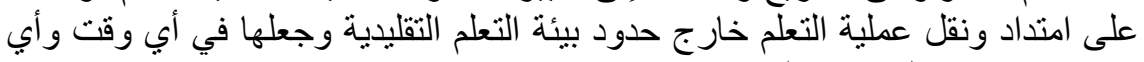
مكان وباستخدام المصادر المناسبة.

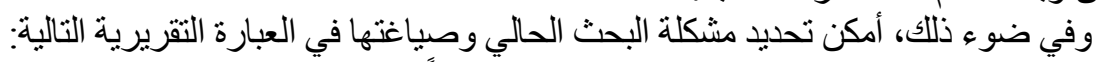

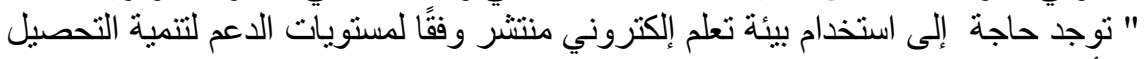

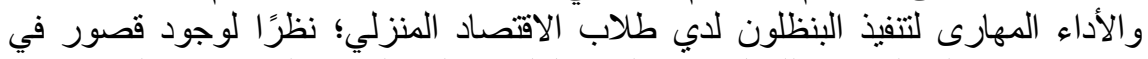

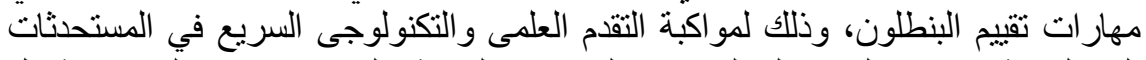

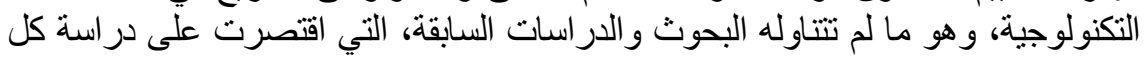
متغير على حده، دون تحديد العلاقة بين هذه المتغيرات.

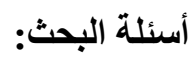 أسلى ضوء صياغة البحثة المشكلة تم صياغة الأسئلة التالية:}

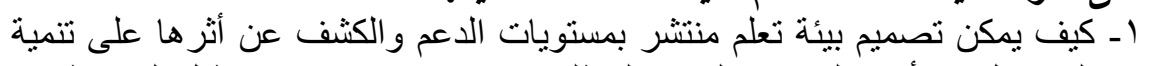

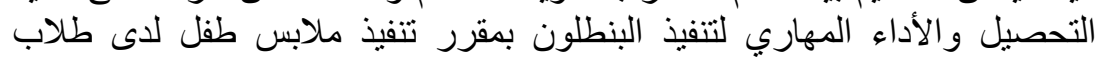

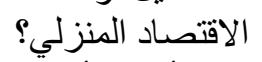
r ـ ما التأثير الأساسي لمستويات الدعم (الموجزة - المتوسطة) في التعلم الإلكتروني

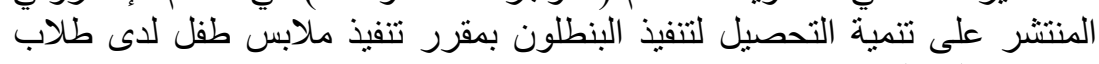

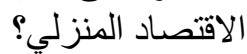

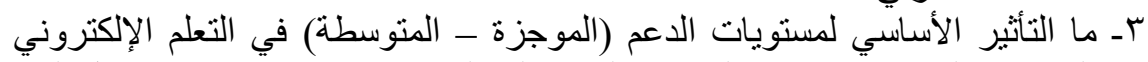

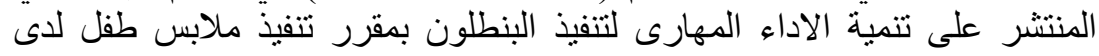
طلاب الاقتصاد المنزلي؟ الإداء

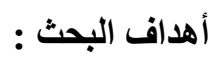

\section{هدف البحث الحالي للتوصل إلى:}

1-بيئة التعلم المنتشر وفقًا لمستويات الدعم (الموجزة- المتوسطة ).

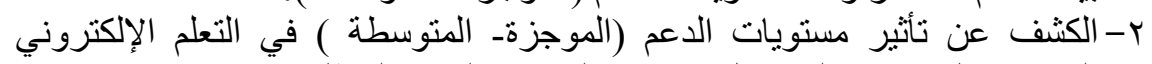

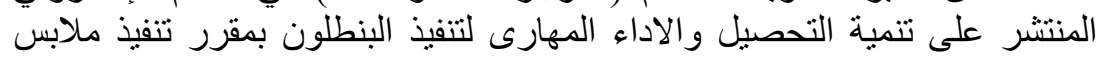
طفل لدى طلاب الاقتصاد المنزلي. ץ-رفع مهار ات تنفيذ البنطلون لدى ألطلاب في ظل التقدم العلمى و التكنولوجى. 


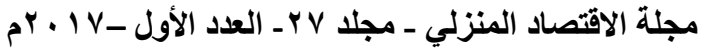

أهمية البحث:

\section{يفيد البحث الحالي فيما يلى :}

ا. تزويد مجال الاقتصاد المنزلي بكيفية تطوير بيئة تعلم إلكتروني منتشر بمستويات

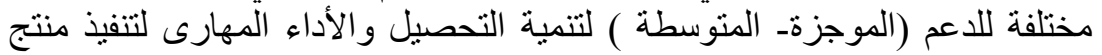

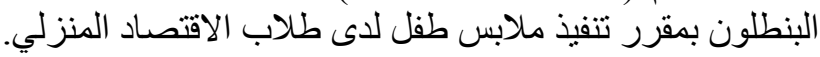

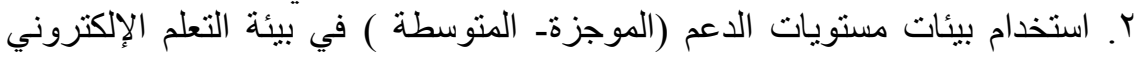

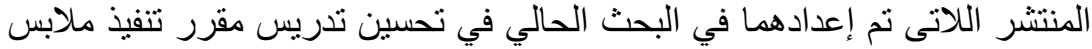

طفل.

ب. توجيه أنظار القائمين على تدريب طلاب الاقتصاد المنزلي لاستخدام تكنولوجيا

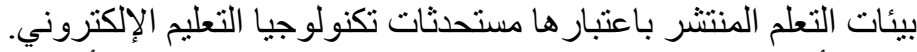
ع. توجيه أنظار القائمين بالتدريس في قسم الاقتصاد المنزلي إلى الى أهمية استخدام التعلم المنتشر في العملية التعليمية.

اعتمدت الباحثة على المنهج الوصفي في إعداد أدوات البحث، والمنه المنهج التجريبي في

\section{منهرج البحث: أبن:}

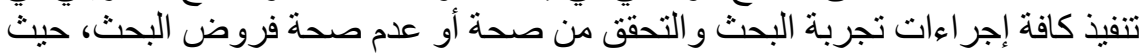

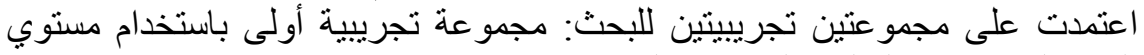

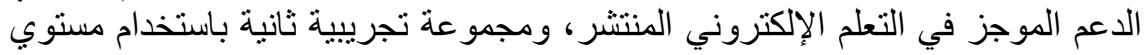

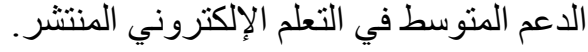

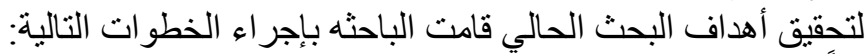

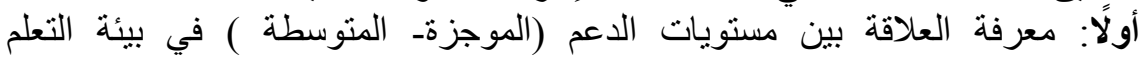

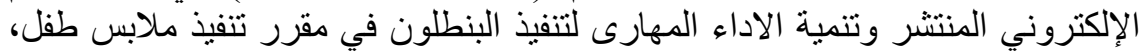

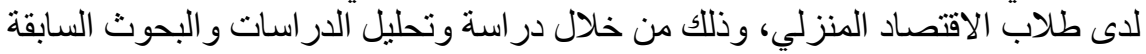

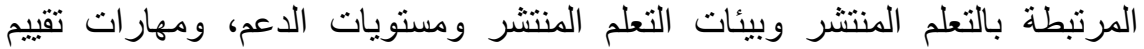
البنطلون، والبحوث التي تجمع بينهم و البحوث التي تتعلق بالتصميم التعليمي لمستويات التئن الدانم. ثانيًا: إثتقاق معايير التصميم التعليمي لبيئة التعلم المنتشر والمحتوى التعليمي وفقًا

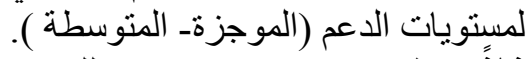

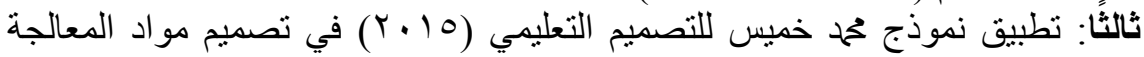

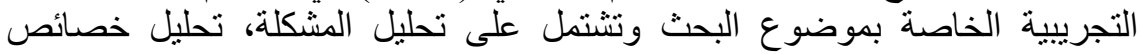

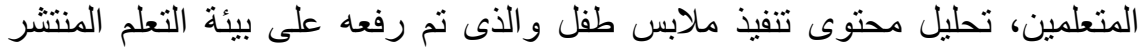

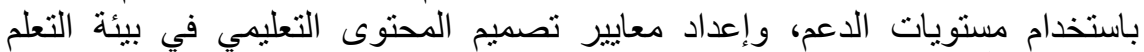

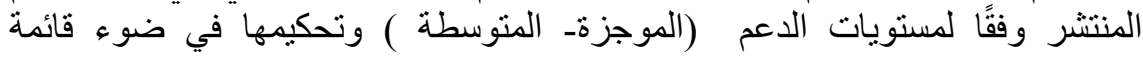
المعابير.

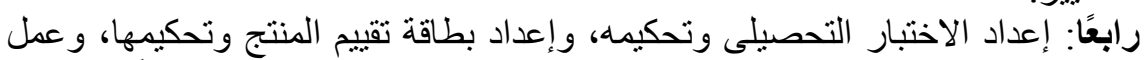

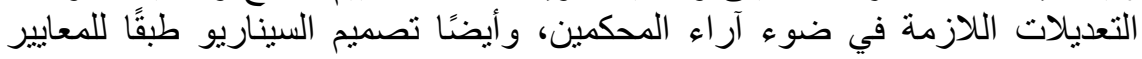




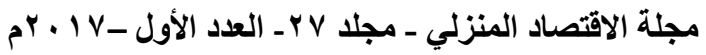

التصميمية التي قامت الباحثه بإعدادها بناءً على الدراسات و الأدبيات السابقة وتحكيمها

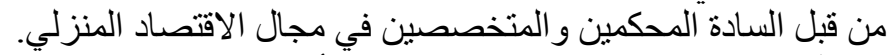

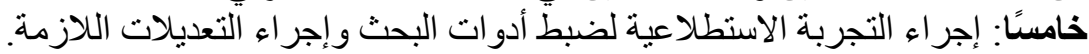

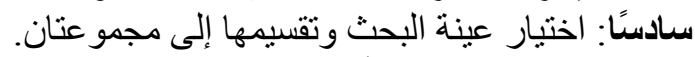

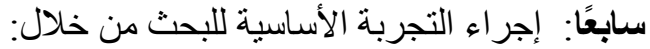

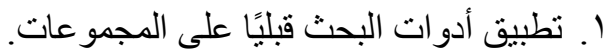

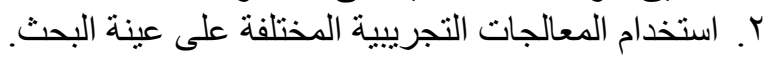

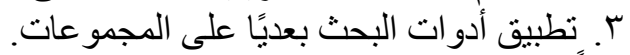

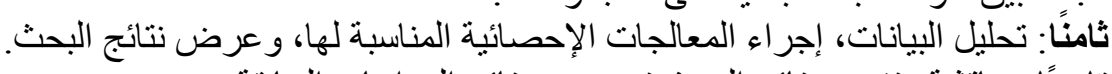

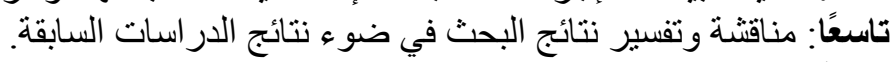
عاشرًا: تقديم التوصيات و والمقترحات.

\section{مصطات الدمات البحث:}

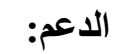

عملية تربوية يستطيع من خلالها المعلمون الأكثر خبرة ومعرفة تقديم الدعم و المساعدة

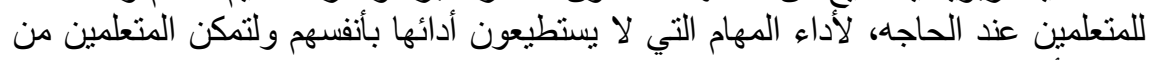

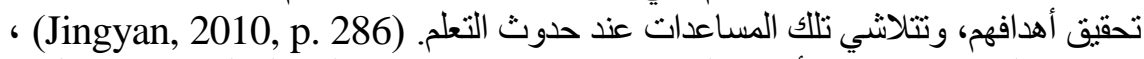

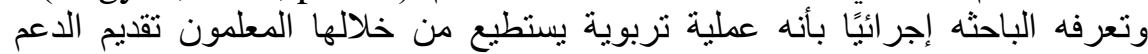

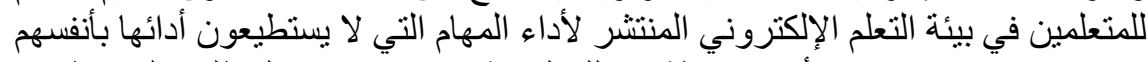

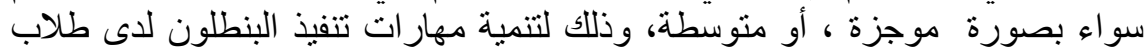

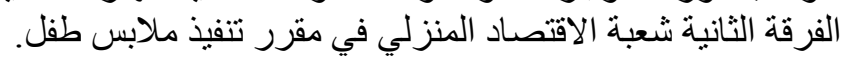

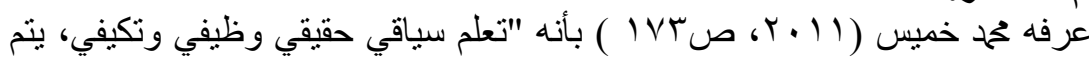
التعلم المنتشر: التخد:

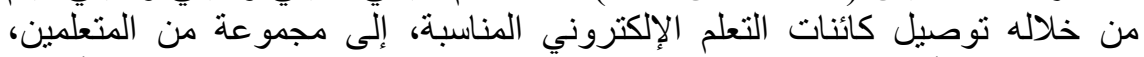

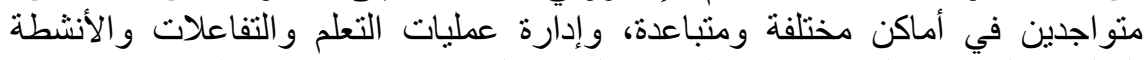

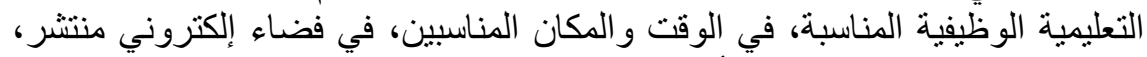

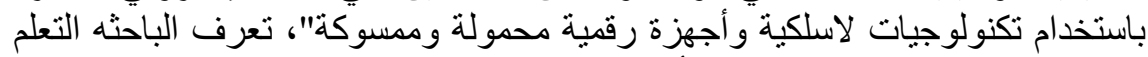

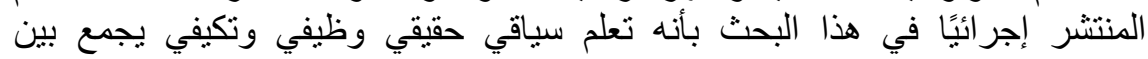

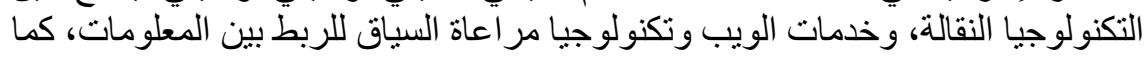

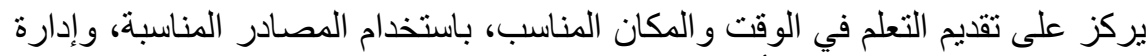
عمليات التعلم و التفاعلات و الأنشطة التعليمية الوظيفية المناسبة التئية

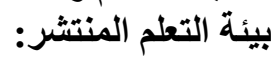

تمثل بيئة التعلم المنتشر أية مواقف تعليمية يمكن للمتعلم أن ينغمس فيها، فالتعلم

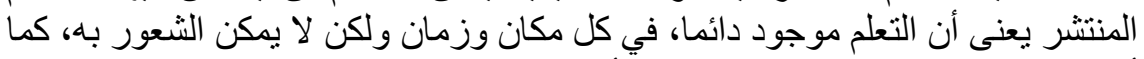

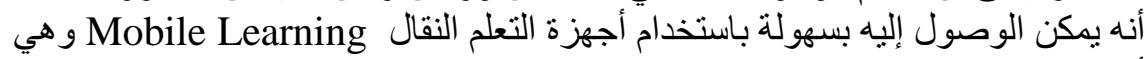

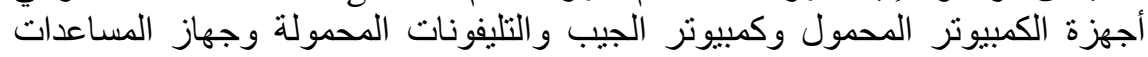

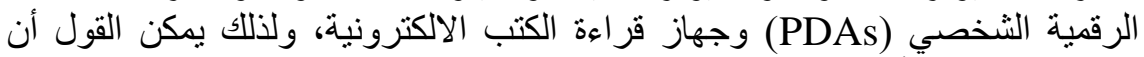

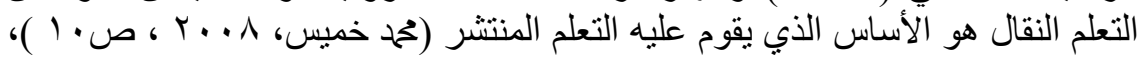




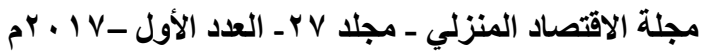

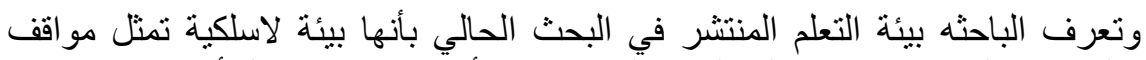

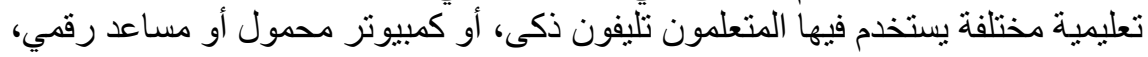

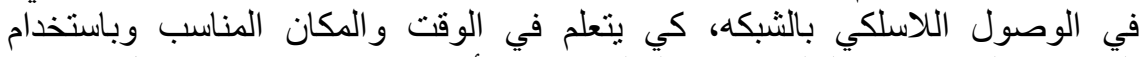

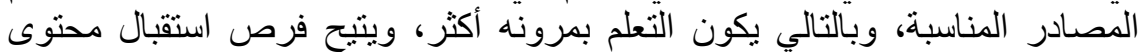

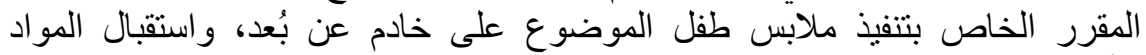

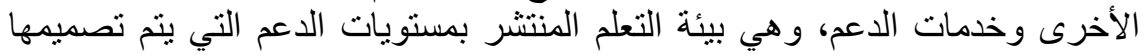

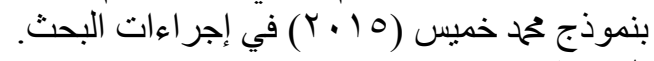

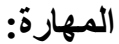

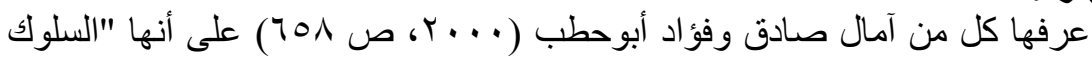

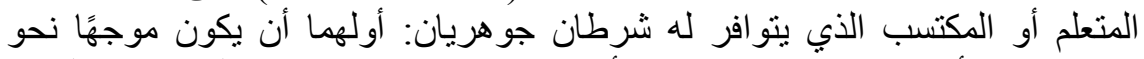

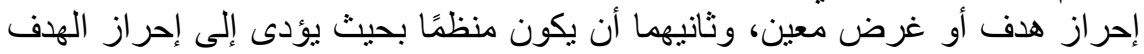

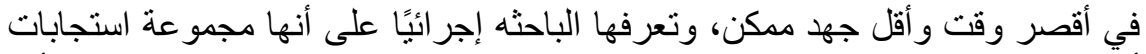

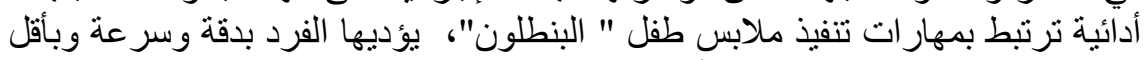

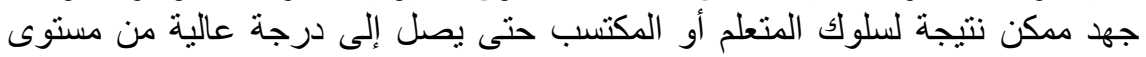

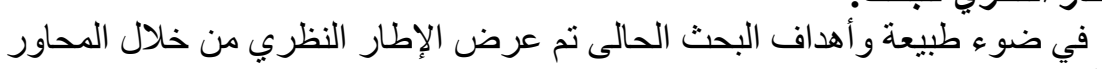

المحور الاول: التعلم الإكتروني المنتشر:

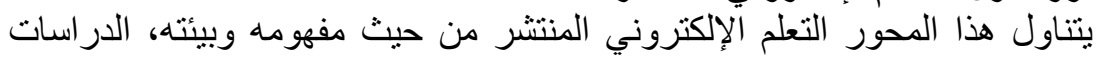

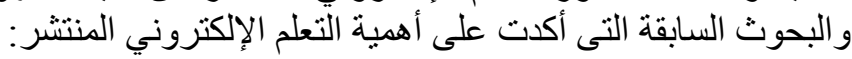

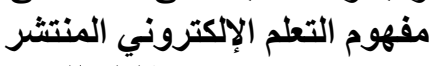

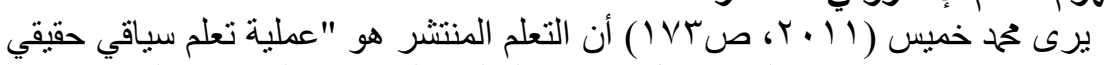

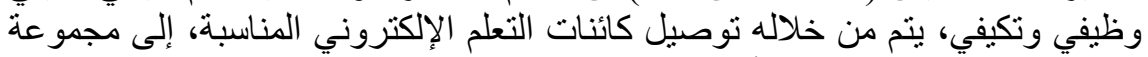

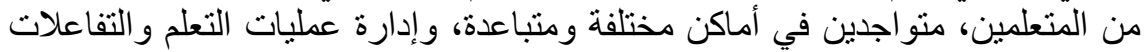

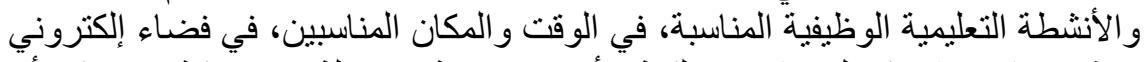

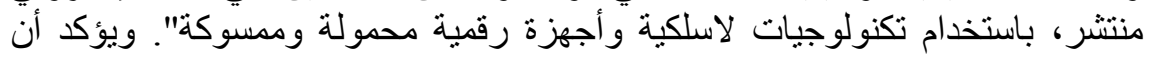

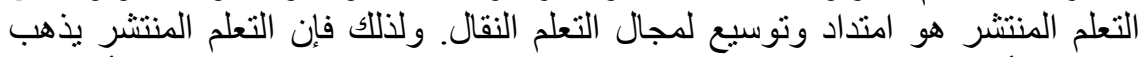

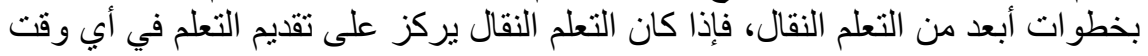

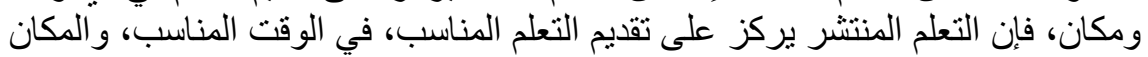

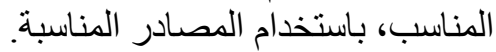
بيئة التعلم الإلكتروني المنتشرام المينر

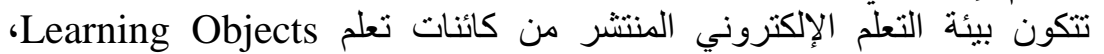

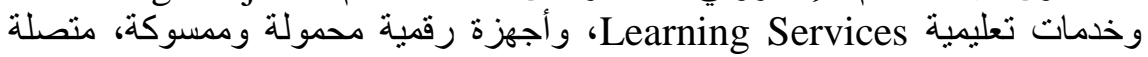

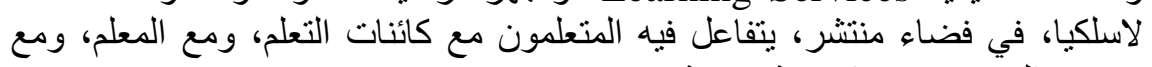

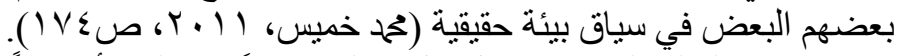

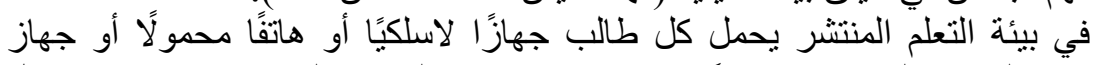
المساعد الرقمي الثخصي مزودًا بسماعات، ثم يقوم الفضاء المنتشر بتحديد مكان كل 


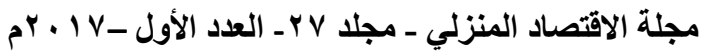

طالب عن طريق المحسات، فعندما يصل الطالب إلى الكائن، تتصل المحسات اللاسلكية

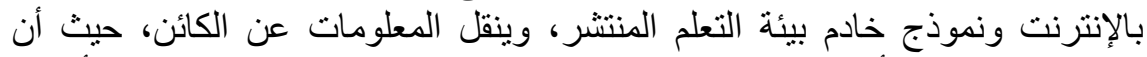

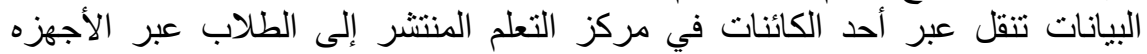

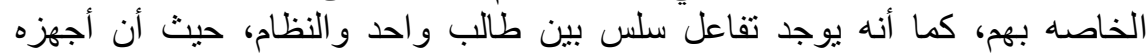

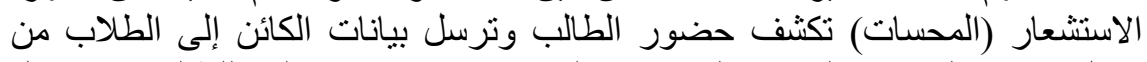

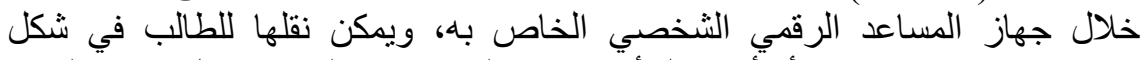

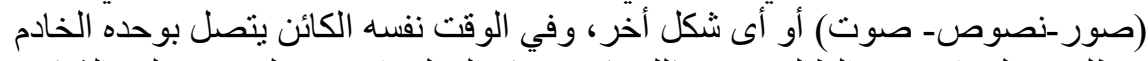

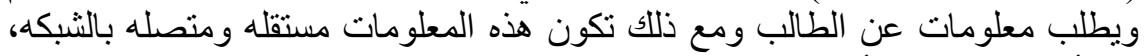

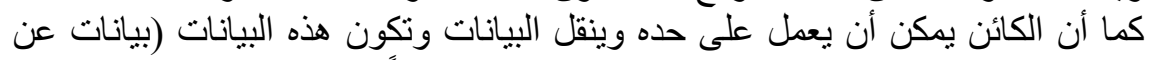

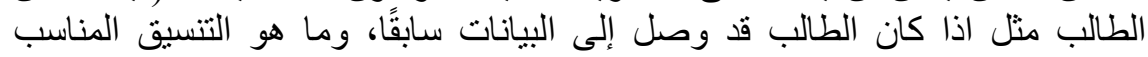

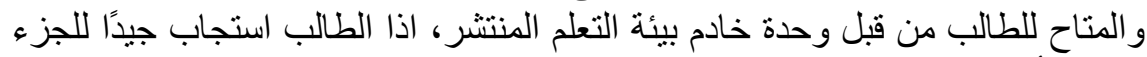

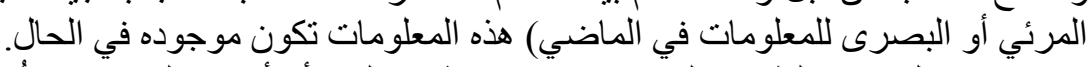

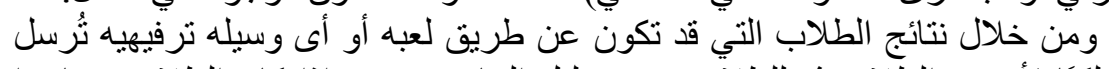

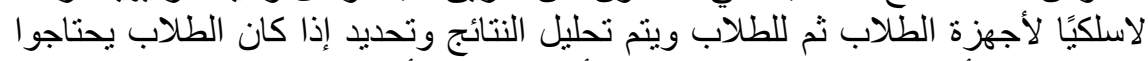

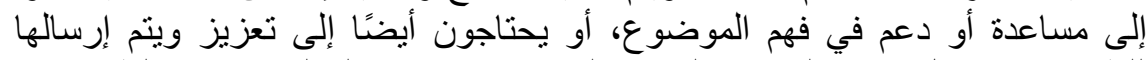

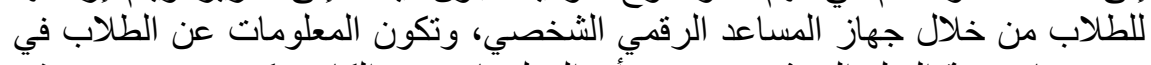

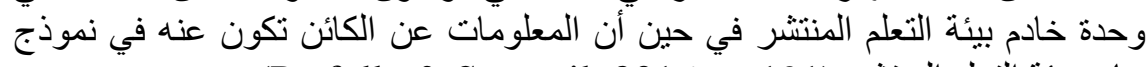
خادم بيئة التعلم المنتشر (Prafulla \& Swapnil, 2016, p. 191)

الاراسات والبحوث التى أكدت على أهمية التعلم الإكتروني المنتشر:

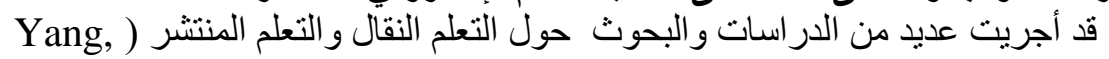
Norman, Din \& ؛Zaho \& Okamoto, 2011 ؛Sung, 2009 2006

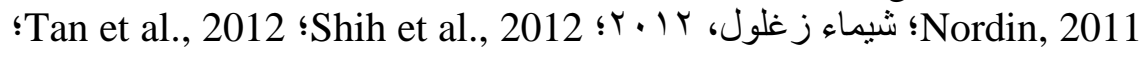
؛ Wen et al., 2013 Chen, Chin, 2013 Chang\& Lui, 2013 10

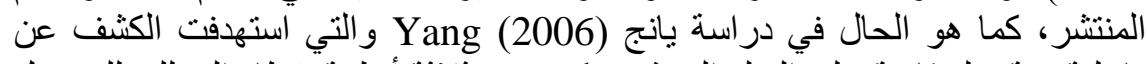

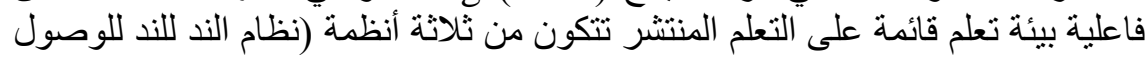

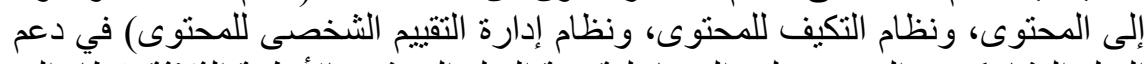

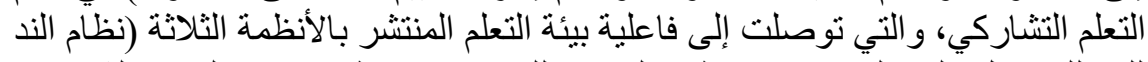

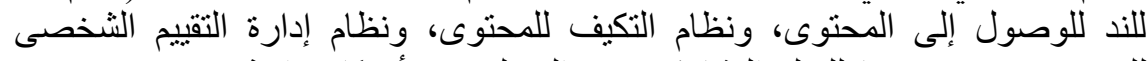

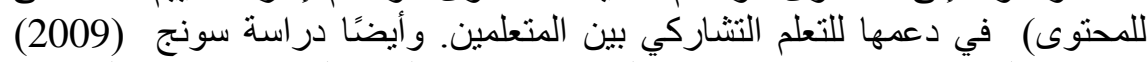

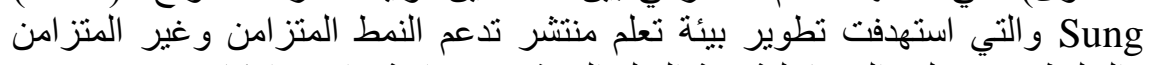

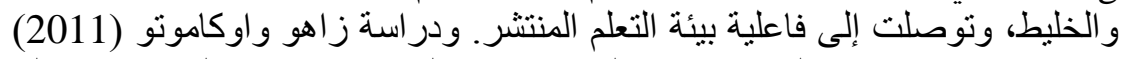
Zaho \& Okamoto

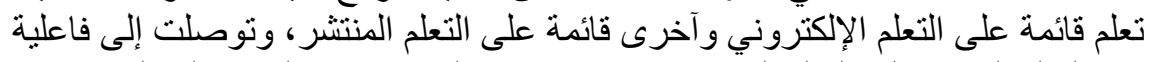

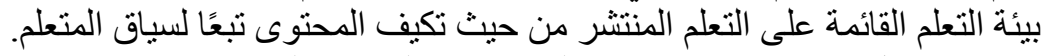

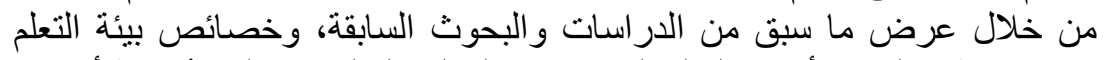
المنتشر، لاحظت الباحثة أهمية التعلم المنتشر في العملية التعليمية، ولكن يُّلاحظ أن أن هذه 


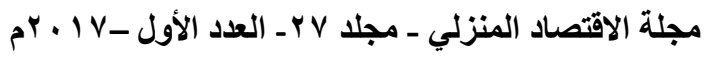

الدر اسات والبحوث السابقة قد اقتصرت على تصميم بيئات تعلم منتشر لتنمية التحصيل

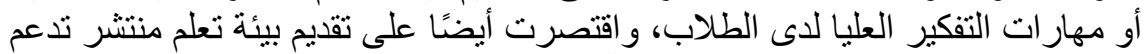

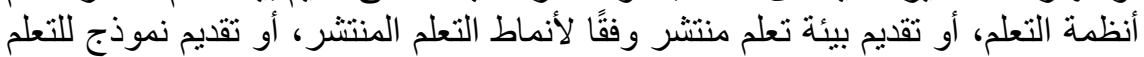
المنتشر، دون التعرض إلى المشكلات التي تواجه الطلاب أثناء العمل في بيئة التعلم

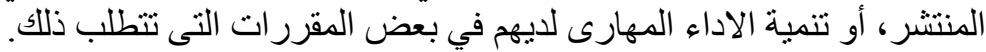

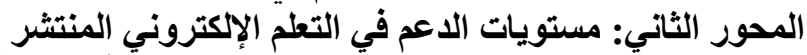

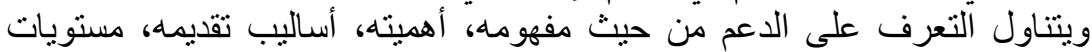

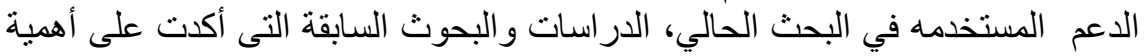
الدعم في العملية التعليمية: مفهوم الأدم التعليمى التمي

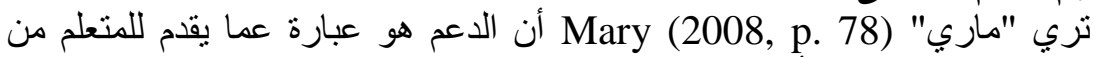

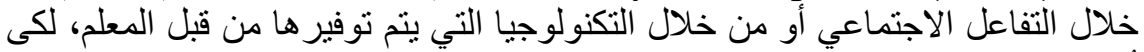

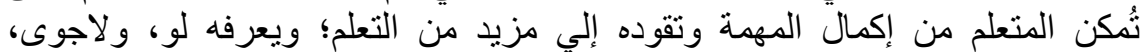

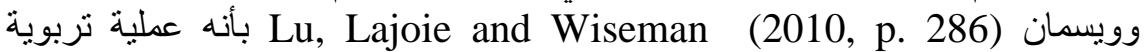
يستطيع من خلالها المعلمون الأكثر دراية وخبرة تقديم المساعدة للمتعلمين عند الحاجة المانة إلى أداء المهام التي لا يستطيعون أدائها بأنفسهم ولتمكين التهين المتعلمين من تحقيق أهدافهم وتتلاشي تلك المساء المباعدات عند حدوث عملية التعلم.

يُعد الدعم عنصرًا ألساسيًا في التعلم الإلكتروني؛ حيث أنه ذو أهية كبيره في العملية

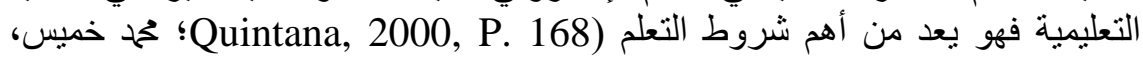

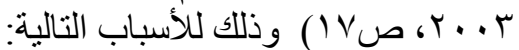

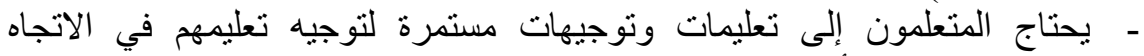

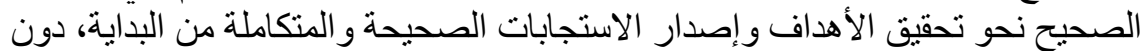
ضياع الوقت في المحاو لات و الأخطاء الفاثلة. - التوجيه البشرى الذي يقدمه المعلم أفضل من التوجيه الآلي في تحقيق التعلم المطلوب.

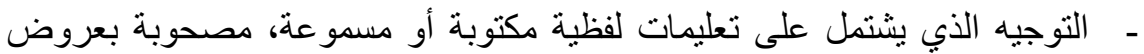

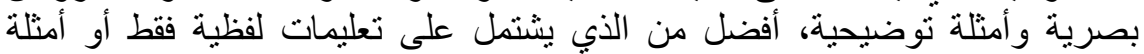

توضيحية فقط. - المساعدة والتوجيه تصاحب عمليات التدريب و الممارسة والتطبيق، ويزداد كم المساعدات و التدريبات في بداية التدريب وتبدأ في الاختفاء التدريجي حتى تهي تنعدم في التي

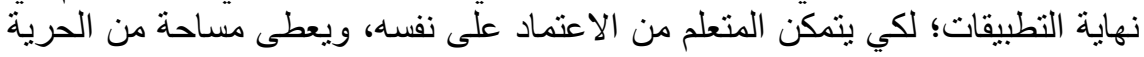

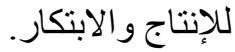

أساليب تقديم الاعم التعليمى في بيئة التعلم المنتشر تتنوع وتختلف أساليب تقديم الدعم التعليمى في بيئة التعلم المنتنر كما ذكر كلا من (Grosch \& Gidion, 2012; Passerine, 2007) 


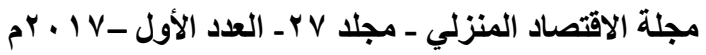

ا ـ تقديم الدعم من خلال الوسائط و المثيرات الرقمية التعليمية المختلفة، مثل الصوت

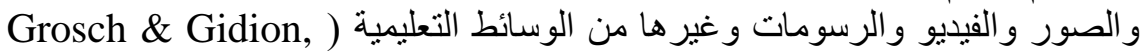

r- تقديم الدعم من خلال تزويد المتعلم ببر امج وتطبيقات تفاعليه متكامله عبر بيئة التعلم

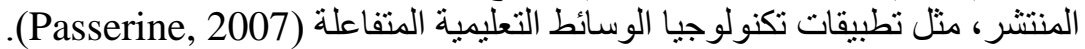

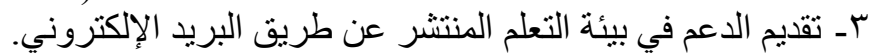

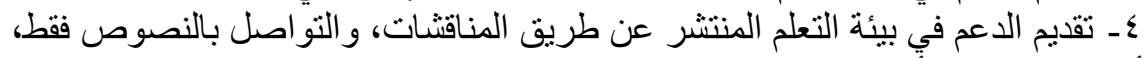

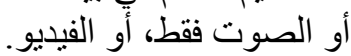
0ـ تستخدم المناقتشات وحلقات البحث التعاونية الإلكترونية عبر بيئة التعلم المنتشر، في لفي

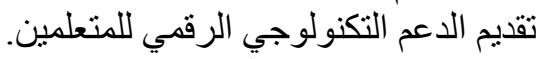

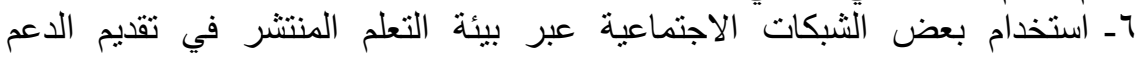

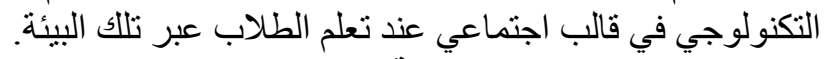

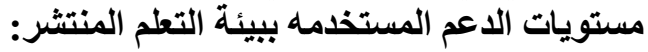

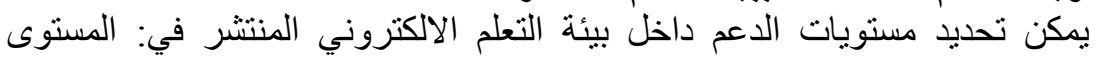

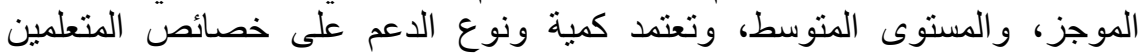

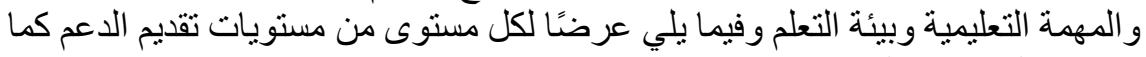
جاءً في الدر اسات السابقة:

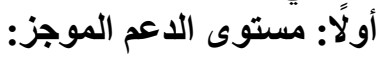

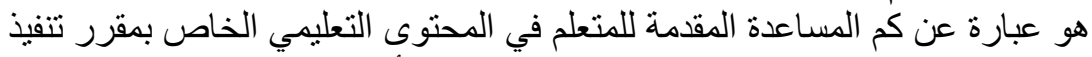

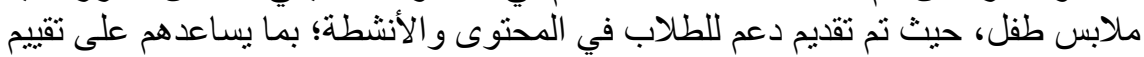

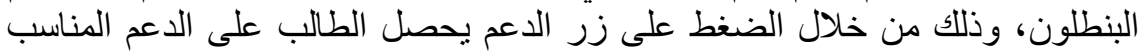

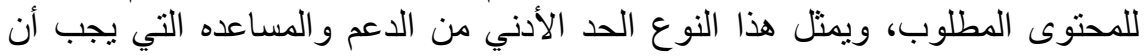

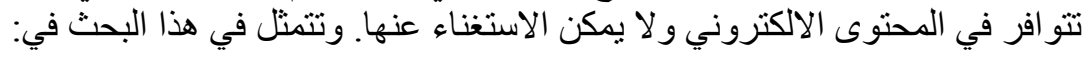

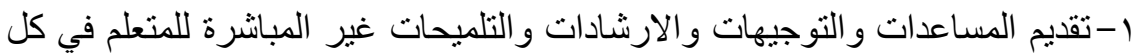

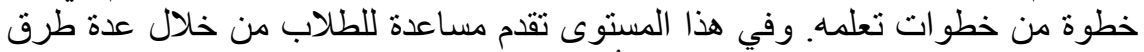

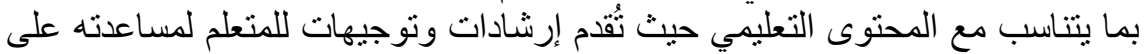

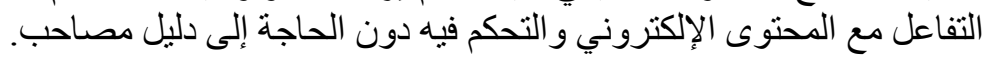

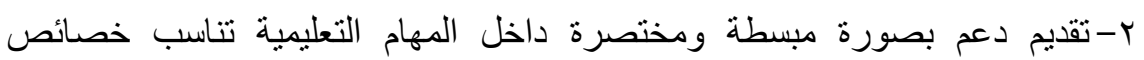

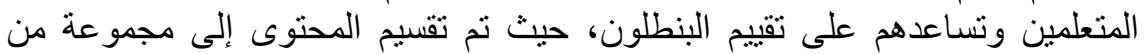
الأهداف التعليمية التي ينبغي أن يصل الطئ الطالب إليها في نهاية المقرر. ب-تقديم كم معلومات مناسبة ودعم مناسب للطلاب بحيث تساعدهم على فهم المهمات التعليمبة.

\section{ثانيًا: مستوى الدعم المتوسط:}

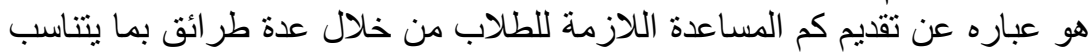

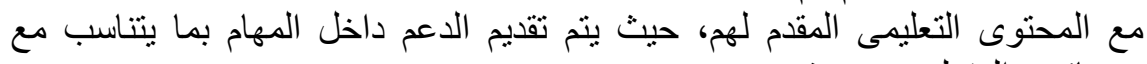
خصائص المتعلمين. بحيث: المئئ 


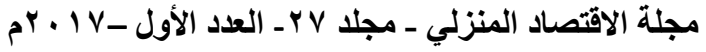

ا- بركز على المهارات المعقدة والصعبة دون الدخول في تفصيلات واستبعاد ماهو

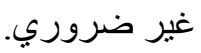

r- يُقدم من خلال استخدام أمثلة وتلميحات أو شرح المصطلحات أو عبار ات تذكيرية.

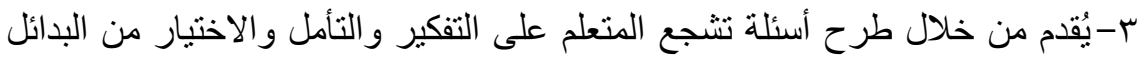

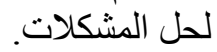

ع-يُقدم من خلال تقديم النصائح و التوجيهات عن طريق النمذجة و العروض و التغذية الراجعة وتبسيط الأوامر المطلوبة.

الاراسات والبحوث السابقة التى أكلت على أهمية الاعم في العملية التعليمية: أكدت عديد من الدراسات والبحوث على أهمية استخدام الدعم في بيئة التعلم المنتشر العبة

(Chen. et al., 2008; Hwang. et al., 2010; Ting. et al., 2011; Phumeechanya \& Wannapiroon,2013; Jeong et al., 2014; Phumeechanya \& Wannapiroon, 2015)

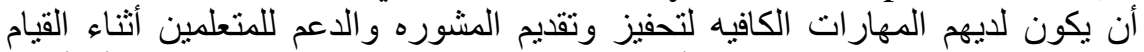

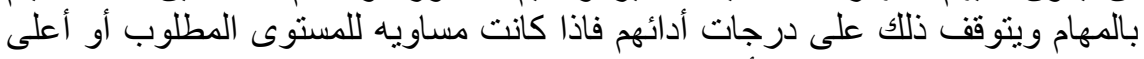

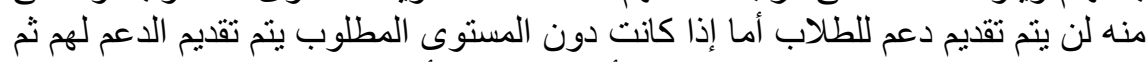

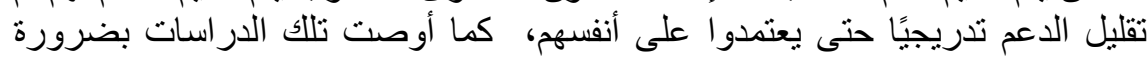

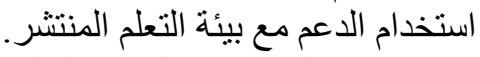

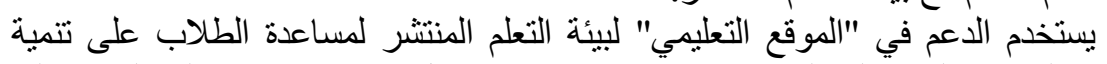

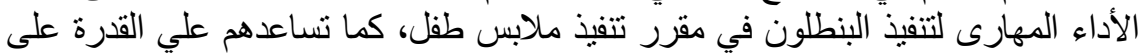

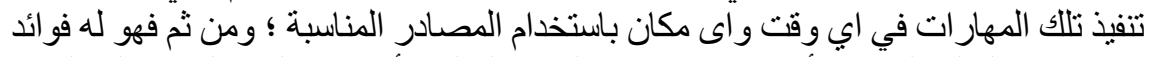

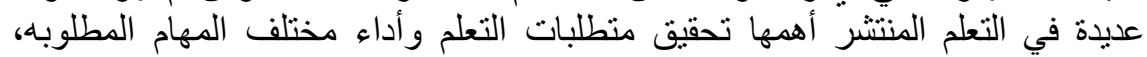

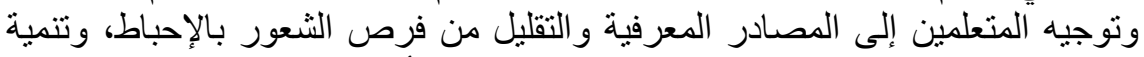

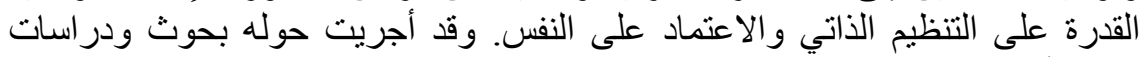

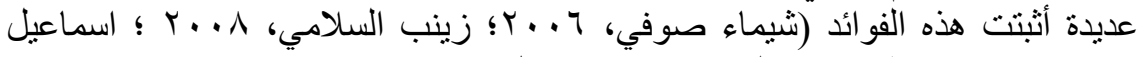

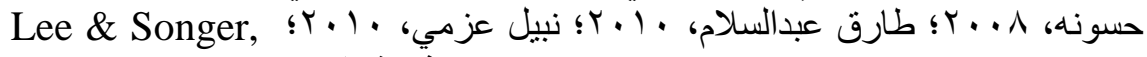

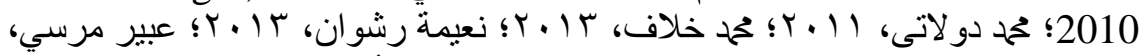

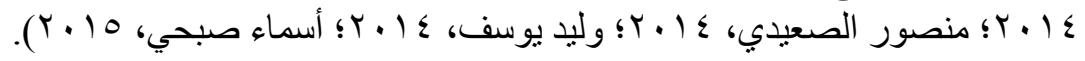

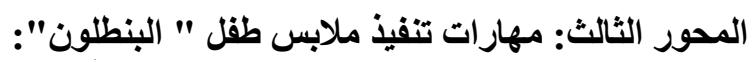

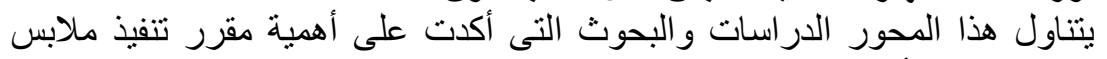

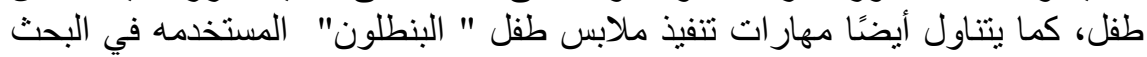

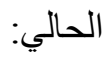

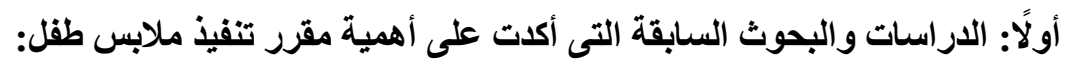

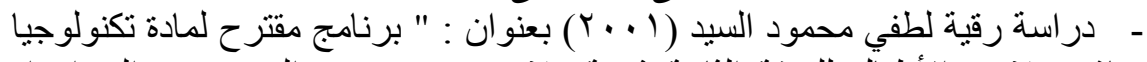

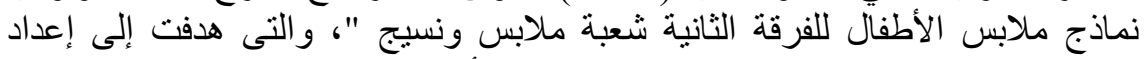

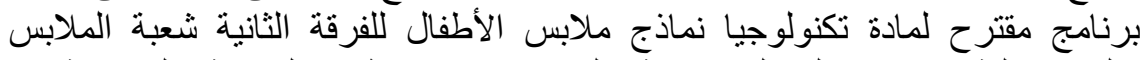

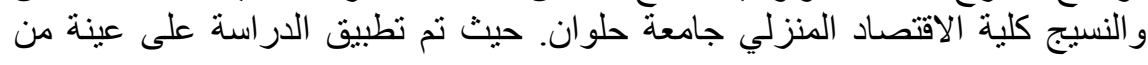




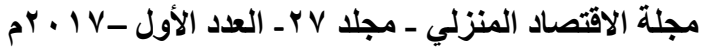

طلاب الفرقة الثانية شعبة الملابس والنسيج بكلية الاقتصاد المنزلي ، جامعة حلوان

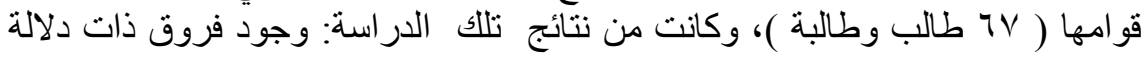

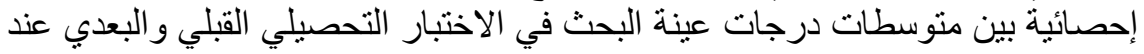

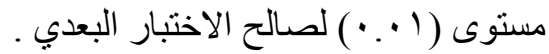

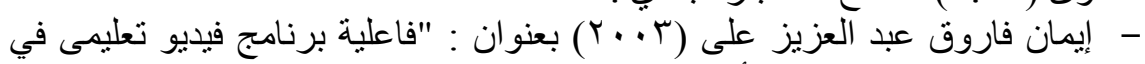

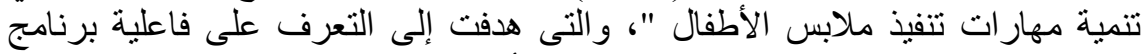

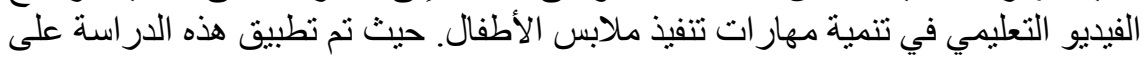

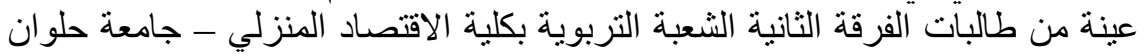

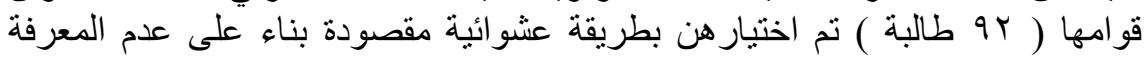

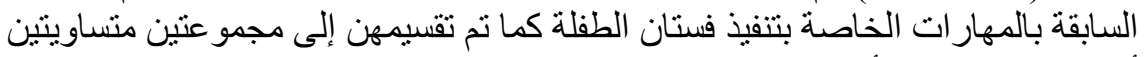

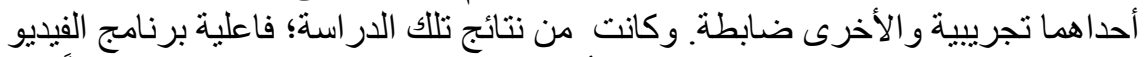

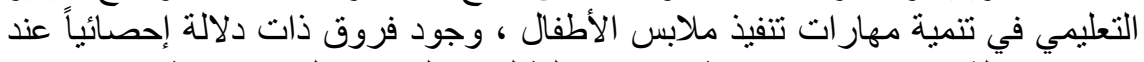

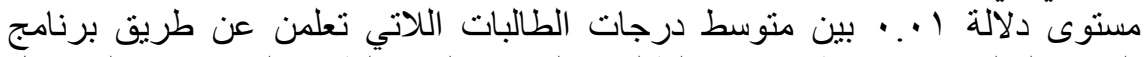

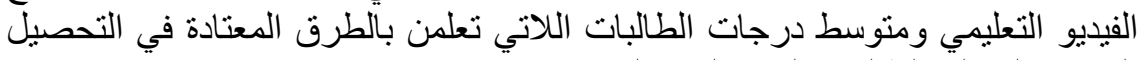

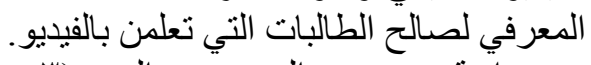

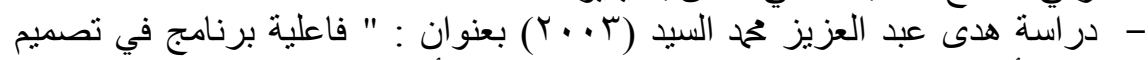

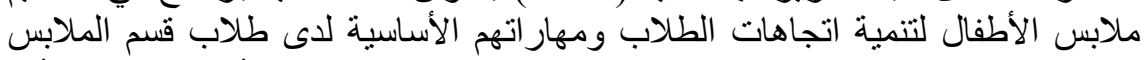

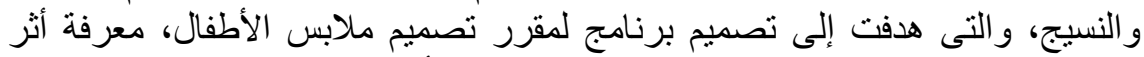

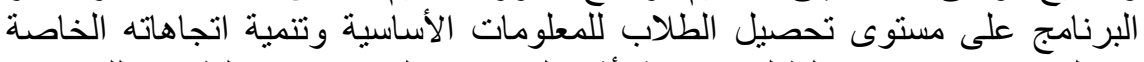

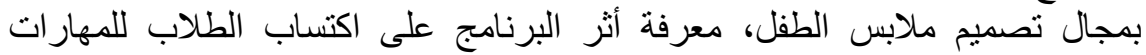

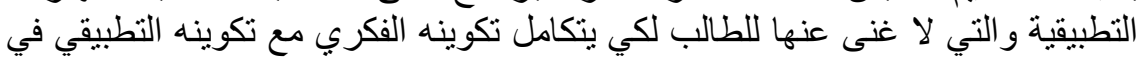

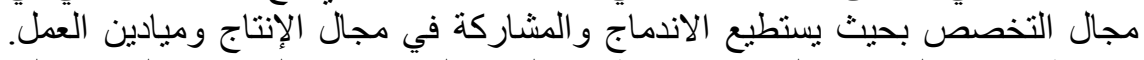

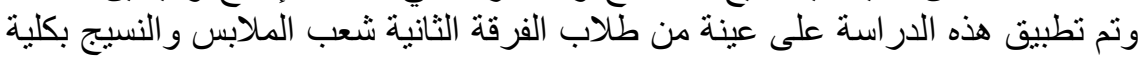

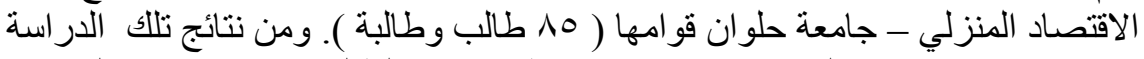

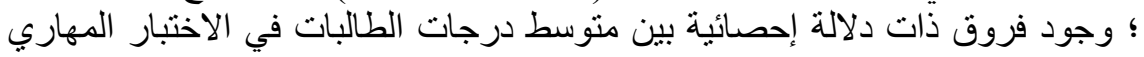

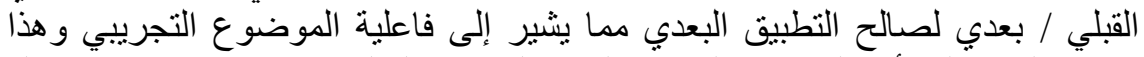

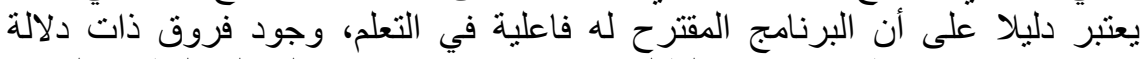

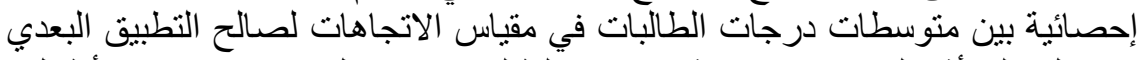

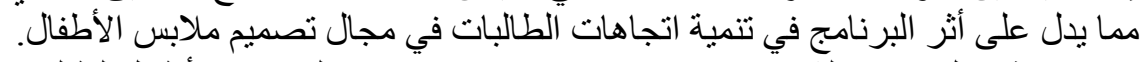

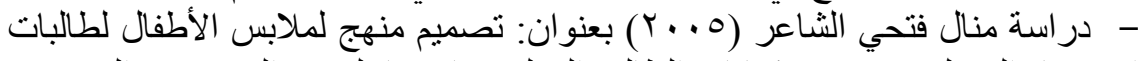

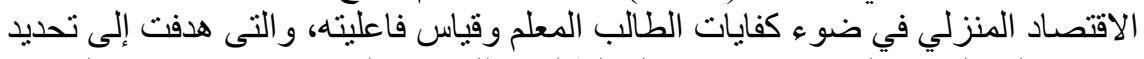

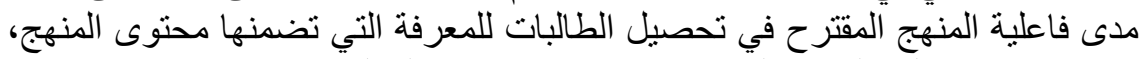

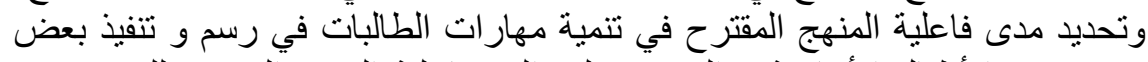

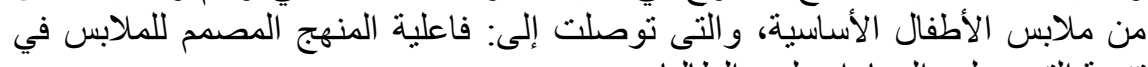
تتمية التحصيل و المهار ات لابى الطالبات. 


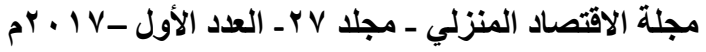

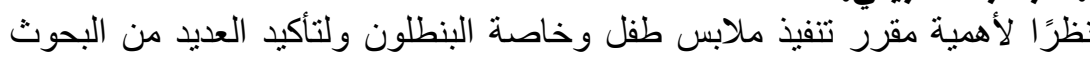

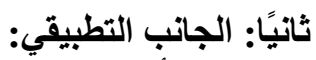

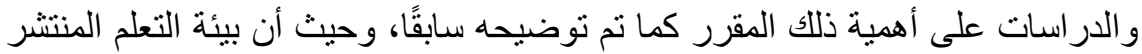

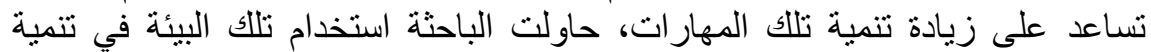

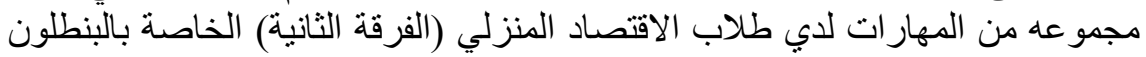
في مقرر تنفيذ ملابس طفل ومنه منها:

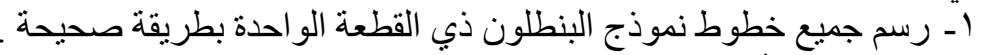

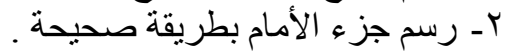

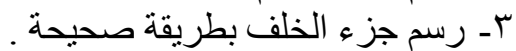

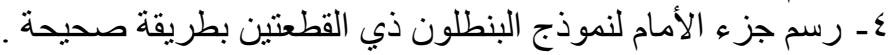

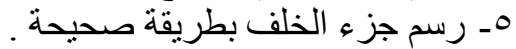

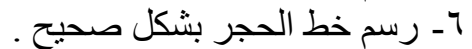

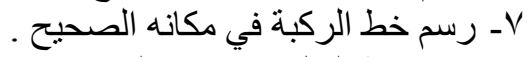

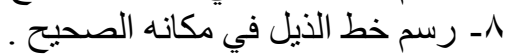

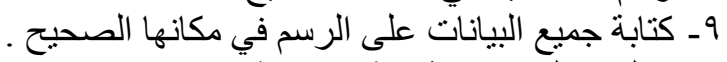

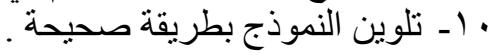

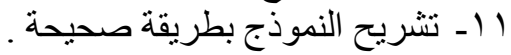
r ا ـ تطبيق طريقة وضع نموذج البنطلون ذي القطعة القونة الواحدة على القماش بطريقة صحيحة . ا ا ـ ـ تطبيق طريقة وضع نموذج البنطلون ذي القطعتين على القماش بطريقة صحيحة .

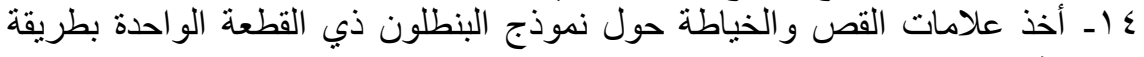

1 ا 1 ـ أخذ علامات القص و الخياطة حول نموذج البنطلون ذي القطعتين بطريقة صحيحة. صحيحة

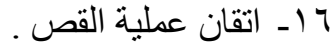

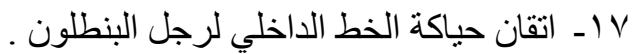

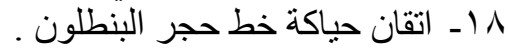
9 ا ـ ـ اتقان حياكة خط الجنب للبنطلون ذي ذي القطعتين .

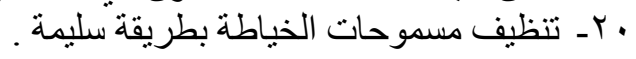

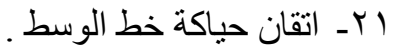

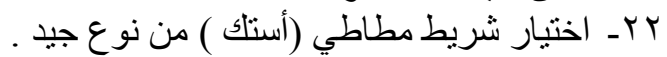

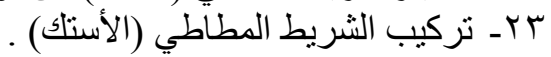

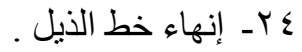
ه ـ ـ اتقان الكي المرحلي بعد كل مرحلة خياطة. تصميم أدوات البحث: البث:

نظرًا لأن البحث الحالي يهذف إلى التهرف التحرف على أثر مستويات الدعم (الموجزةـ المتوسطة)

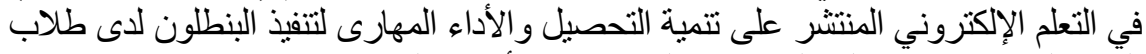

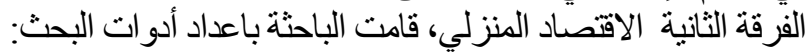
أـ اختبار تحصيلي لقياس المعارف المرتبطة بتنفيذ البنطلون. 


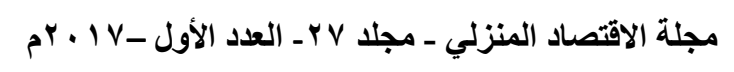

ب- بطاقة تقييم منتج لتتمية الأداء المهارى للطلاب في تتفيذ البنطلون.

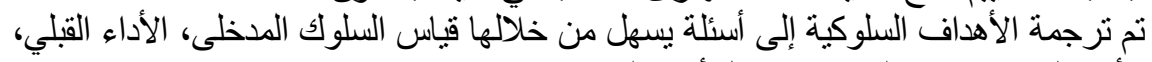

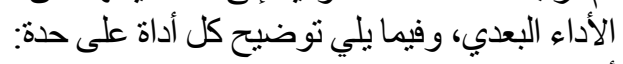

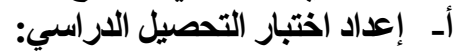

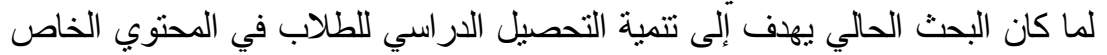

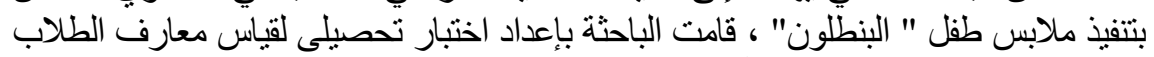

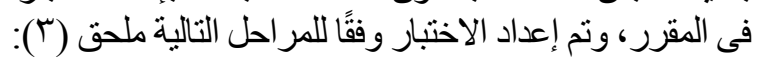
- تحيد الهُف من الاختبار التحصيلي: يهدف الاختبار التحصيلي إلى فياس الجانب التبالب المعرفى لطلاب الفرقة الثانية الاقتصاد المنزلي

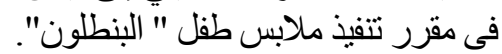

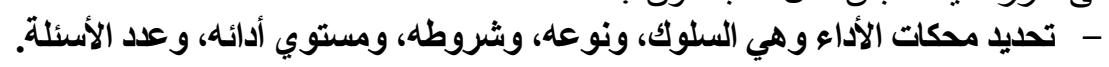
- - تحديد ظروف تطبيق الاختبار وتصحيحه:

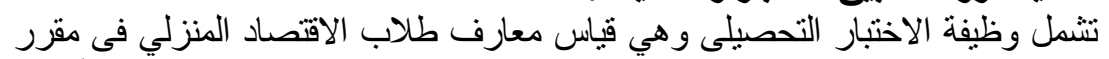
تنفيذ ملابس طفل " البنطلون" ، وكنلك زمن الاختبار ويحدد الزمن بناءً على على عدد الأسئلة،

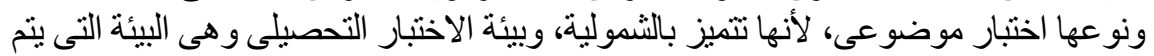

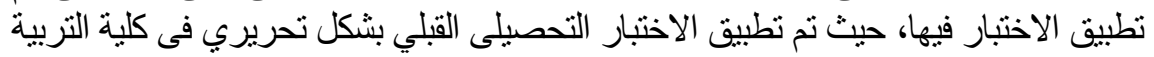

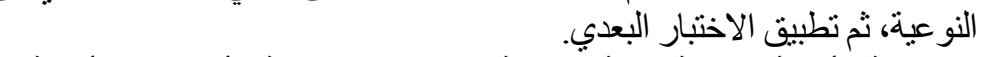

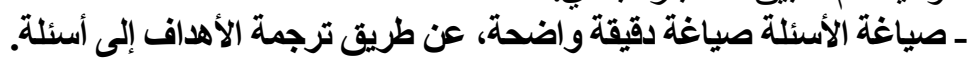
ـ تحليد جلول المواصفات الاختبار. - وضع تعليمات الاختبار التحصيلي:

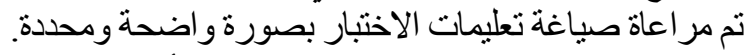

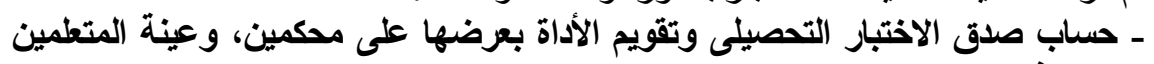
تم عرض الصورة الأولية للاختبار التحصيلى على المحكمين وظلك لحساب صدق المستهدفين:

$$
\begin{aligned}
& \text { الاختبار و ابداء الر أى حول ما يلى لئي: } \\
& \text { - مدى قياس الأسئلة للاهداف. - مئل }
\end{aligned}
$$

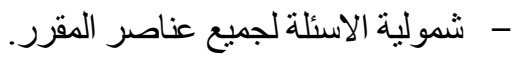

$$
\begin{aligned}
& \text { - مدى مناسبة الاسئلة لعينة البحث. } \\
& \text { - - الدقة العلمية و اللغوية للبنود. } \\
& \text { - - التعديل المقترح لبنود الاختبار . }
\end{aligned}
$$

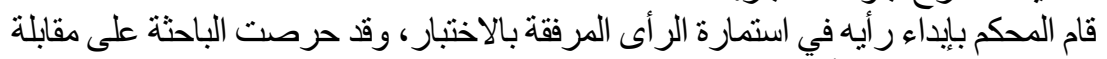

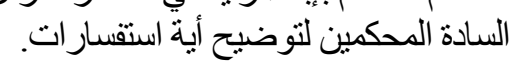

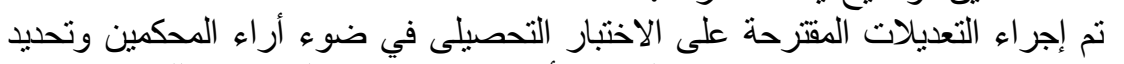

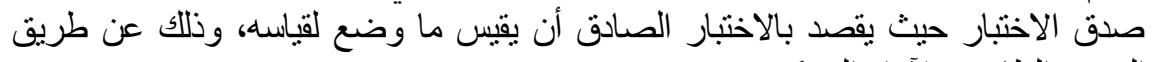
تم تقدير الصدق الظاهرى للاختبار وذلك بتحليل أراء المحكمين وقامت الباحثة باجراء الصدق الظاهرى لآر اء المحكمين. التعديلات التى اقترحها المحكمون. 


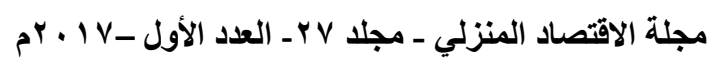

ـ التجرية الاستطلاعية للاختبار التحصيلى:

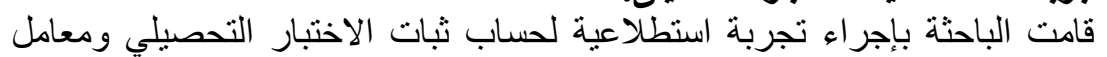

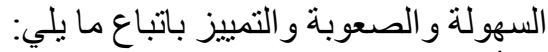

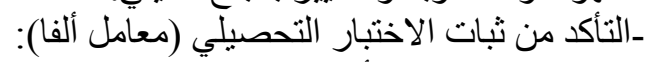

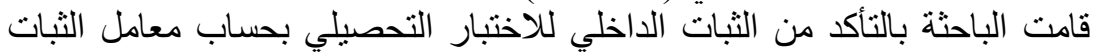

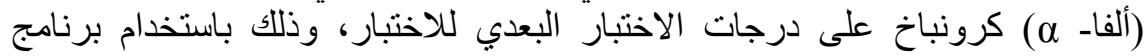
(SPSS)

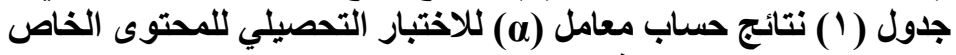
بتنفيذ ملابس طقل " البنطلون

\begin{tabular}{|c|c|c|c|}
\hline قيمة معامل الثبات & مفردات الاختبار & عدد العينة & معامل الثبات \\
\hline$\cdot . \wedge \wedge \xi$ & $1 \pi$ & $\leqslant \Lambda$ & معامل ألفا Cronbach \\
\hline
\end{tabular}
التحصيلي ويمكن الاعتماد عليه.

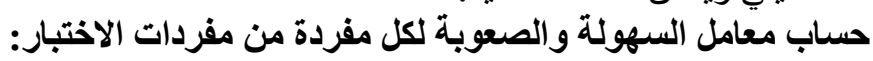
تم استخدام المعادلتين التاليثين لحساب معامل السهولة و والصعوبة الصغية لكل مفردة من مفردات

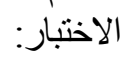
ا ـ معامل السهولة = عدد الإجابات الصحيحة / (عدد الإجابات الصحيحة+ عدد

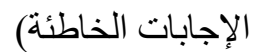
Y بـ معامل الصعوبة = ( ـ ـ معامل السهولة.

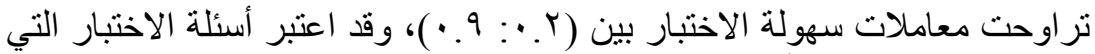

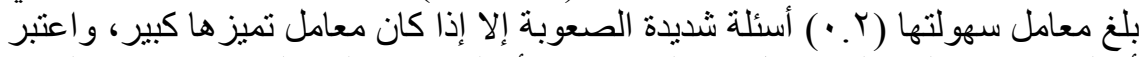

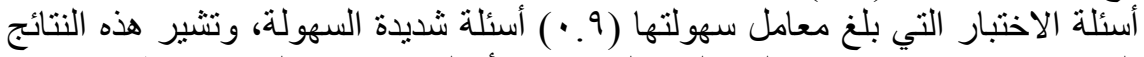

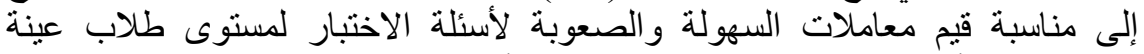

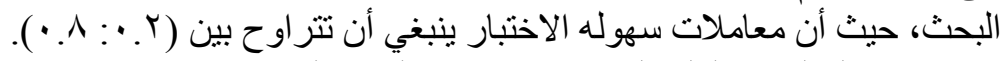

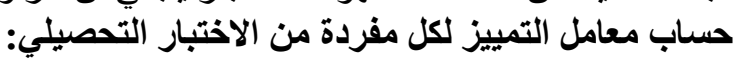

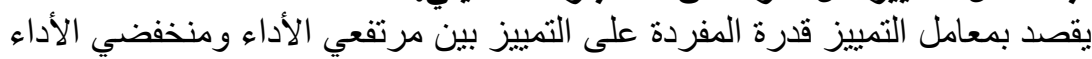

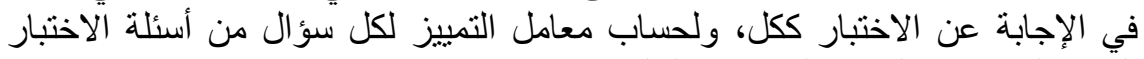
التحصيلي اتبعت الباحثة الخطوات التئية التالية: اـ ترتيب درجات الطلاب في التجربة الاسنطلاعية ترنيًا تتازليًا حسب الدرجة المعطاة لكل

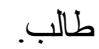

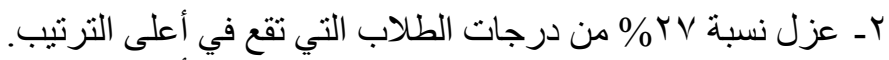

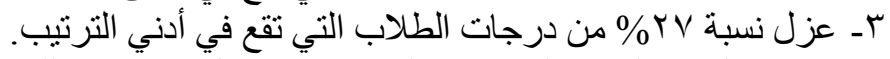

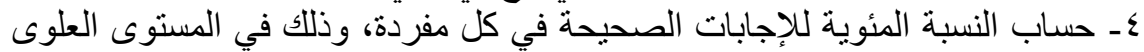

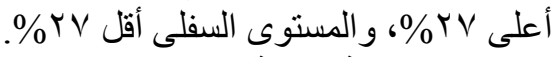
تستخدم المعادلة التالية لحساب معامل التمييز:

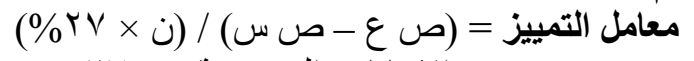

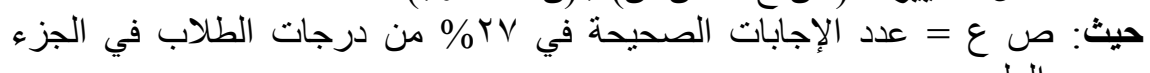
العلوي. 


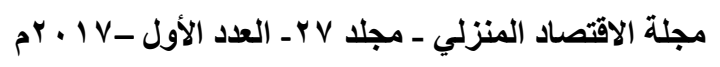

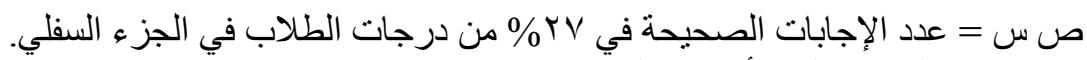
ن = عدد الطلاب الذين أجابو الابت على الاختبار.

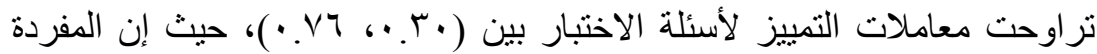

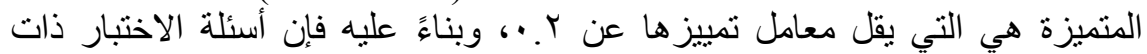

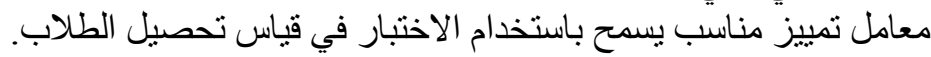

الصورة النهائية للاختبار التحصيلي ومعامل السهولة والصعوبة والتمييز: بالئية

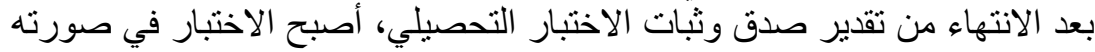

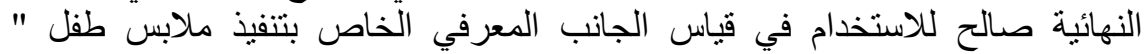

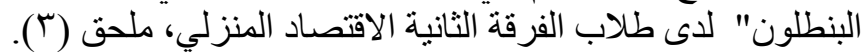

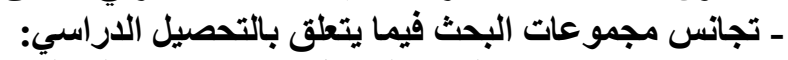

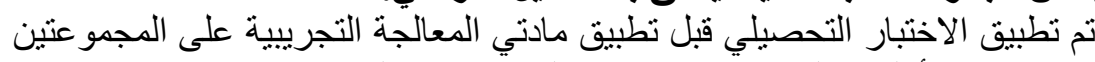

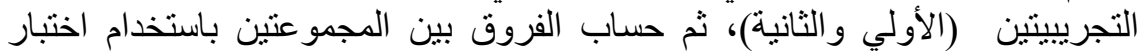

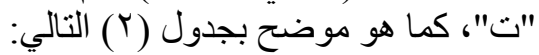

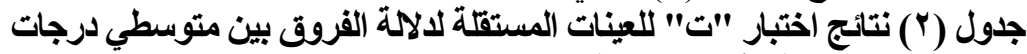

\begin{tabular}{|c|c|c|c|c|c|c|}
\hline مستوى الدلالة & درجات الحرية & المحسة "تبة & الانحراف المعياري & المتوسط & العينة & المجموعة \\
\hline \multirow{2}{*}{ וT. } & \multirow{2}{*}{$\vee \wedge$} & \multirow{2}{*}{ r } & Y.rY & $1.7 \mathrm{~V} \cdots$ & $\varepsilon$. & دعم موجز \\
\hline & & & r.qA & $1.9 \mathrm{~V} \ldots$ & $\varepsilon$ & دعم متوسط \\
\hline
\end{tabular}

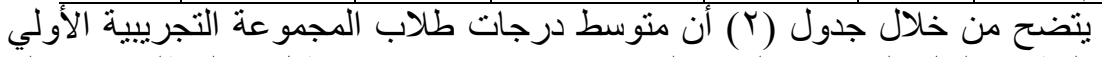

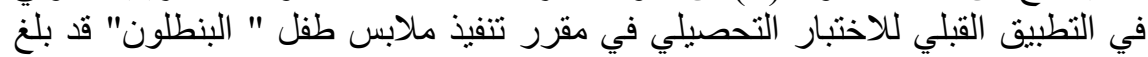

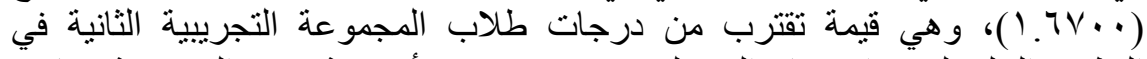

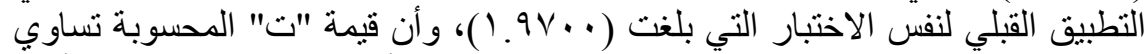

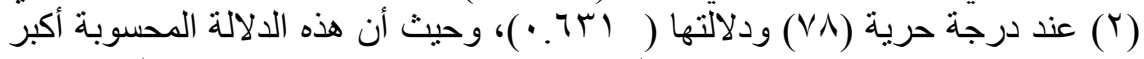

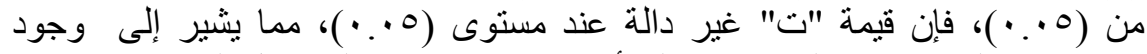

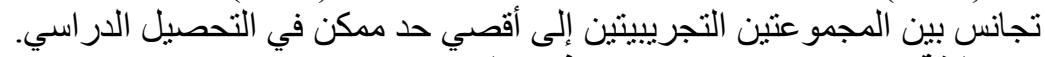

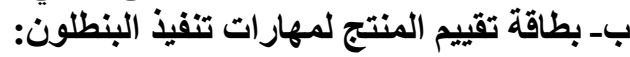

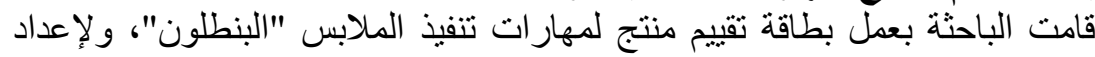
بطاقة تقييم المنتج قامت الباحثة بالإجر اءعات البات التالية:

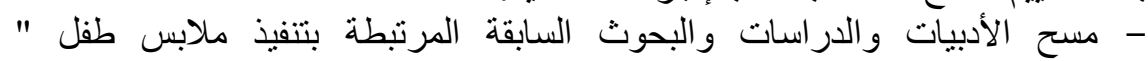
البنطلون"، كما ورد في الفصل الثاني للبحثث.

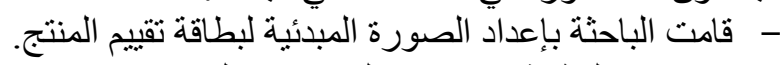

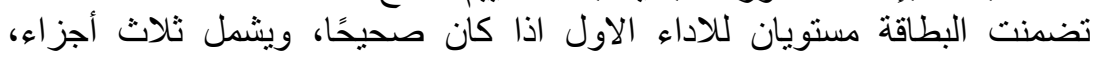

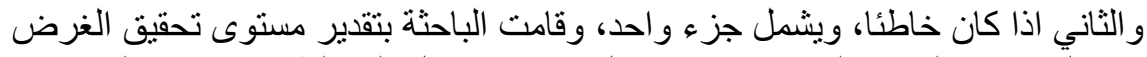

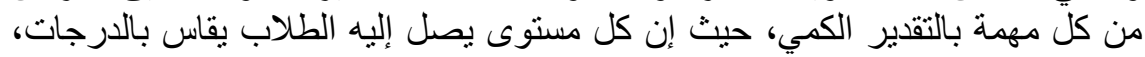

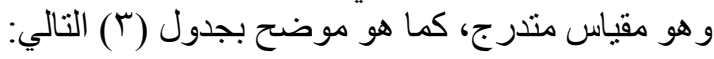




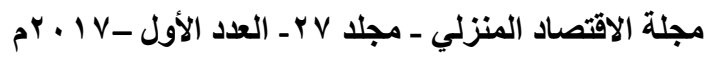

\begin{tabular}{|c|c|c|c|}
\hline \multicolumn{4}{|c|}{ جدول (ץ) نظام تقدير الدرجات لبطاقة تقييم المنتج } \\
\hline تفسير الدرجة & الارجة & مستوى الأداء & 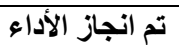 \\
\hline التزم بتففيذ البند بصورة صحيحة & $r$ & مرتفع & \multirow{3}{*}{ 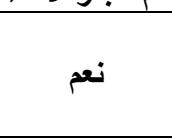 } \\
\hline تم تنفيذ البند مع وجود خطأ & r & متوسط & \\
\hline تم تنفيذ البند بصورة ضعيفه & 1 & منخفض & \\
\hline لم ينفذ البند & • & - & 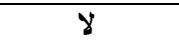 \\
\hline
\end{tabular}

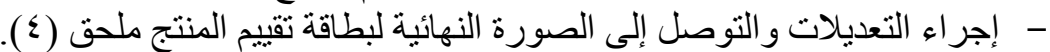

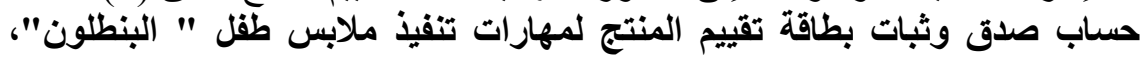

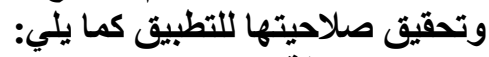

\section{1 - حساب صدق بطاقة تقييم المنتجج:}

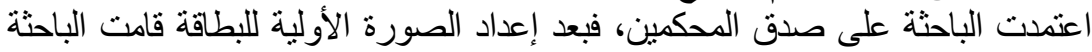

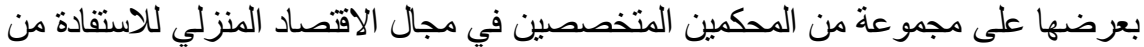

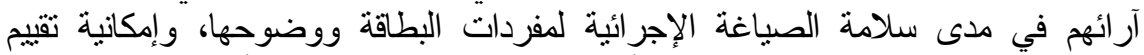
الخطوات التي تضمنتها، ومدى مناسبة أسلوب تصميم البطاقة لتحقيق أهدافها. وتم مراعاة التهات الملاحظات عند إعداد الصورة الصنات النهائية للبطاقة.

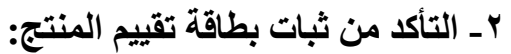

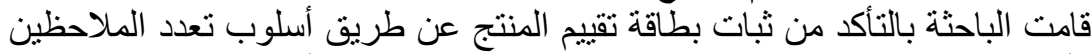

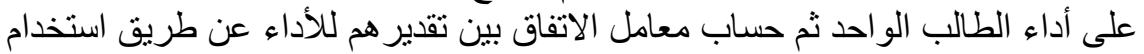

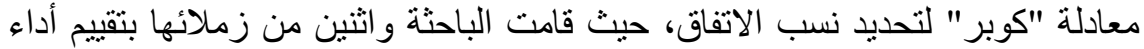

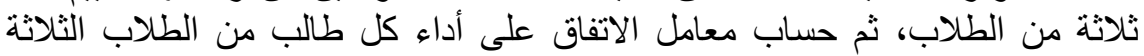

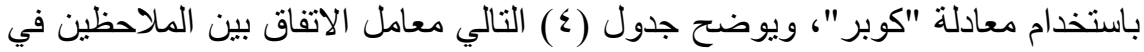
حالات الطلاب الثلاثة. جدول (ع ) معامل الاتفاق بين الملاحظين لبطاقة تقييم المنتج

\begin{tabular}{|c|c|c|c|}
\hline معامل الاتفاق & معامل الاتفاتث للملاحظ & معامل الاتفاتى للملاحظ & معامل الآفاق للملاحظ \\
\hline$\% 90$ & $\% 90$ & $\% 97$ & $\% 9 \varepsilon$ \\
\hline
\end{tabular}

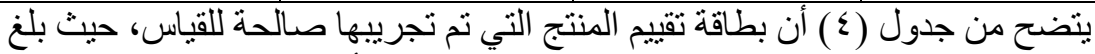
متوسط معامل الاتفاق في الحالات الثلاث الاعتماد عليها.

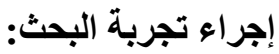
ا ـ تقسيم الطلاب حسب أنسة التصميم التجريبي للبحث. r ـ تحديد خطة السير في المقرر ، تم تحديد خطة السيب السير. أ- تبيق التجربة:

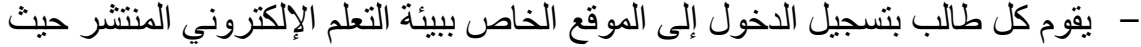

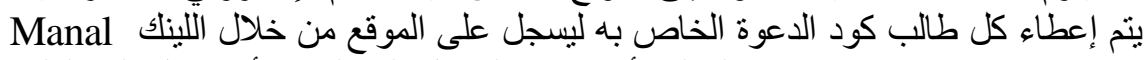

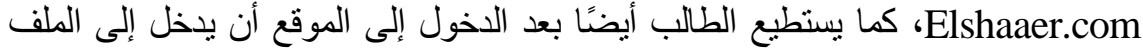




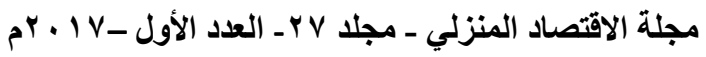

الشخصي له وتعديل بياناته مثل الصورة الشخصية والبريد الإلكتروني، الاسم، وكلمة

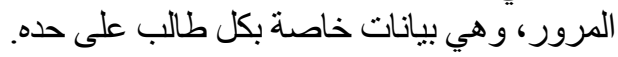

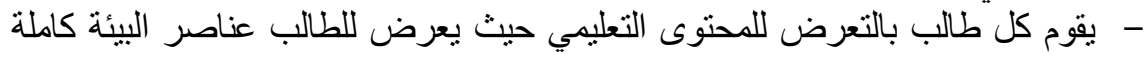
ويمكنه التعامل مع البيئة والمجموعه التي سوف يتعلم فيها من خلال الاطلاع على دلى دليل

الطالب ملحق (ب).

ب-بالنسبة للمجموعة التجريبية الأولي: دعم موجز البئية

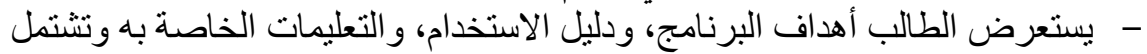

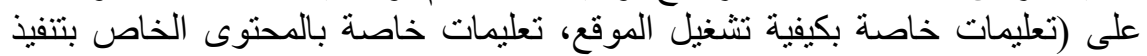

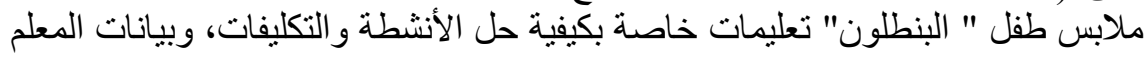
المقدم للمقرر ).

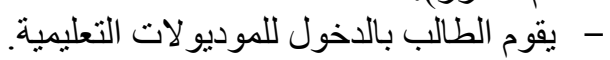

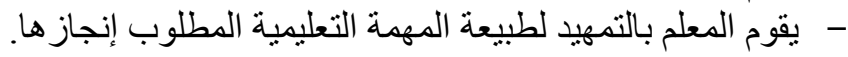

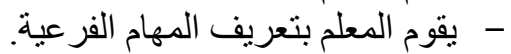

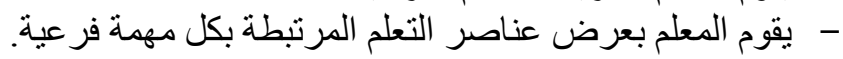

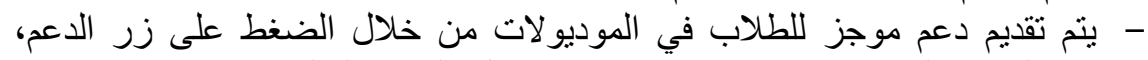

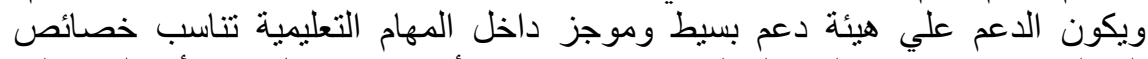

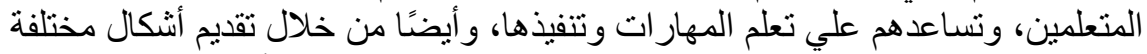

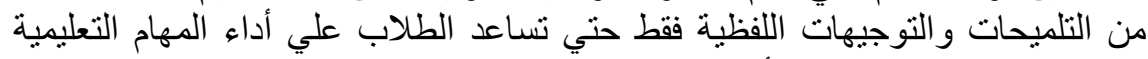

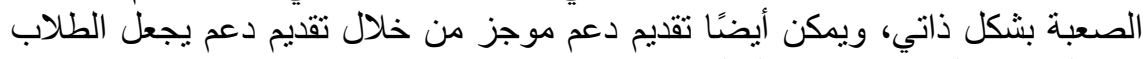

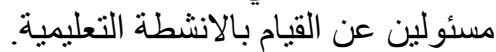
- - ميقوم المعلم بعرض الأنشطة التعليمية. - بدء الطلاب في عمليات البحث و التقصي لإنجاز المئة المهمات التعليمية المحددة.

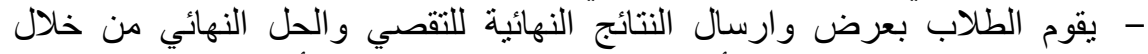
الصندوق الموجود في الموقع، أو من خلال البريد الإلكتروني أو الفيس بولئ لإلى الخاص بالمعلم. - بتم تقييم الطلاب من خلال إجاباتهم ثم إرسال باقي الاجابات الصحيحة لهم لاتمام

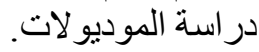

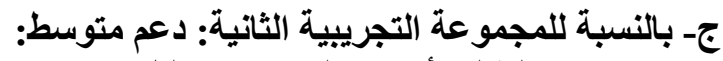

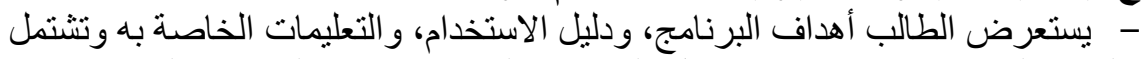

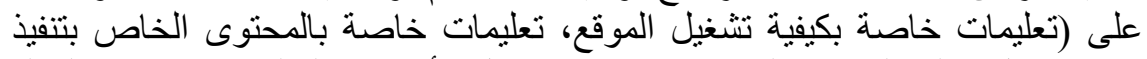
ملابس طفل " البنطلون" تعليمات خاصة بكيفية حل الأنشطة و التكليفات، وبيانات خلئ المعلم المقدم للمقرر ). - - يقوم الطالب بالاخول للمون بلموديو لات التعليمية.

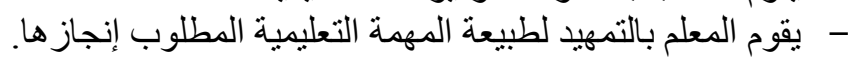
- - يقوم المعلم بتعريف المهام الفرعية.

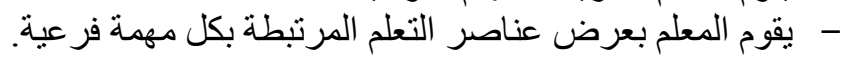

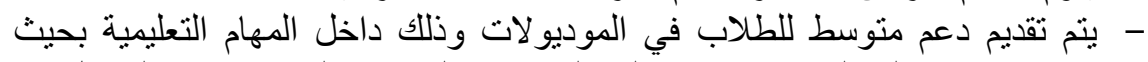

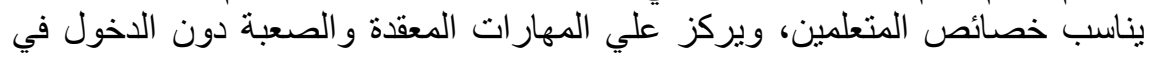




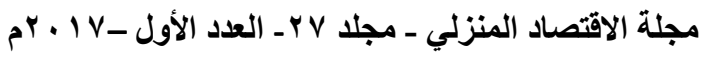

تفصيلات واستبعاد ماهو غير ضروري، وأيضًا يمكن تقديم دعم متوسط من خلال

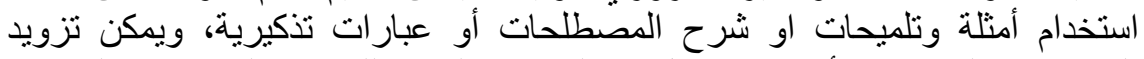

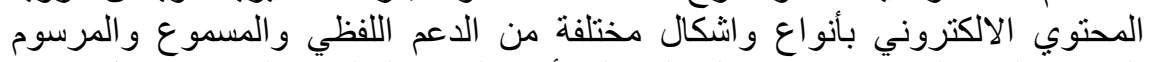

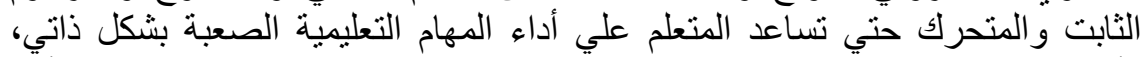

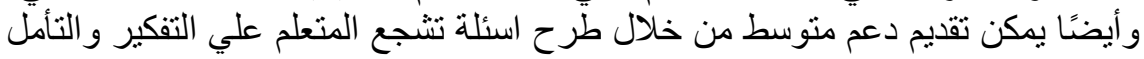

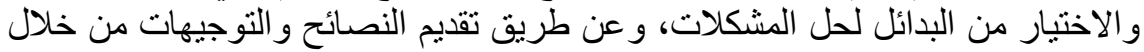

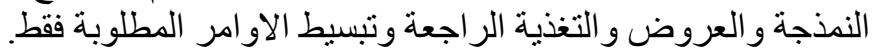
- - يقوم المعلم بعرض الأنشطة التعليمية.

- - بدء الطلاب في عمليات البحث و التقصي لإنهة لإنجاز المهمات التعليمية المحددة.

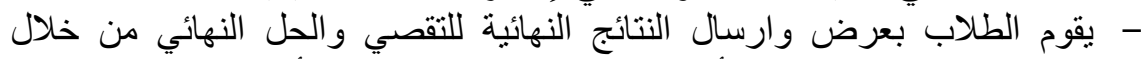

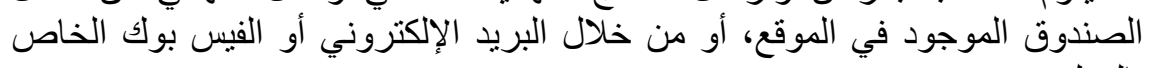
بالمعلم. - بتم تقييم الطلاب من خلال إجاباتهم ثم إرسال باقي الاجابات الصحيحة لهم لاتمام

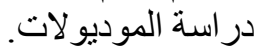
- - ملاحظات الباحثة أثناء التطبيق:

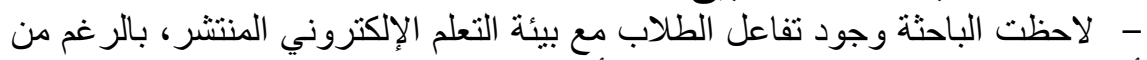

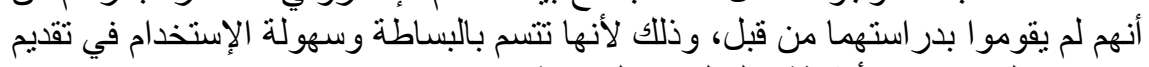

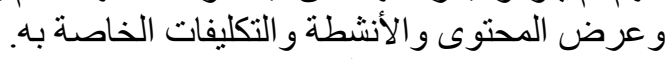
تطبيث أدوات البحث بعديًا:

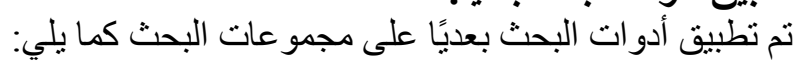

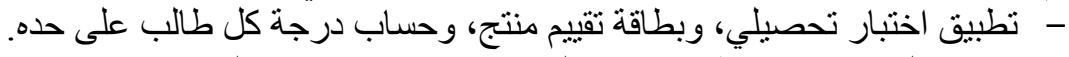

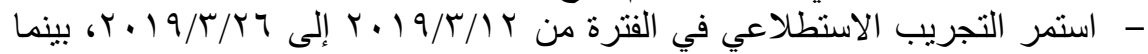

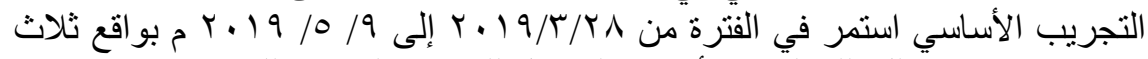

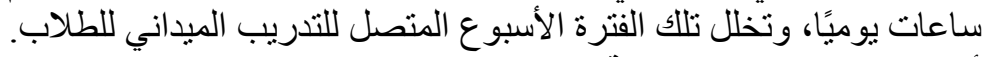

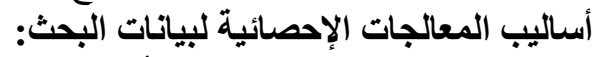

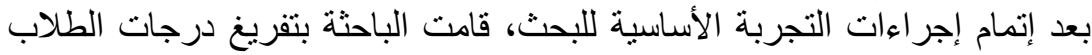

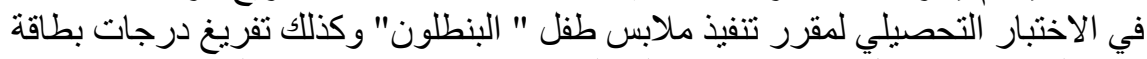

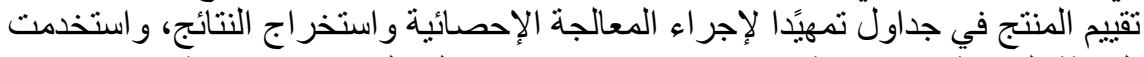

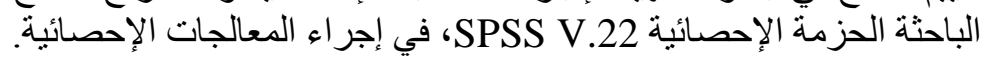
تتائج البحث، وتفسيرها: الإحها:

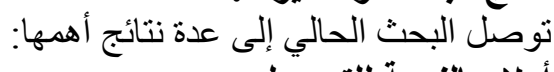
أولا: بالنسبة للتحصيل:

- توجد فروق دالة إحصائًا عند مستوى دلالة ه ـ.

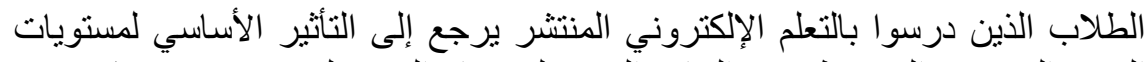

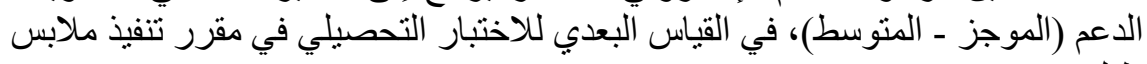
طفل.

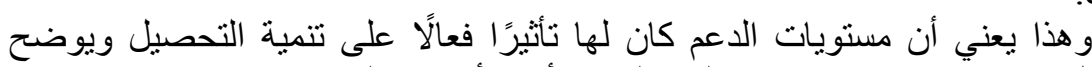

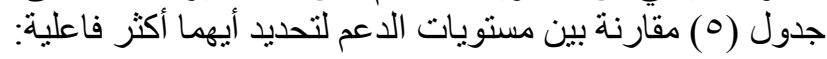




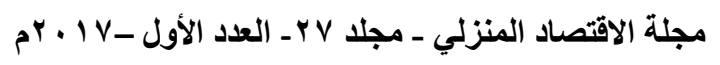

\begin{tabular}{|c|c|c|c|c|c|}
\hline \multicolumn{6}{|c|}{ جدول (0) تأثير مستويات الاعم على الاختبار التحصيلي } \\
\hline 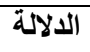 & 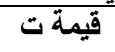 & الانحراف المعياري & المتوسط & عدد العينة & مقارنة بين مستويات الدعم \\
\hline \multirow{2}{*}{$\because \cdots$} & $1 \cdot .79-$ & $r .7 r$ & 17.180. & « & دعم موجز \\
\hline & & r.9r & YO.YYO. & \&. & دعم متوسط \\
\hline
\end{tabular}

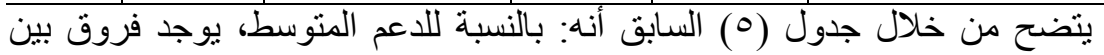

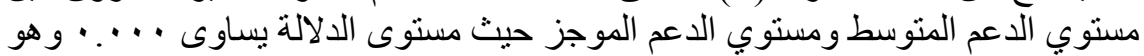

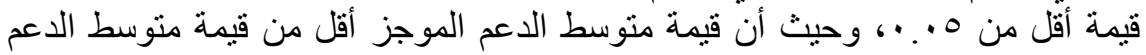

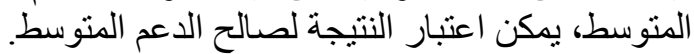

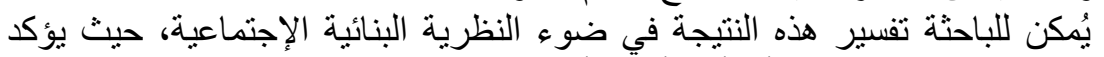

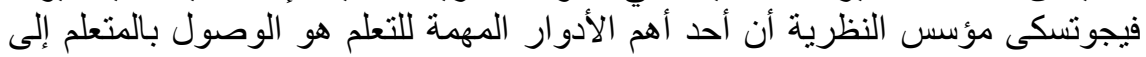

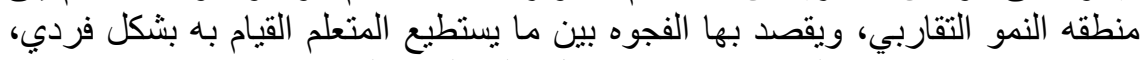

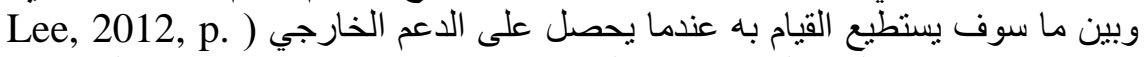

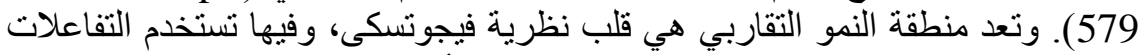

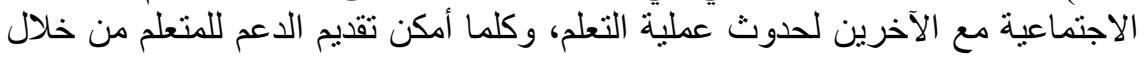

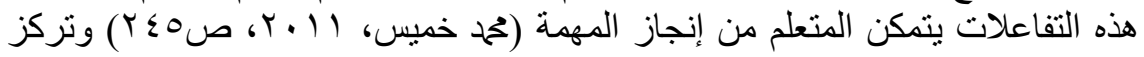

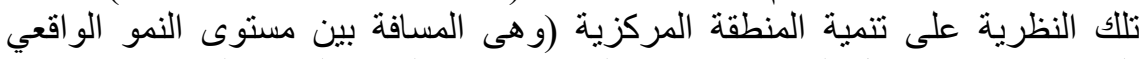

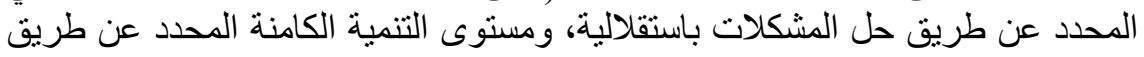

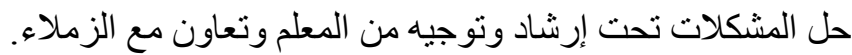

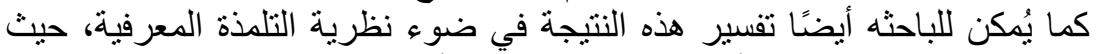

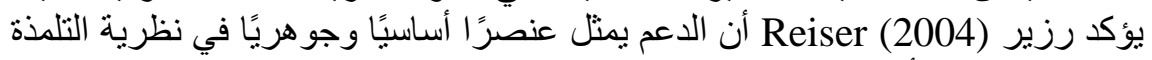

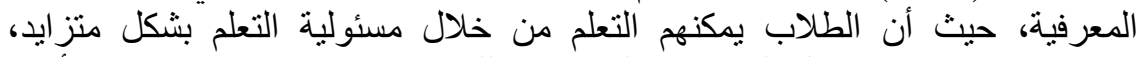

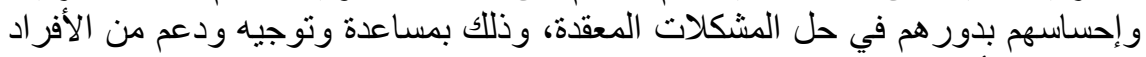

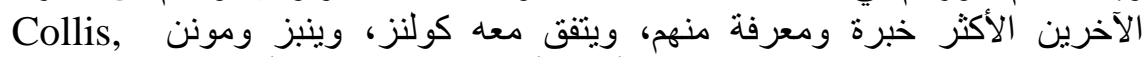
فinnips\& Moonen (2000)

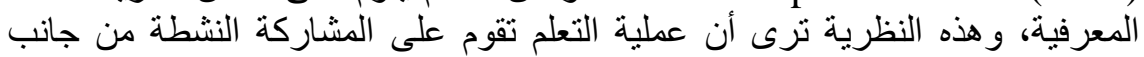

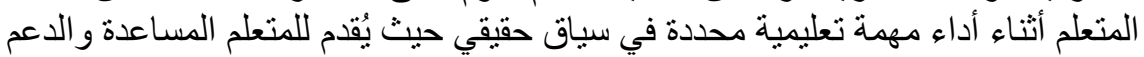

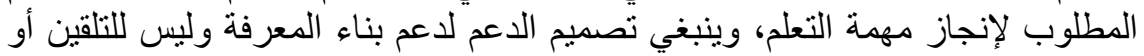
الحفظ.

ويُمكن للباحثه تفسير هذه النتيجة في ضوء بيئة التعلم المنتشر حيث تعمل بيئة التعلم

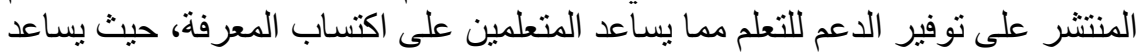

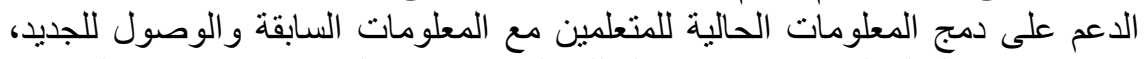

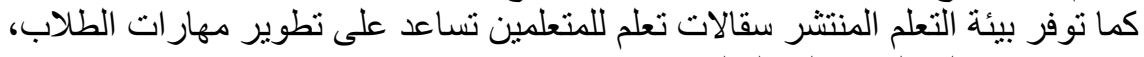

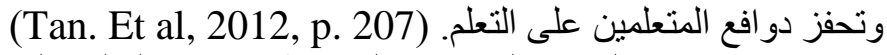
- تحقق مستويات الدعم ( الموجز - المتوسط) في بيئة التعلم الالكتروني المنتشر تأثيرًا

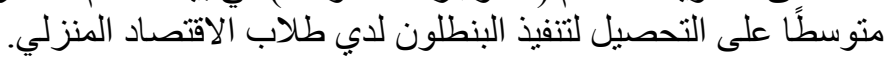




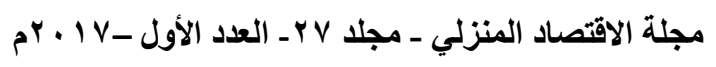

- للتحقق من ذلك قامت الباحثة بحساب حجم تأثثير مستويات الدعم ( الموجز -

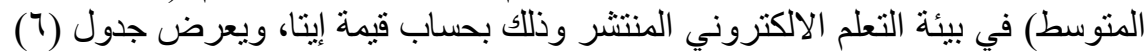
نتائج حجم التأثير. جلول (آ) حجم تأثير ايتا على مستويات الاعم ( الموجز - المتوسط) في بيئة التعم الاكتروني المنتشر على التحصيل لتنفيذ البنطلون المون المنون

\begin{tabular}{c|c}
\hline قيمة ايتا مقار حجم التأثير & \\
\hline متوسط & \\
\hline
\end{tabular}

يتضح من جدول (T) أن قيمة حجم تأثثير مستويات الدعم ( الموجز - المتوسط) في لأني

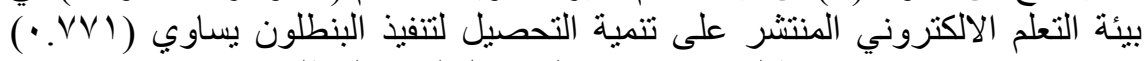

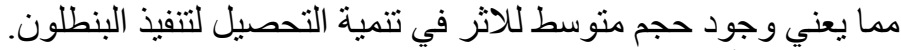
ثانيا: بالنسبة للاداء المهارى لتنفيذ البنطلون:

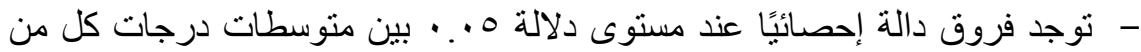

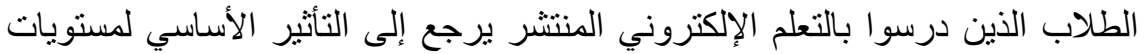

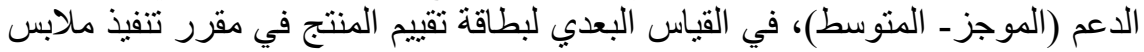
طفل.

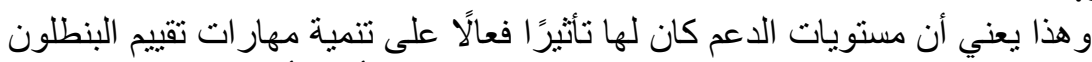
ويوضح الجدول رقم (V) مقارنة بين مستويات الدعم لتحديد أيهما أكثر فاعلية

\begin{tabular}{|c|c|c|c|c|c|}
\hline الالالة & قيمة ت & الانحراف المعياري & المتوسط & عدد العينة & مقارنة بين مستويات الدعم \\
\hline \multirow{2}{*}{$\because \cdots 1$} & \multirow{2}{*}{$r_{.} \leqslant \Delta r_{-}$} & $91.51 \leq$ & rN1.0YO & $\varepsilon$ & دعم موجز \\
\hline & & A..1 & $r 0 . .0$. & $\varepsilon$ & دعم متوسط \\
\hline
\end{tabular}

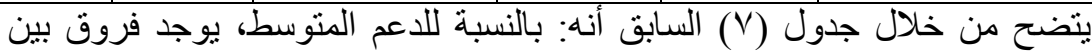

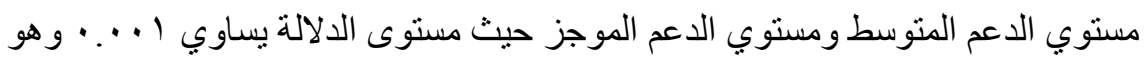

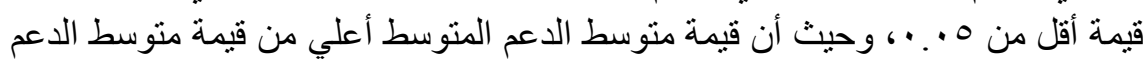

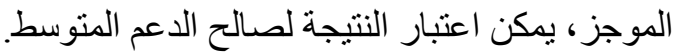

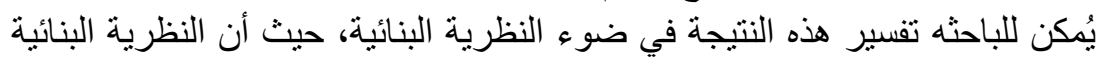

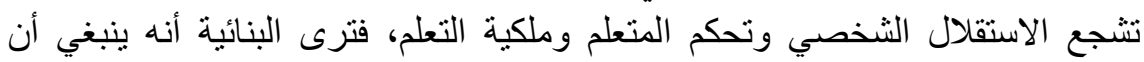

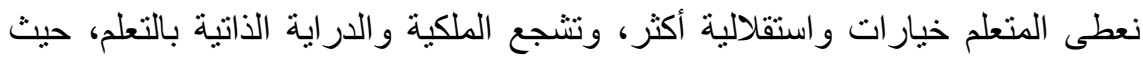

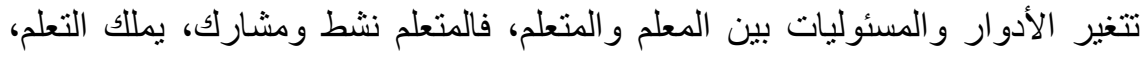

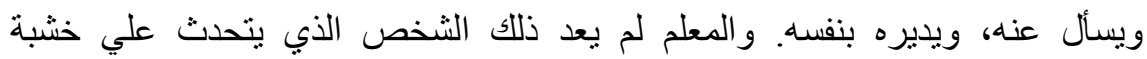

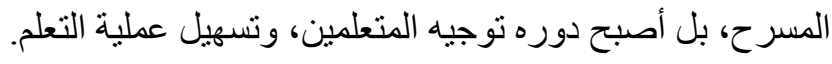




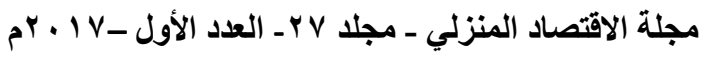

كما يُمكن للباحثه تفسير هذه النتيجة أيضًا في ضو ء نظرية الحضور الاجتماعي حيث ترى هذه النظرية أن التعليم ليس فقط عملية توصيل المعلومات، ولكن يجب أبن أن يكون

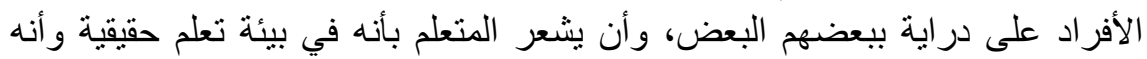
يخاطب شخص آخر، وأن بشعر بالتقدير والرضا، ويشارك في في التعلم (تحم خميس

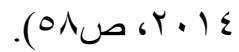

ويُمكن للباحثه تفسير هذه النتيجة في ضوء أله أن البيئة التعليمية المستخدمة في التعلم

الإلكتروني المنتشر "الموقع التعليمي" ساعدت على تتمية استعدادات و إمكانيات وقدرات

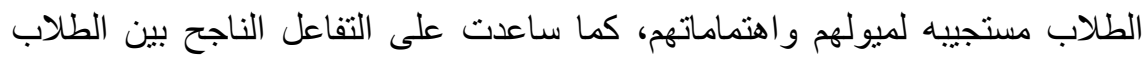

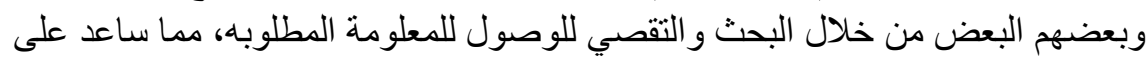
التعلم وتتمية مهار ات تقييم البنطلون لدى البعن الطلاب. - تحقق مستويات الدعم ( الموجز - المتوسط) في بيئة التعلم الالكتروني المنتشر تأثيرًا

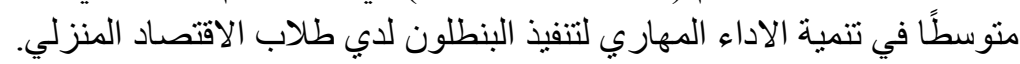

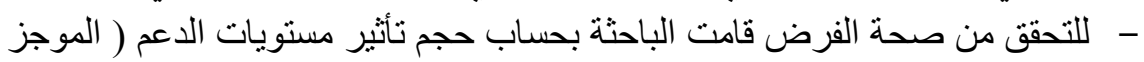

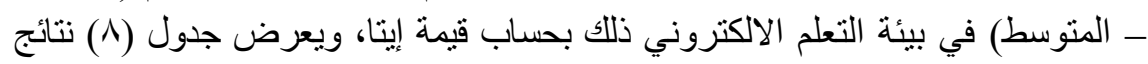
حجم التأثير.

جول (^) حجم تأثير ايتا علي مستويات الاعم ( الموجز - المتوسط) في بيئة التطلم

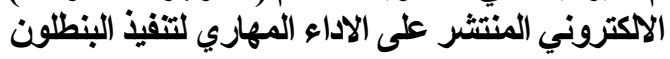

\begin{tabular}{|c|c|}
\hline مقدار حجم التأثير & قيمة \\
\hline متوسط & .978 \\
\hline
\end{tabular}

يتضح من جدول (^) أن قيمة حجم تأثثر مستويات الدعم ( الموجز - المتوسط) في ماتي

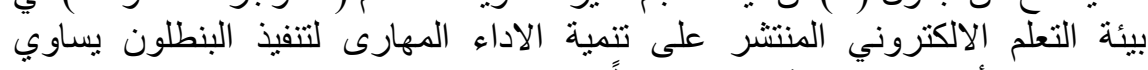

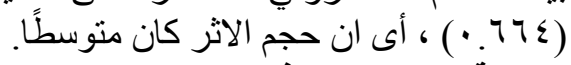
خلاصة نتائج اختبار فروض ان البح البرث:

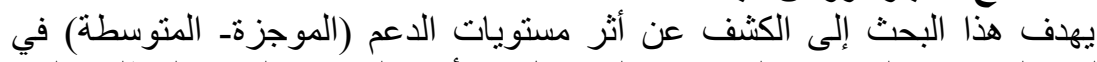

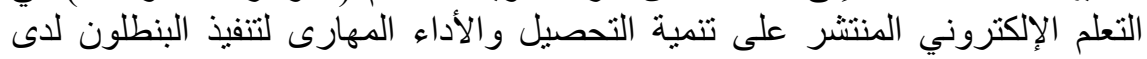

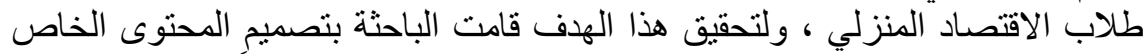

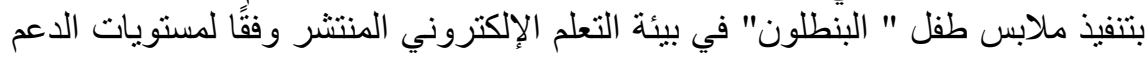

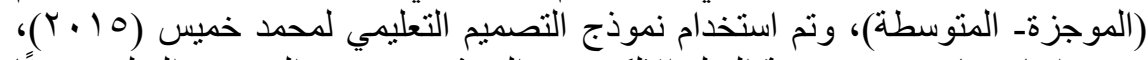

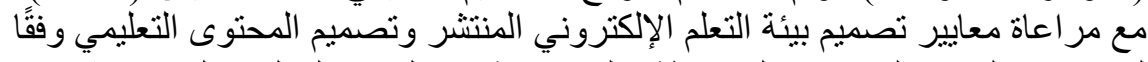

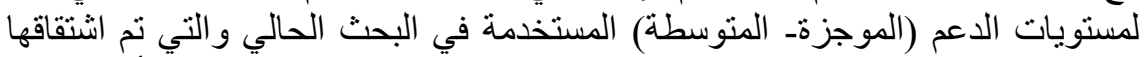

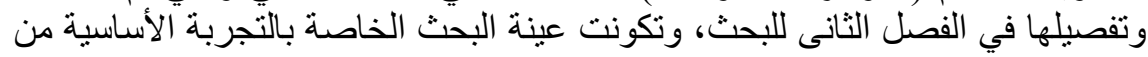

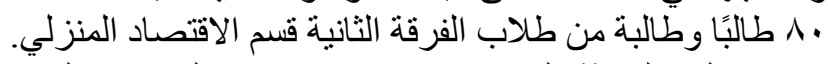

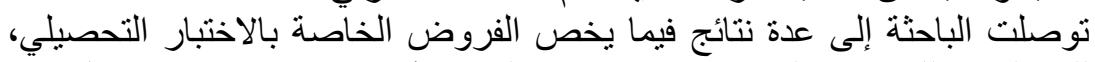

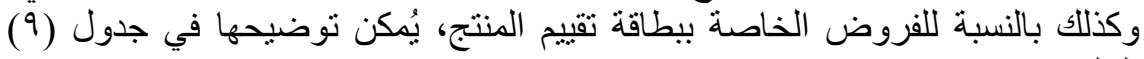
النالي: 


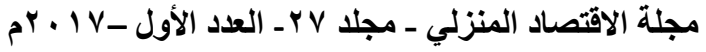

\begin{tabular}{|c|c|c|}
\hline \multicolumn{2}{|c|}{ 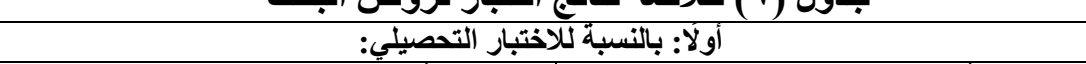 } & 1 \\
\hline 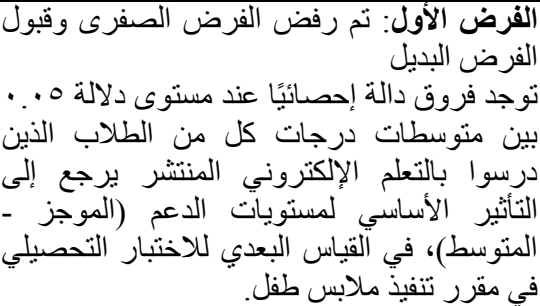 & 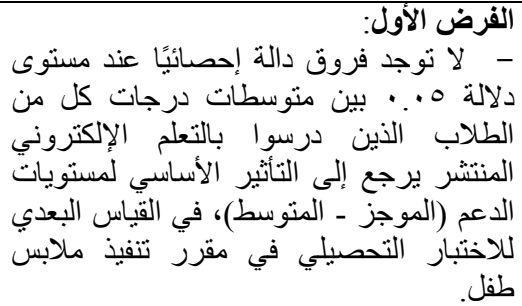 & \\
\hline & ثُاتيًا: بالنسبةٌ للاداء المهارى لتنفيذ منتج البنطل & $r$ \\
\hline 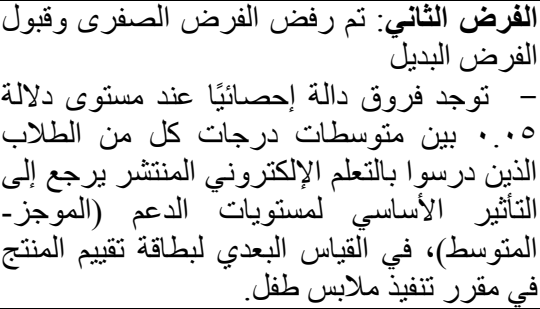 & 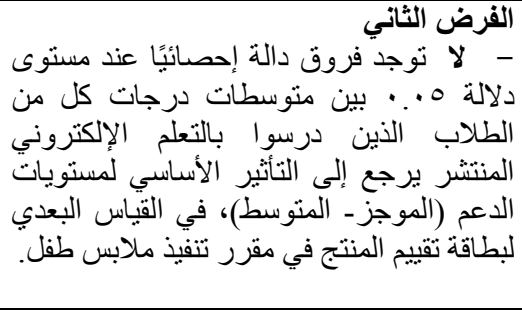 & \\
\hline
\end{tabular}

توصيات البحث:

في ضوء مأ أسفرت عنده نتائج البحث الحالي توصي الباحثنه بما يلي:

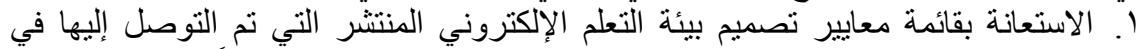

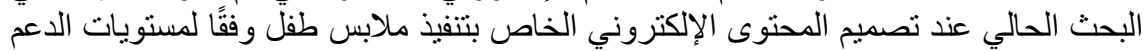

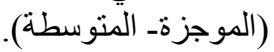
ץ. استخدام بيئة التعلم الإلكتروني المنتشر في تتمية مهار ات تقييم البنطلون للطلاب في تنفيذ

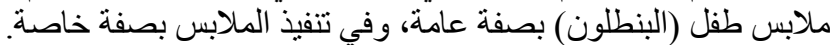

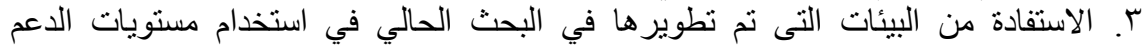

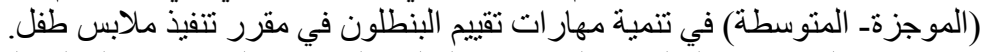
ـ. تشجيع المؤسسات التعليمية على تطبية فئ التعلم الإلكتروني المنتشر في العملية التعليمية. مقترحات البحث:

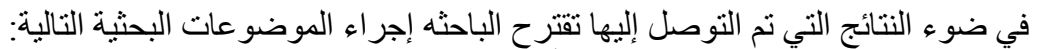

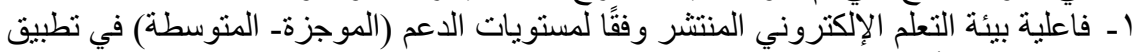

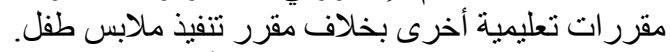

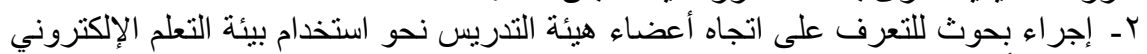

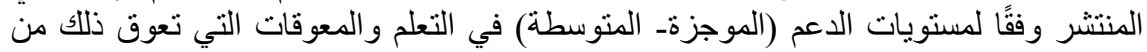
وجهة نظر هم. ب- در اسة و اقع مدى امتلاك المعلمين و الطلاب لأسس ومهار ات استخدام بيئة التعلم الإلكتروني

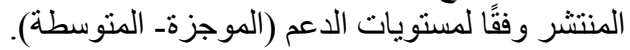

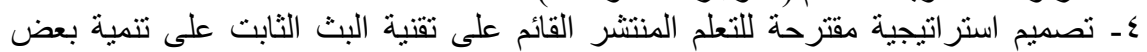

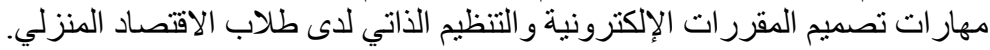

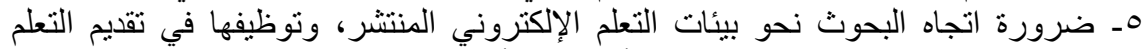

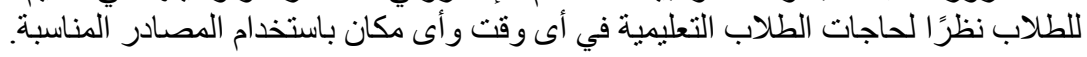




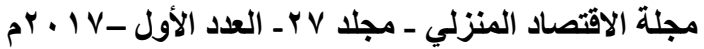

\section{قائمة المراجع \\ أولًا: المراجع المراجع باللغة العربية:}

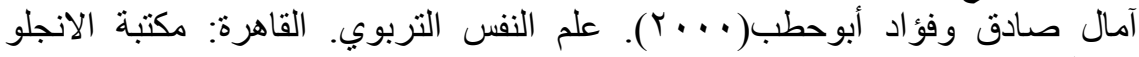

المصرية.

إسماعيل حسونة(^ . . ץ). أثر التفاعل بين بعض متغيرات أساليب المساعدة والتوجيه

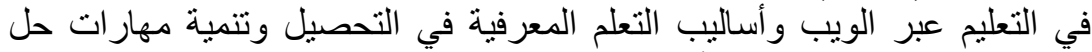

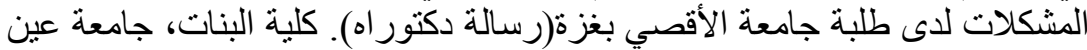
شمس، عين شمس.

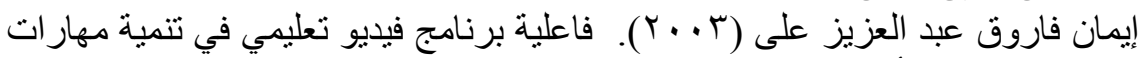

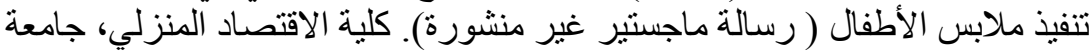
حلوان.

أسماء صبحي عبدالحميد(0 1 ب ب). أثر التفاعل بين دعامات التعلم البنائية وأسلوب التعلم

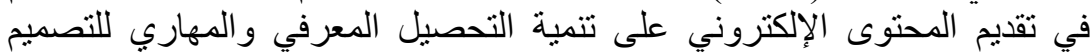

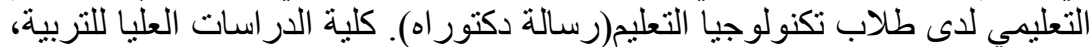

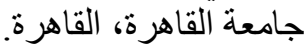
جيهان عبد الحميد نوار (797 (99 ). علاقة المعارف النظة النظرية بالمهار ات اليدوية في تنفيذ

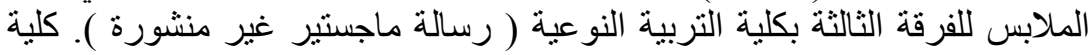
الاقتصاد المنزلي، جامعة المنوفية، المنوفية.

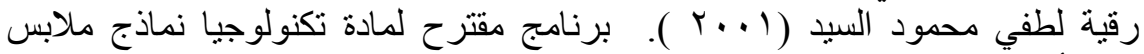

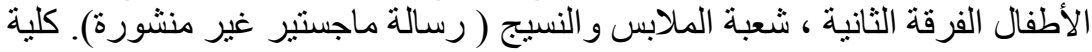

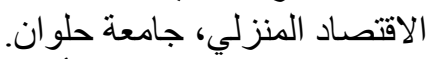

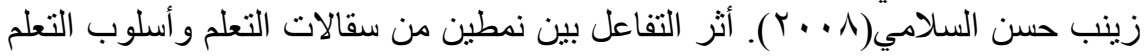

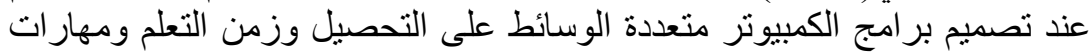

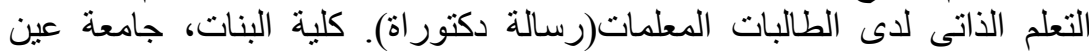

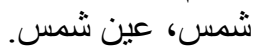

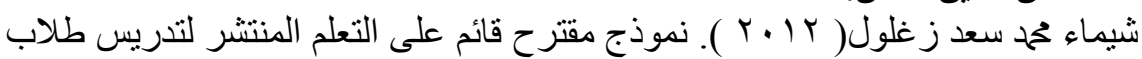

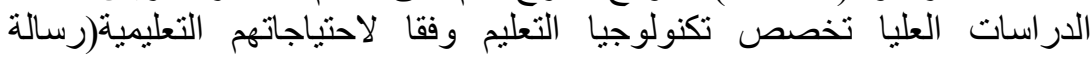

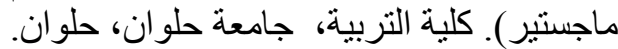

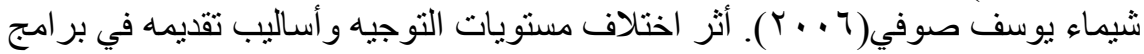

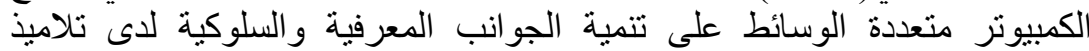
مدر اس التربية الفكرية(رسالة ماجسنير). كلية البنات، جامعة عين شمس، عين الفين

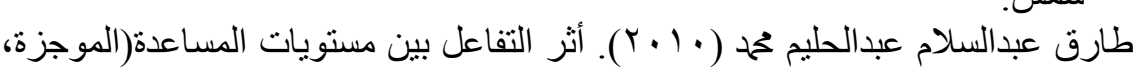
المتوسطة، التفصيلية)، وبين أساليب التعلم، على تلى تنمية كفايات تصميم التفاعلية التهاتية ببر امج الوسائط المتعددة، لطلاب أخصائي تكنولوجيا التعليم(رسالة دكتور اهنياه). كلية

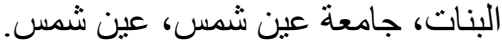

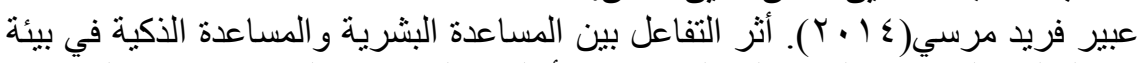

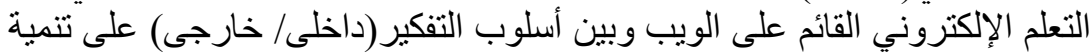




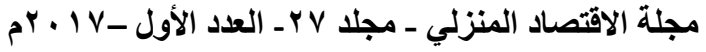

الكفاءة الذاتية ومهارات اتخاذ القرار(رسالة دكتوراه). كلية البنات، جامعة عين

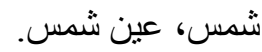
محهد حسن خلاف(ب ( • ب). أثر التفاعل بين طريقة تقديم دعامات التعلم(مباشرة/ غير

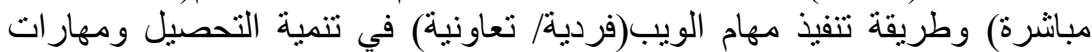

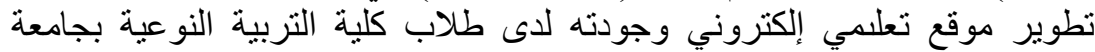

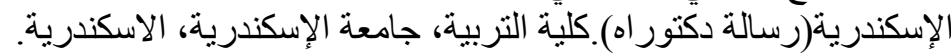

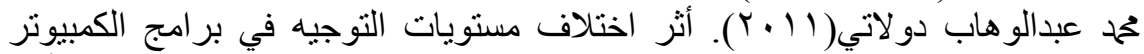

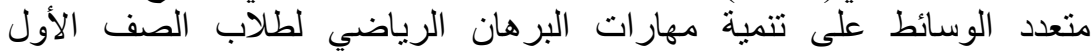

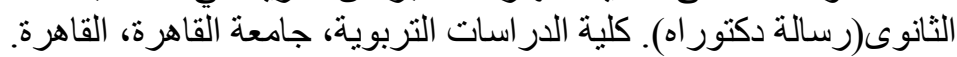

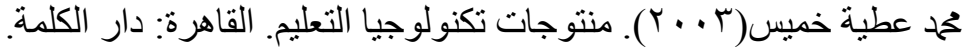

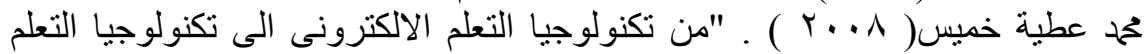

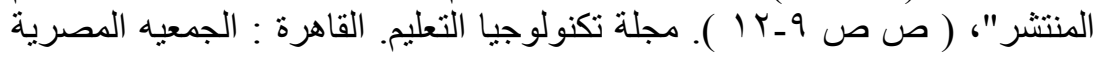
لتكنولوجيا التعليم.

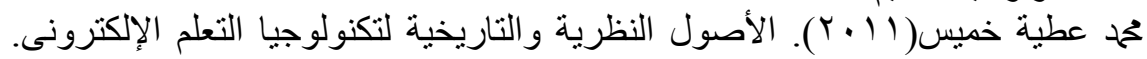
القاهرة: دار السحاب.

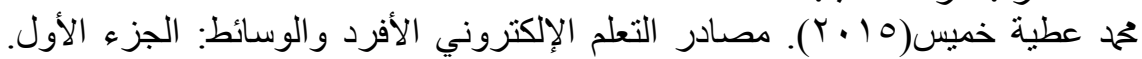

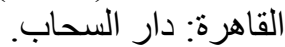
محهد محمود عكاثة (10 (Y). فاعلية موقع الكتروني قائم على التعلم المنتشر في تنمية

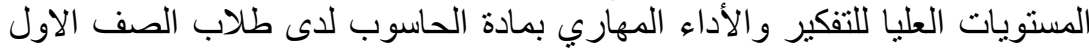

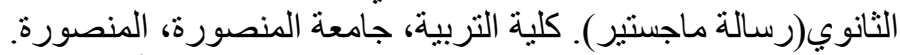

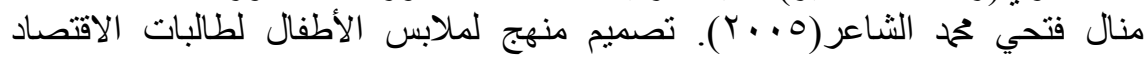

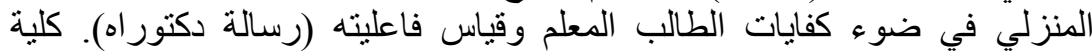

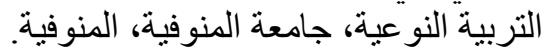

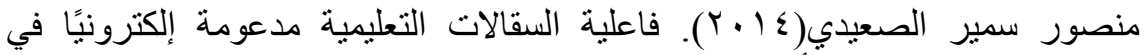

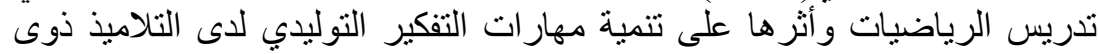

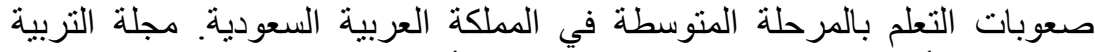

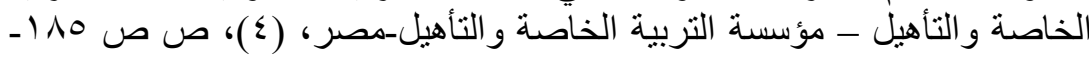

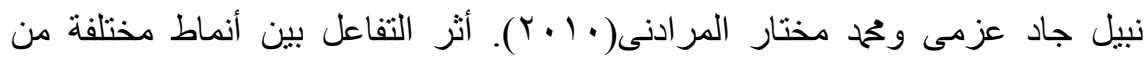

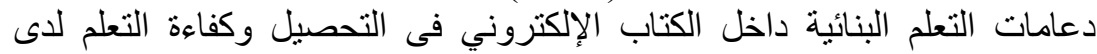

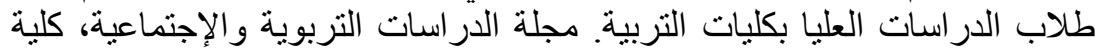

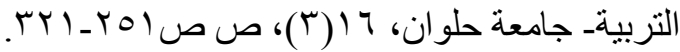

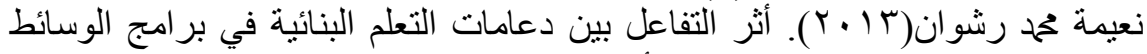

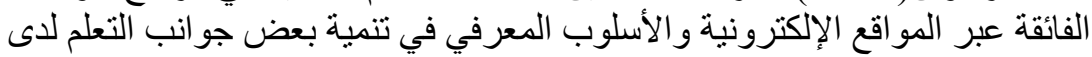

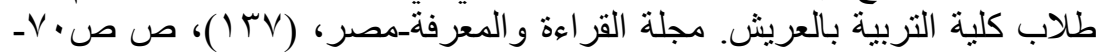




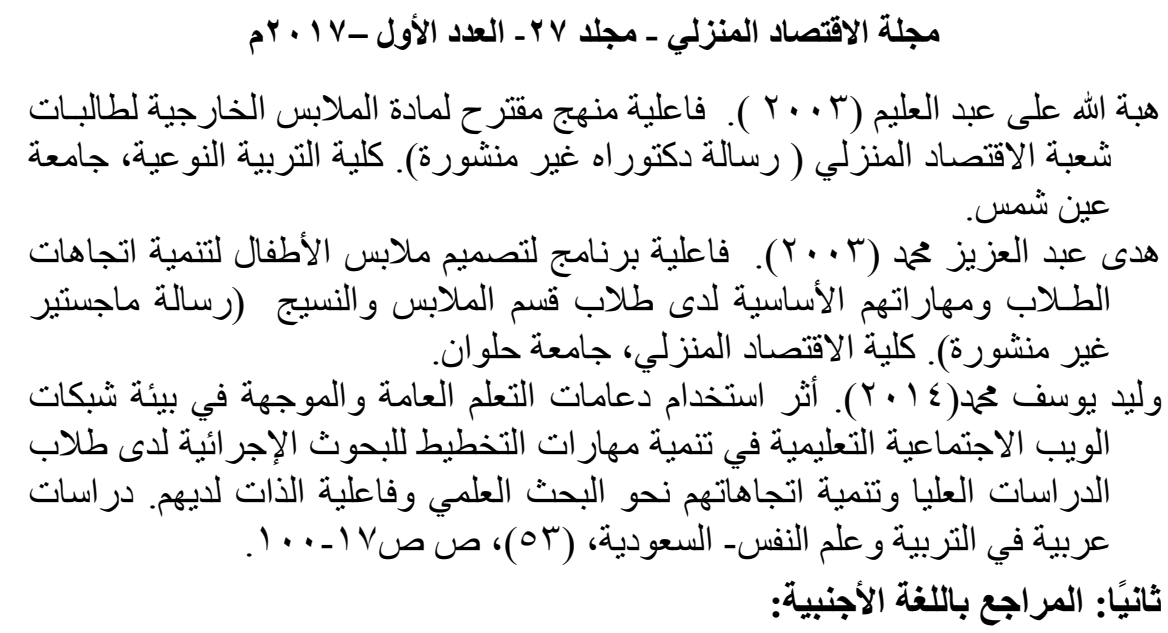

Chin\& Chen, Kai-Yi,Yen-Lin. (2013). A Mobile Learning Support System for Ubiquitous Learning Environments ,Procedia - Social and Behavioral Sciences 73, PP.14-21.

Chu, H. C., Hwang, G. J., \& Tsai, C. C. (2010). A knowledge engineering approach to developing MindTools for context-aware ubiquitous learning. Computers \& Education, 54(1), pp289-297.

Collis, B., Winnips, K.,\&Moonen, J.(2000). Structured support versus learner choice via the world wide web(www): where is the payoff? Journal of Interactive learning Research, 11(2), pp163-196.

Elgazzar, Abdel-latif E.(2014). Developing e learning Environments for Field practitioners and Developmental Researchers: A Third Revision of An ISD model to meet e learning Innovations. Open Journal of Social Sciences, 2014, 2, 29-37 Published Online February 2014 in SciRes. http://www.scirp.org/journal/jss http://dx.doi.org/10.4236/jss.2014.22005

Grosch, M.\&Gidion, G.(2012). Media use for learning by students in higher education an international empirical survey. In t. bastiaens\&g.marks(eds.), proceedings of world conference on $e$ learning in corporate, government, healthcare, and higher education 2012, 1805-1812.

H. Ogata, \& Y. Yano ,\& Yin,C. (2004). “ Context-Aware Support for Computer-Supported Ubiquitous Learning", Paper presented at the 2nd IEEE International Workshop on Wireless and Mobile Technologies in Education, March 23-25, 2004.pp.27

Lee, H. S., \& Songer, N.B.(2010). Expanding an understanding of scaffolding theory using an inquiry fostering science program. Retrived January 01. From www. Biokids, umich. Edu/about /papers/56leesongerscaffolding.pdf. 


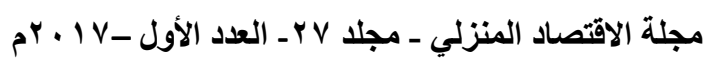

Mary Ann Stahr(2008). Different effectiveness of two scaffolding methods for web evaluation achievement and vetention in high school student, adissertation of doctor of philosophy, kent stata university education, health, and human services.

Norman, H., Din, R., \& Nordin, N(2011). A preliminary study of an authentic ubiquitous learning environment for higher education. pp89-94.

Shih, K. P., Chen, H. C., Chang, C. Y., \& Kao, T.C.(2012). The Development and Implementation of Scaffolding -Based SelfRegulated Learning System for e/m-learning. Educational Technology \& Society, 13(1), pp80-93.

Sung Joung-Souk (2009), "U-learning model design based on ubiquitous environment .International journal of science and technology .13, desember, pp 17-88 www.raypub.com/pdf2003 /chapter/mobiles.pdf

Tan, T.-H., Lin, M.-S., Chu, Y.-L., \& Liu, T.-Y. (2012). Educational Affordances of a Ubiquitous Learning Environment in a Natural Science Course. Educational Technology \& Society, 15(2), pp206219.

Ting, sung, t.-w., huang, y.-m., yang, c.-s\& Yang, j.-t.(2011). Ubiquitous English learning system with dynamic personalized guidance of learning portofolio. Educational technology \& society, 14(4), pp164-180.

Wen, j.- R, Chen, k.-M, Chen, c.-p \& Hsieh, Y.-H.(2013). A study on the application of ubiquitous learning environment to english learning in elementary schools. Universal Journal of Education and General Studies (ISSN: 2277-0984) Vol. 2(2) pp.053065,February,2013Availableonline http://www.universalresearchjournals.org/ujegs.

Yahya, S., Ahmad, E., \& Abd Jalil, K. (2010, February 28). The definition and characteristics of ubiquitous learning: A discussion. International Journal of Education and Development using information and communication technology (IJEDICT), 2010, vol.6, issue1, pp.117-127

Yang, S. J.H.(2006). Context aware ubiquitous learning environment for peer-to-peer collaborative learning. Educational technology \& society, 9(1), pp188-201

Zaho, x., okamoto, t(2011). Adaptive multimedia content delivery for context aware u-learning. International journal of mobile learning and organization, 5(1). 


\section{مجلة الاقتصاد المنزلي - مجلا VY Y العدد الأول _ V + Y م

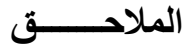

ملحق (1)

الار اسة الاستطلاعية (1) ملانية

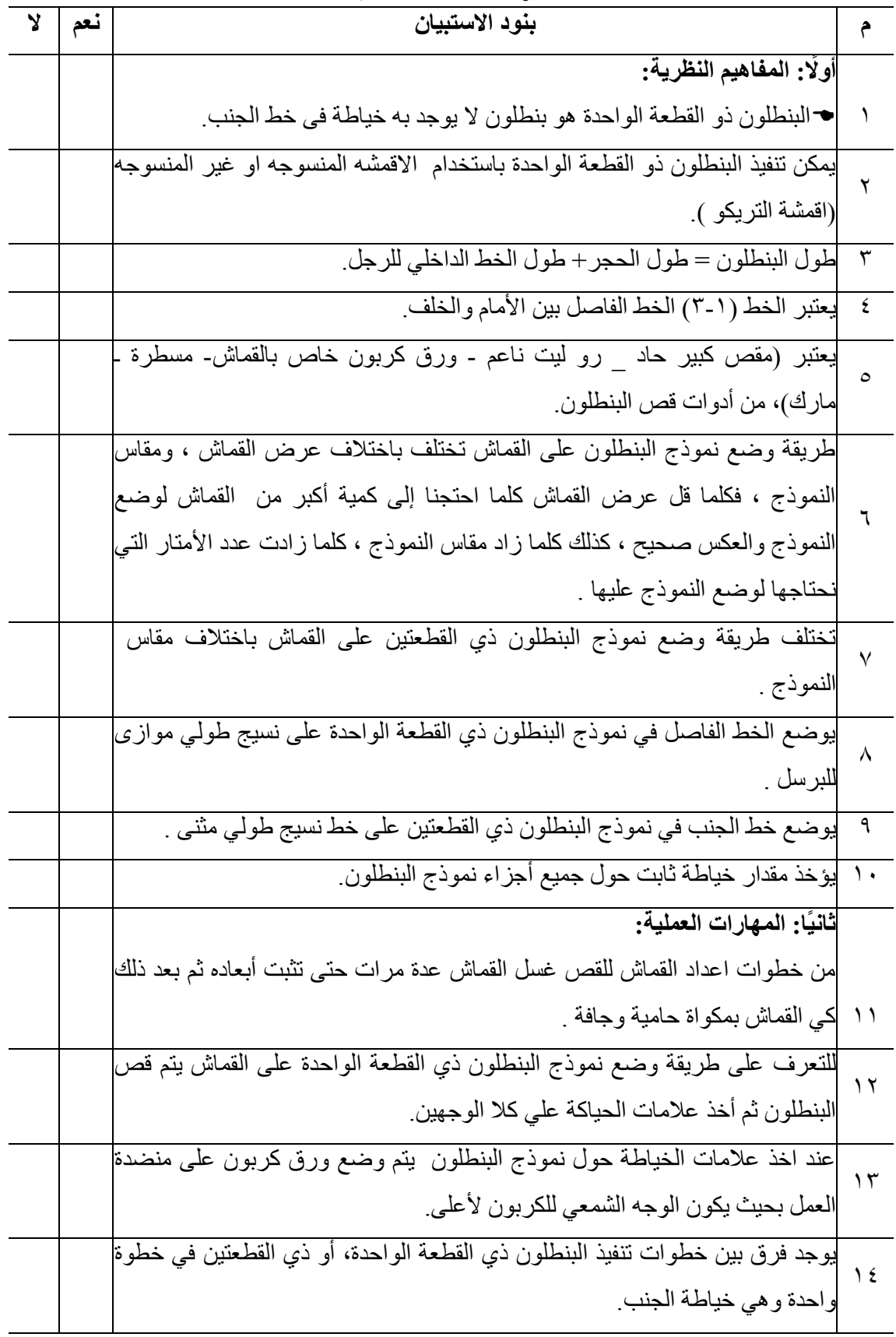


مجلة الاقتصاد المنزلي ـ مجلد V V - العدد الأول _ V - Y م

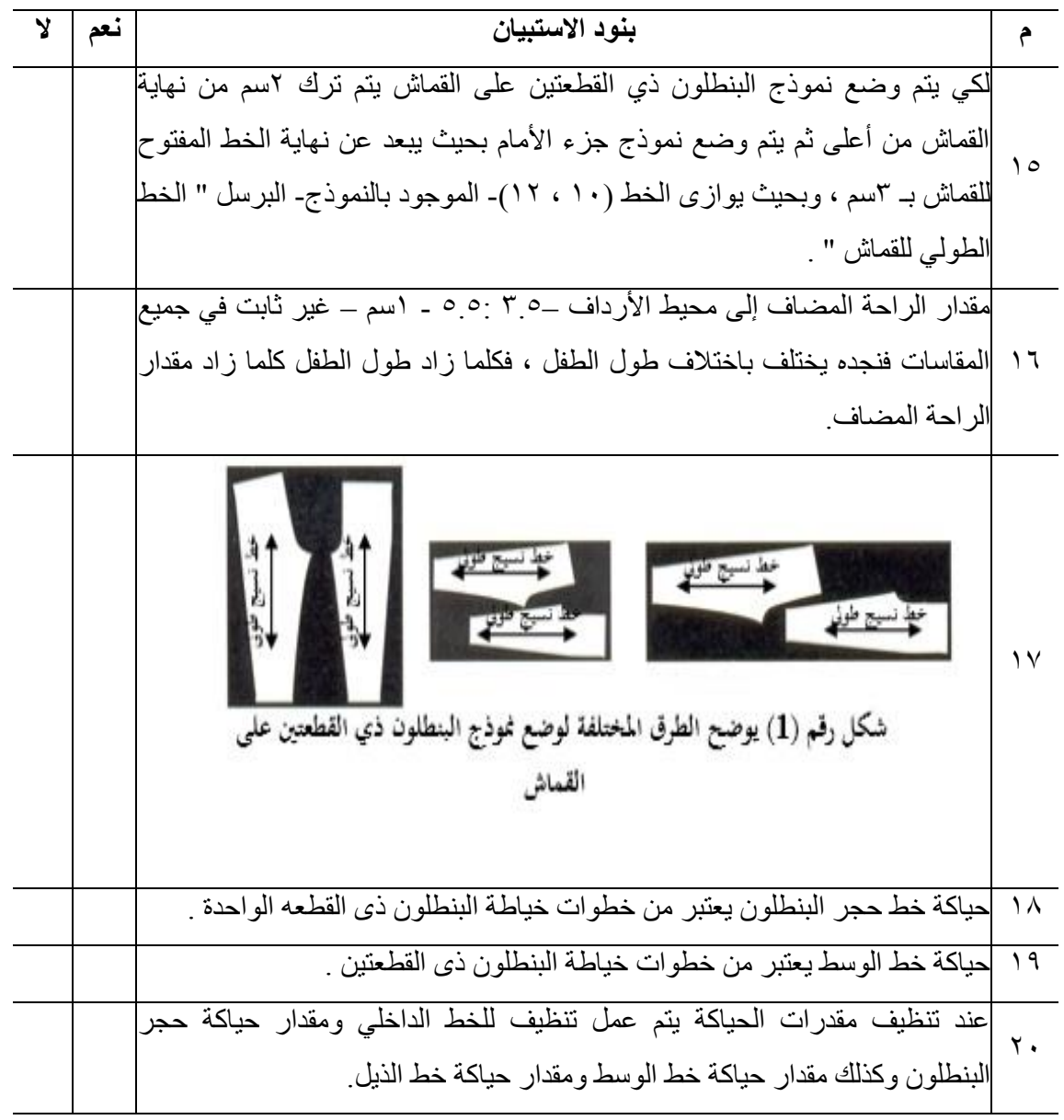




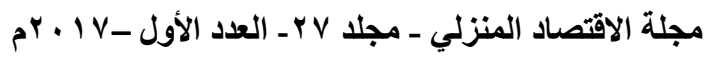

ملحق (r)

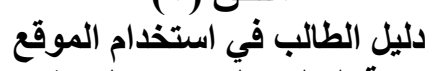

(بيئة التعلم الإلكتروني المنتشر)

الشاشات الافتتاحية للموقع: تحتوى على:

ـ شاثة الترحيب والتعريف بالبيئة:

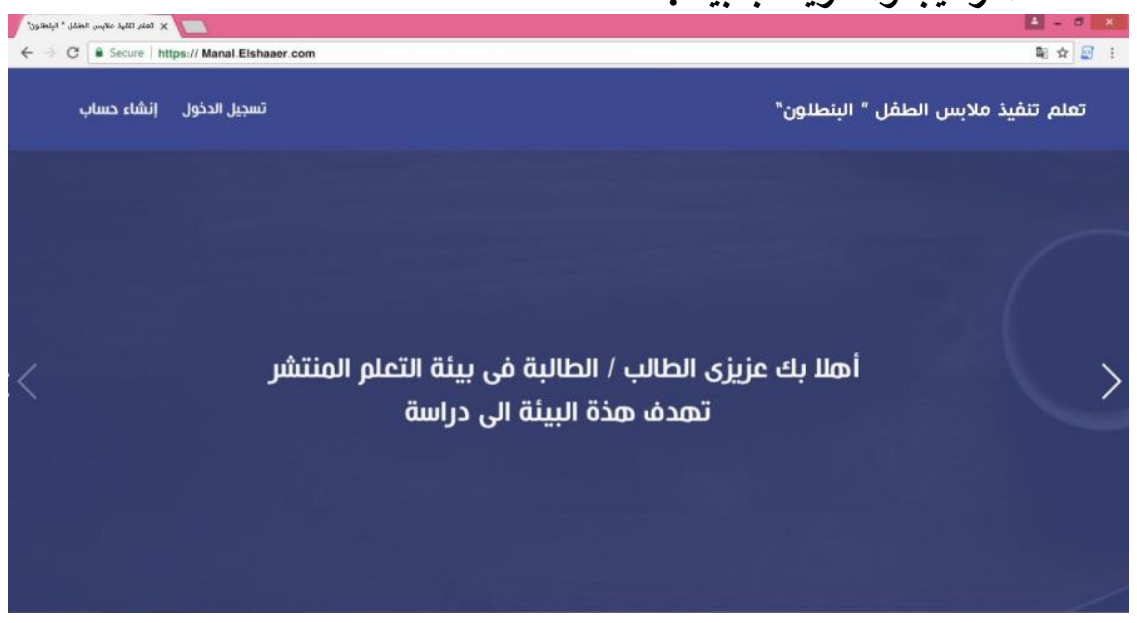

ـ شاشة عنوان البحث وبيانات الباحثة:

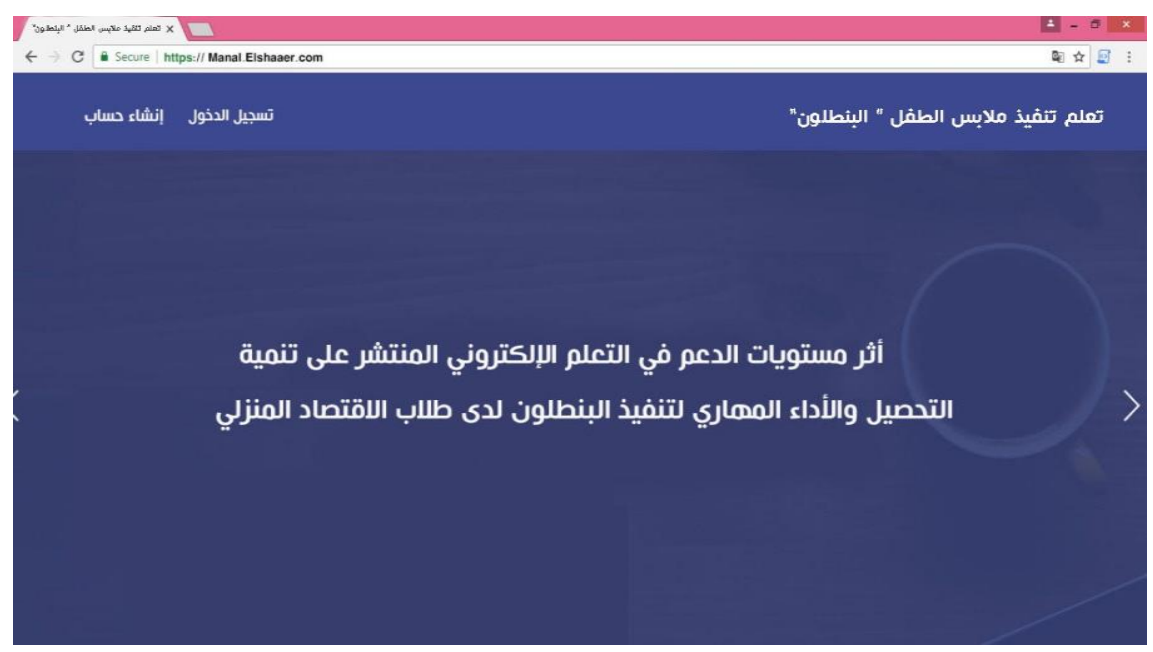



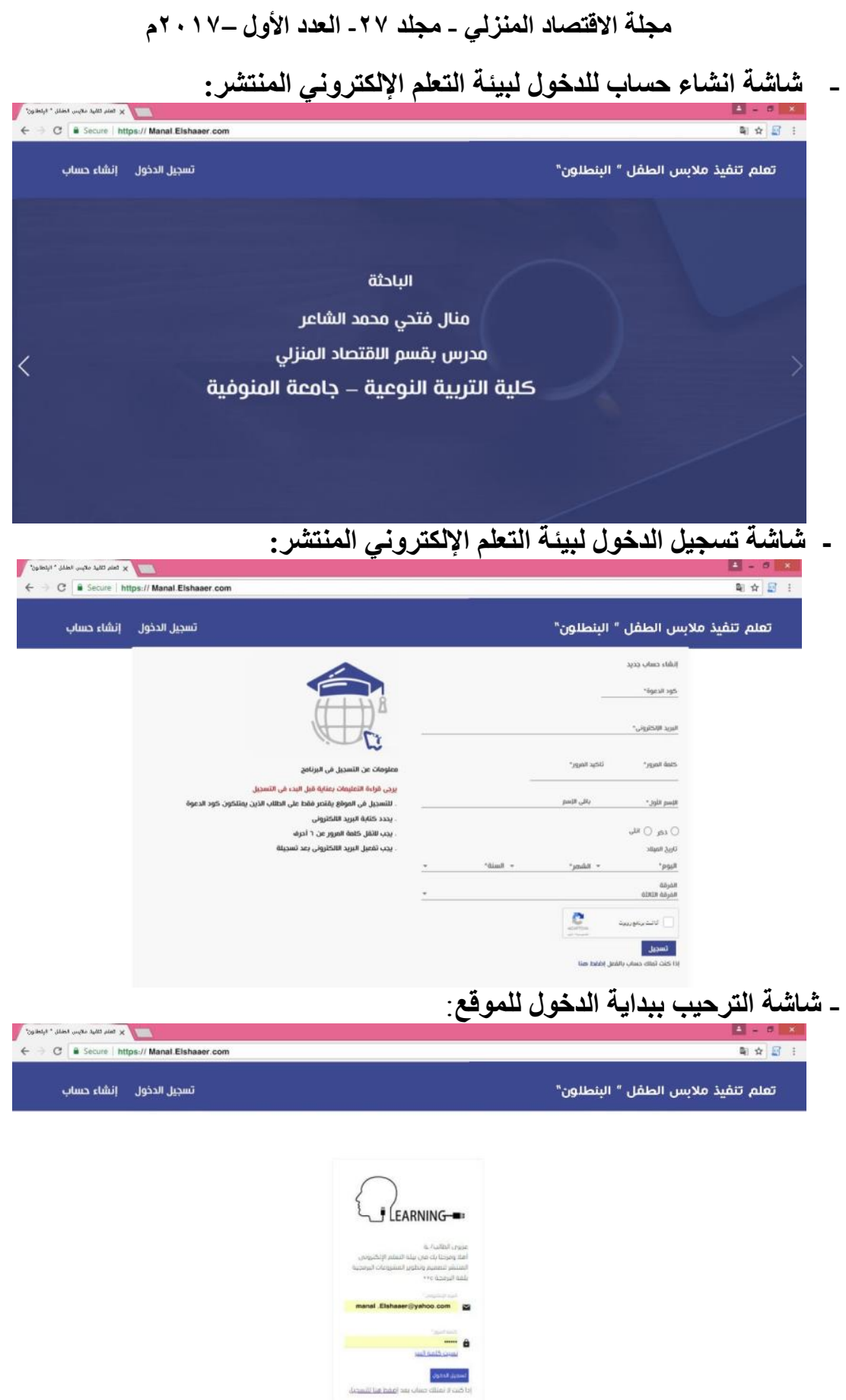


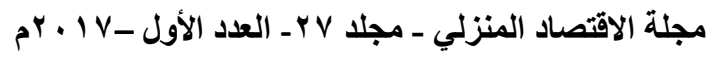

ـ ـ ـاشة واجهة التفاعل و التعليمات العامة لطلاب المجموعات التجريبية:

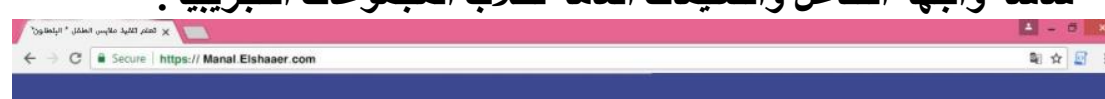

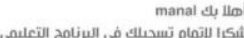

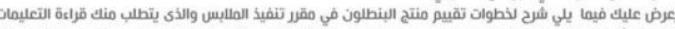

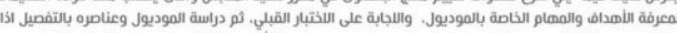

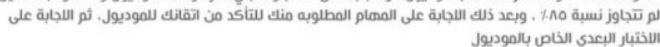

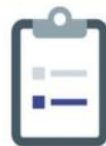

- شاشة الأهداف العامة لمقرر تنفيذ ملابس طقل " البنطلون" ( وتثمل تعليمات كل مجموعة حسب المجموعة التجريبية التي تم توزيع الطلاب بها في البحث البحث الحالي)

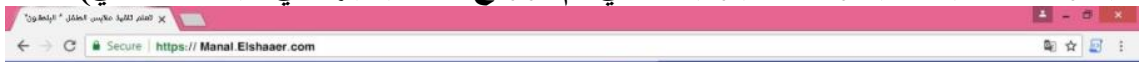
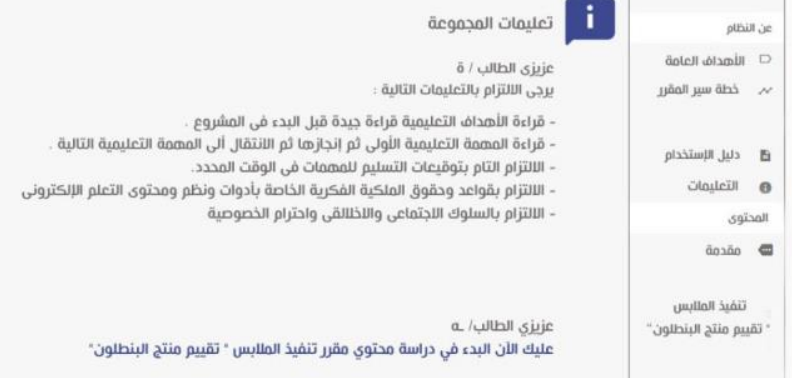

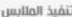

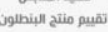

- شاشة المقدمة للمحتوي الخاص بتنفيذ ملابس طفل " البنطلون":

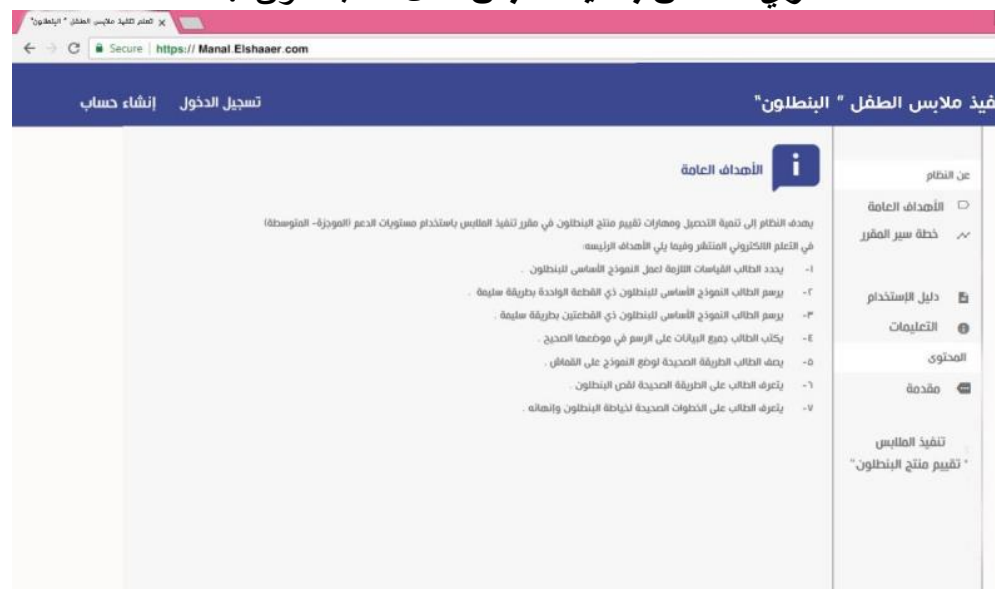




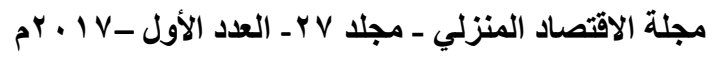

- - شاشـة الأهداف المهارية للمحتوي الخاص بالأداء المهارى لتنفيذ البنطلون:
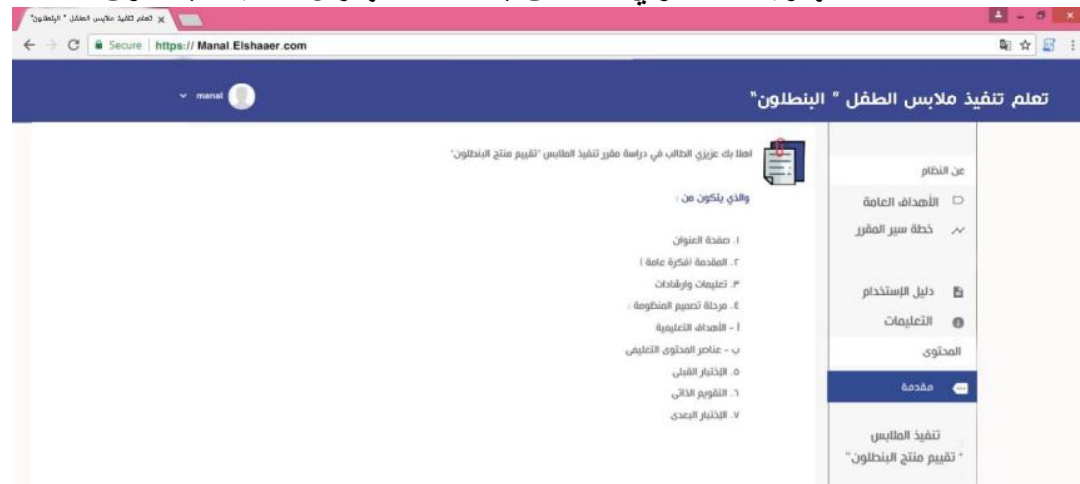

شاشة الاختبار القبلي للموديول:

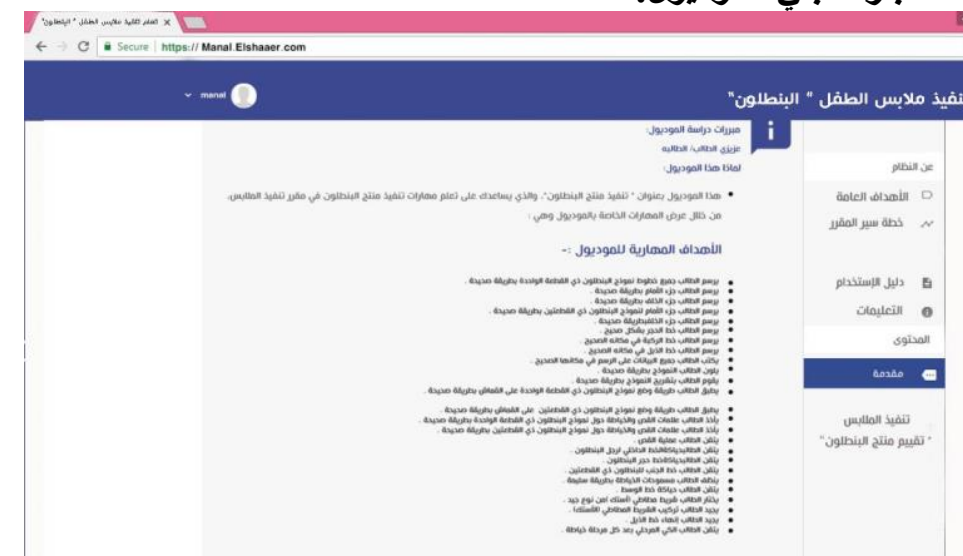

- شاشة عرض عناصر المحتوى الخاصة بالموديول وتقديم الدعم حسب المستوي

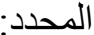

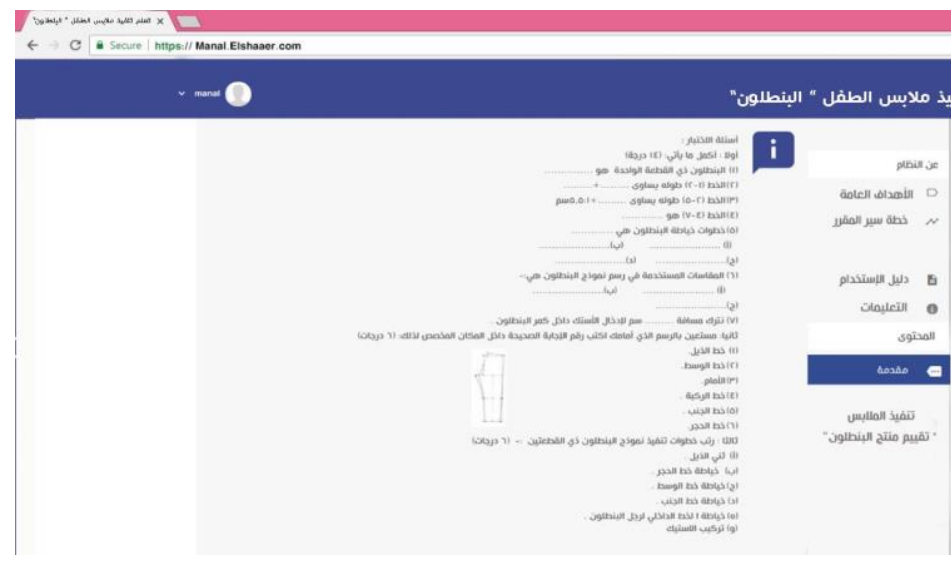




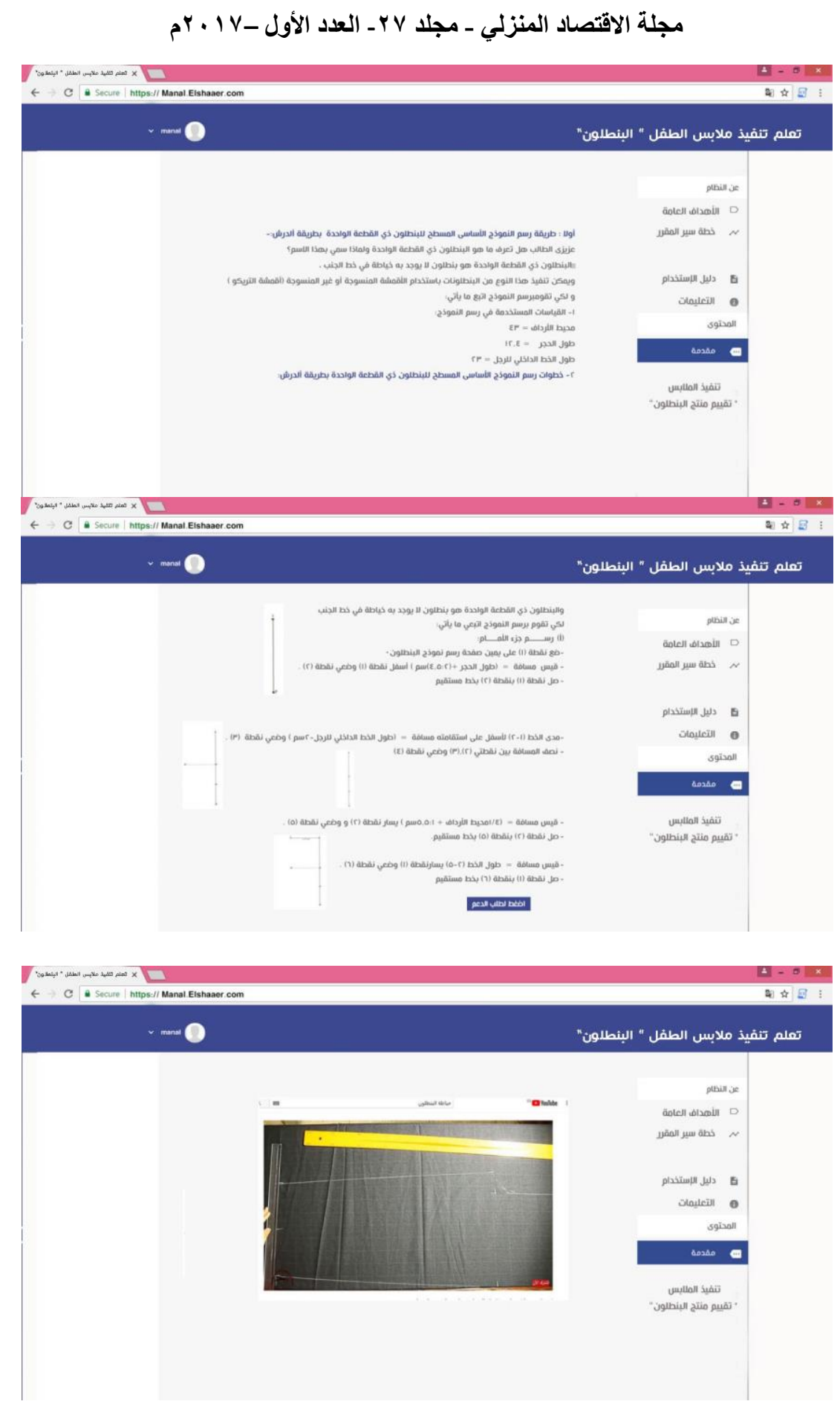




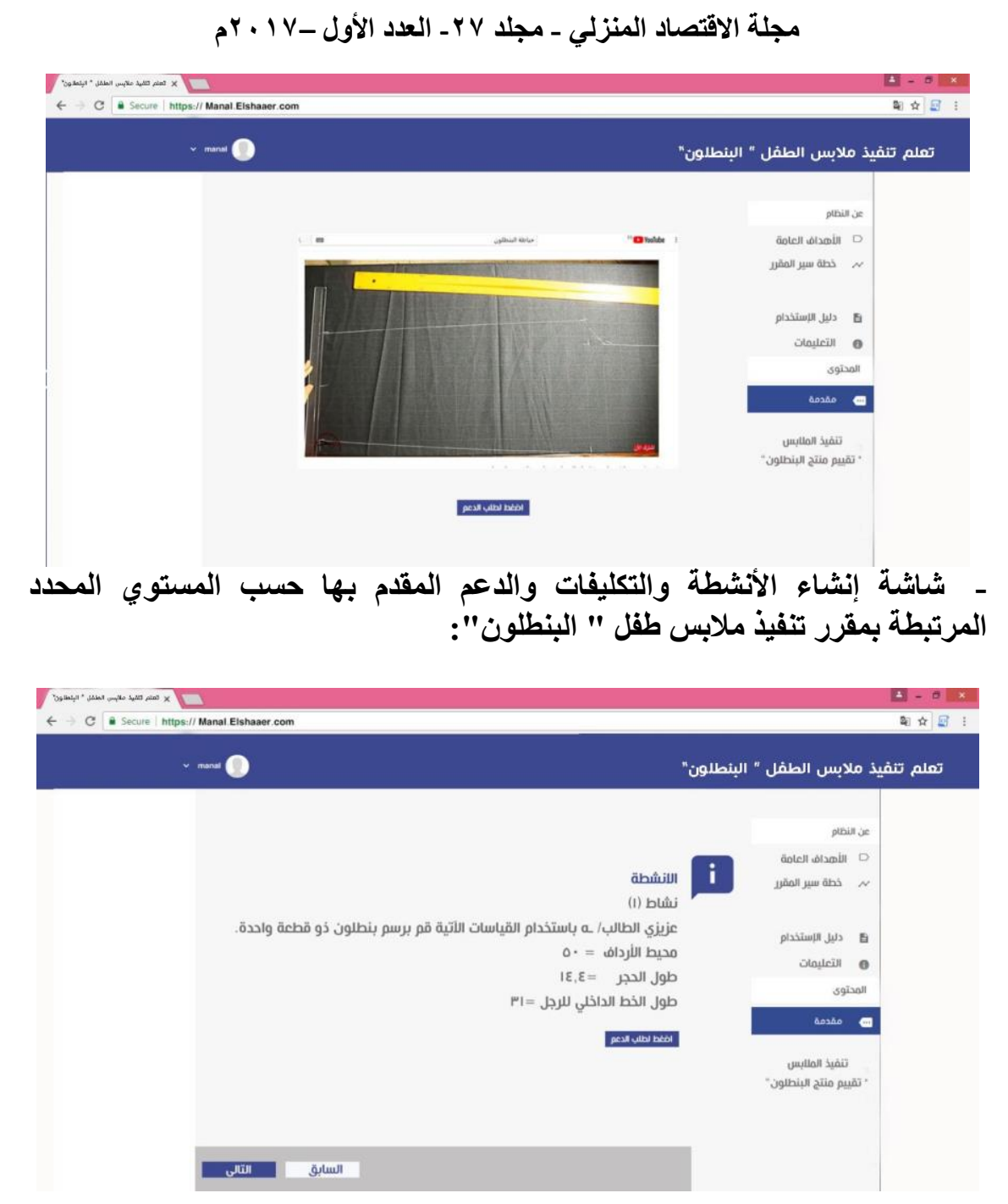




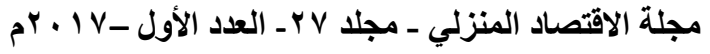

$$
\begin{aligned}
& \text { ملحق (r) } \\
& \text { الاختبار التحصيلي }
\end{aligned}
$$

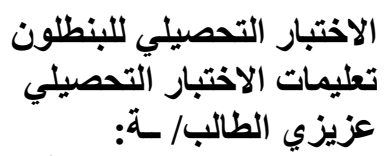

اقرع هذه التعليمات بعناية قبل الطبل أن تبدء في الإجابة على الاختبار:1 ـ صمم هذا الاختبار لقياس مدى تحصيلك للمادة العلمية لمقرر تنفيذ ملابس فلابس طفل

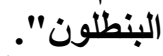

r ـ هذه الكراسة التي بين يايك هي كراسة الأسئلة وهنالك كراسة أخرى للإجابة .

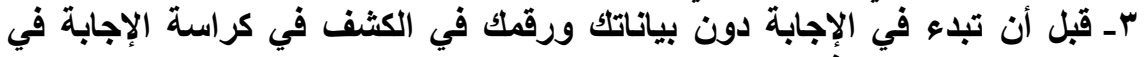

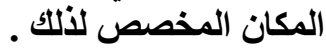

ــ استخدم القلم الرصاص في الإجابة حتى يمكنك تغيلة الإسيلة الإجابة بمحو الإجابة الخاطئة

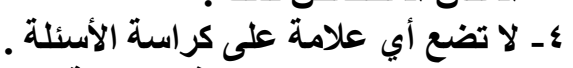

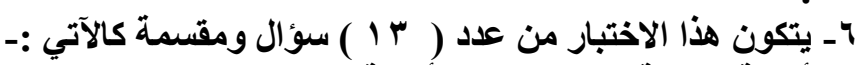

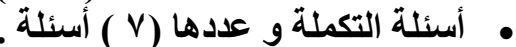

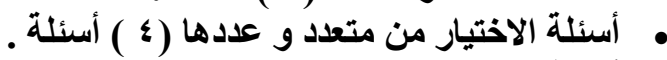

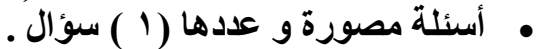

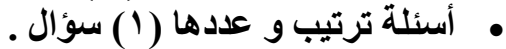

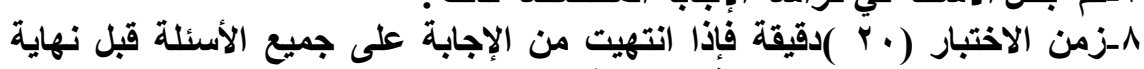

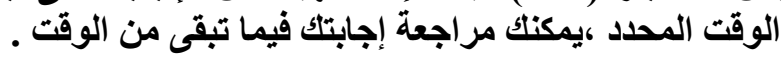

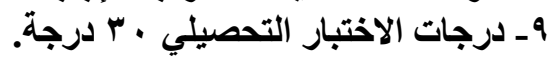

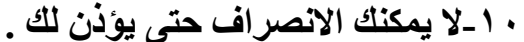

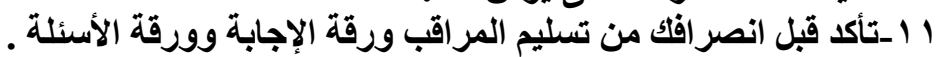

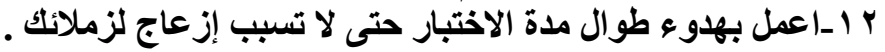
مع تمنياتي للك بالتوفيق ، ، الباحثة 


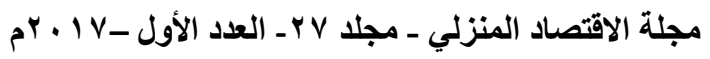

أسئلة الاختبار :

أولا : أكمل ما يأتي: (ع ا درجة)

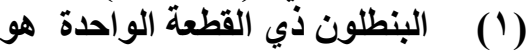

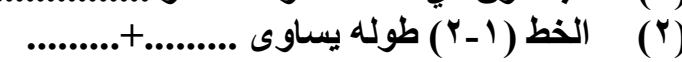

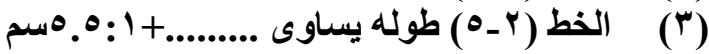

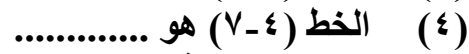

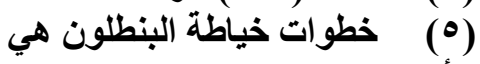

(ب)

(د) (د) (د) (د) (4)

(") (المقاسات المستخدمة في رسم نموذج البنطلون هي:-

(ب)

(ج)

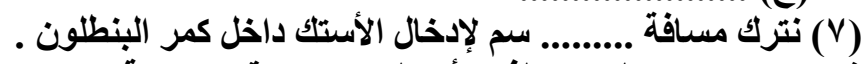

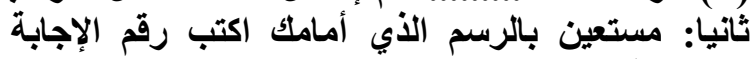

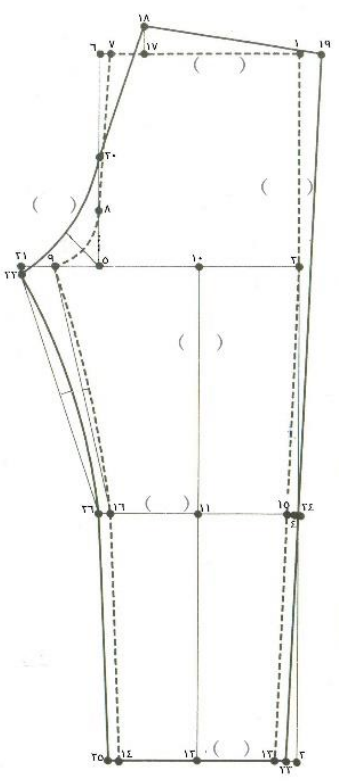

الصحيحة داخل المكان المخصص لذلكت: († درجات)

(1) (1) خ خط الذيل.

(r) (r) خط الوسط.

الأمام.

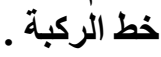

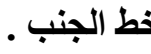

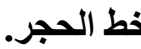

ثالثا : رتب خطوات تنفيذ نموذج البنطلون ذي القطعتين :- (ף درجات)

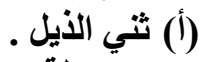

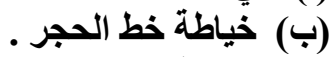
(ج) (ب) خيطة خط خط الوسط .

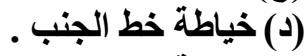

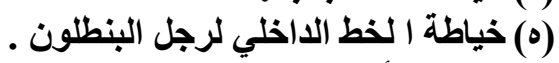
(و)تركيب الأستك . ل 


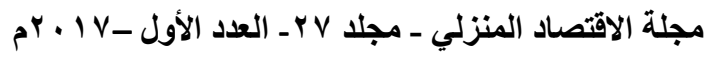

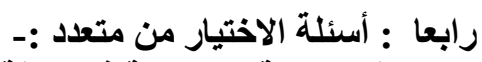

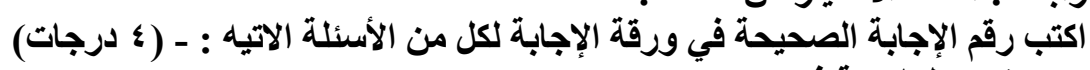
(1)

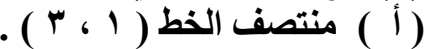

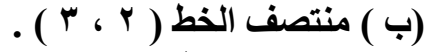

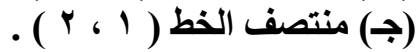

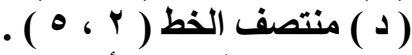

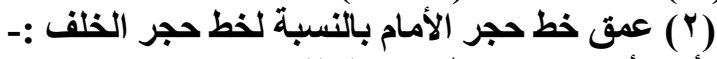

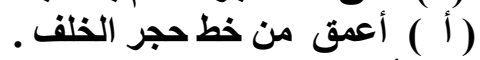

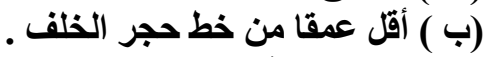

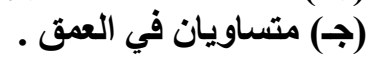

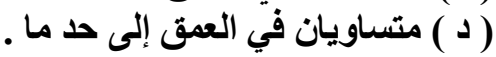

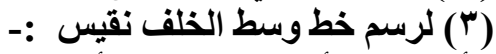

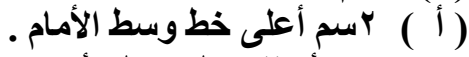

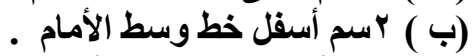

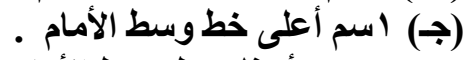

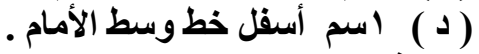

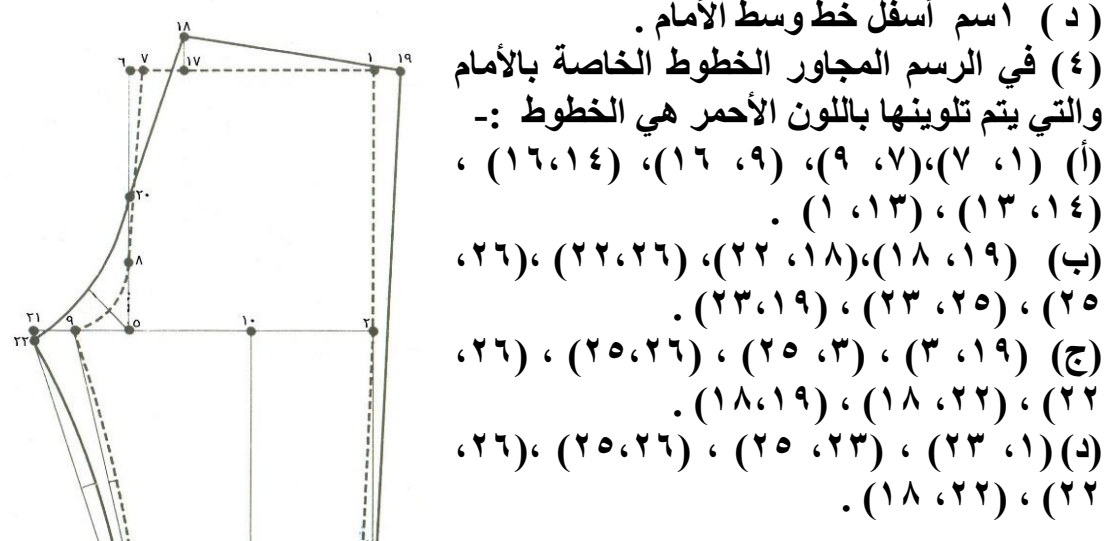




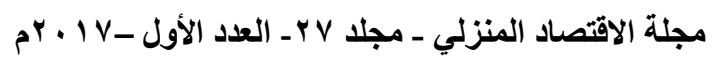

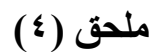

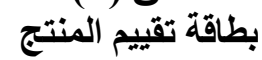

أولا : خطوات رسم النموذج الأساسى المسطح للبنطلون ذي القطعة الواحدة بطريقة ألارش:

\begin{tabular}{|c|c|c|c|c|c|c|}
\hline$\overline{\bar{y}}$ & \multicolumn{4}{|c|}{ تم إنجاز الأكاء } & \multirow{5}{*}{ بطاقة تقييم المنتج } & \\
\hline & \multirow{3}{*}{$y$} & \multirow{2}{*}{\multicolumn{3}{|c|}{ نعستوى الأداء }} & & \\
\hline & & & & & & \\
\hline & & منفضض & متوبط & موتخع & & \\
\hline & $\cdot$ & 1 & r & r & & \\
\hline & & & & & تضع نقطة ( ) على يمين صفحة رسم نموذج البنطلون. & \\
\hline & & & & & 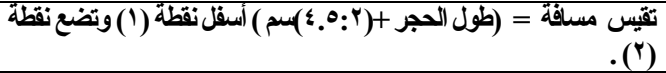 & \\
\hline & & & & & تصل نقطة (1) بنقطة (r) بخطمستقيم & \\
\hline & & & & & 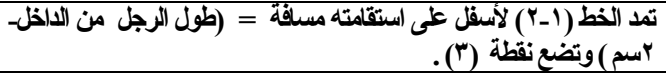 & 3 \\
\hline & & & & & تتصف المسافة بين نقطتي (Y),(Y')وضعي نقطة (؟) & $d$ \\
\hline & & & & & 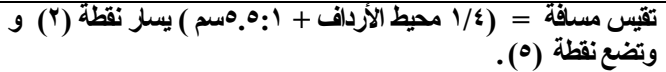 & \\
\hline & & & & & تصل نقطة (ץ) بنقطة (0) بخطمستقيم. & a \\
\hline & & & & & تقيس مسافة = طول الخط (Y،0) يسلر نقطة (1) )وتضع نقطة ("). & $\bar{x}$ \\
\hline & & & & & تصل نقطة (1) بنقطة (7) بخطمستقيم . & \\
\hline & & & & & 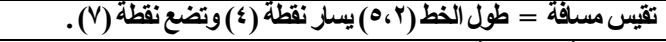 & \\
\hline & & & & & تصل نقطة (؟) بنقطة (V) بخطمستقيم. & \\
\hline & & & & & تكتب عبارة خط الركبة بمحاذّة الخط (V-\&) & \\
\hline & & & & & تقيس مسافة = طول الخط (Y،O) يسلر نقطة (r) وتضع نقطة (^) . & \\
\hline & & & & & تصل نقطة (r) بنقطة (^) بخطمستقيم. & \\
\hline & & & & & 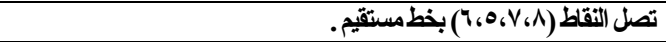 & \\
\hline & & & & & 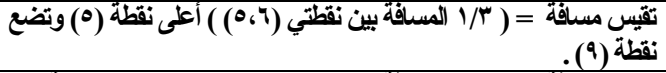 & \\
\hline & & & & & 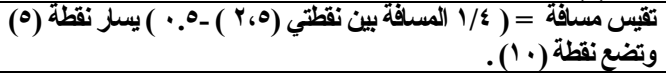 & \\
\hline & & & & & تمد الخط (r-0) لليسلر على استقامتّه الى نقطة (• (1). & \\
\hline & & & & & ه v. اسم نقطة (9) بنقطة (• ( ) بخط منحنى بحيث ييعد عن نقطة (0) مسافة & \\
\hline & & & & & 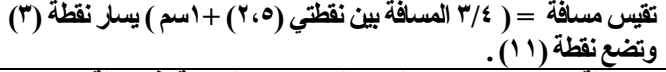 & \\
\hline & & & & & 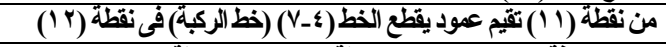 & \\
\hline & & & & & 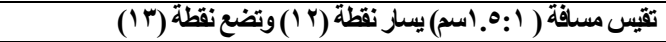 & \\
\hline & & & & & تصل نقطة (• (1) بنقطة (r ا ) بخطمستقيم. & \\
\hline & & & & & 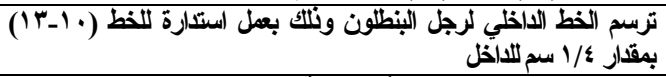 & \\
\hline & & & & & تمد الخط المنحنى اللسلق حتى أعلى نقطة (1 ') ب عسم & \\
\hline & & & & & تكمل الخط السلق على استقامته إلى نقطة (' ') & \\
\hline & & & & & 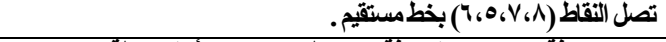 & \\
\hline & & & & & 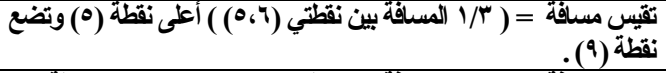 & \\
\hline & & & & & 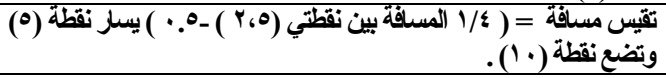 & \\
\hline
\end{tabular}


مجلة الاقتصاد المنزلي - مجلد V V- العدد الأول _ V - Y م

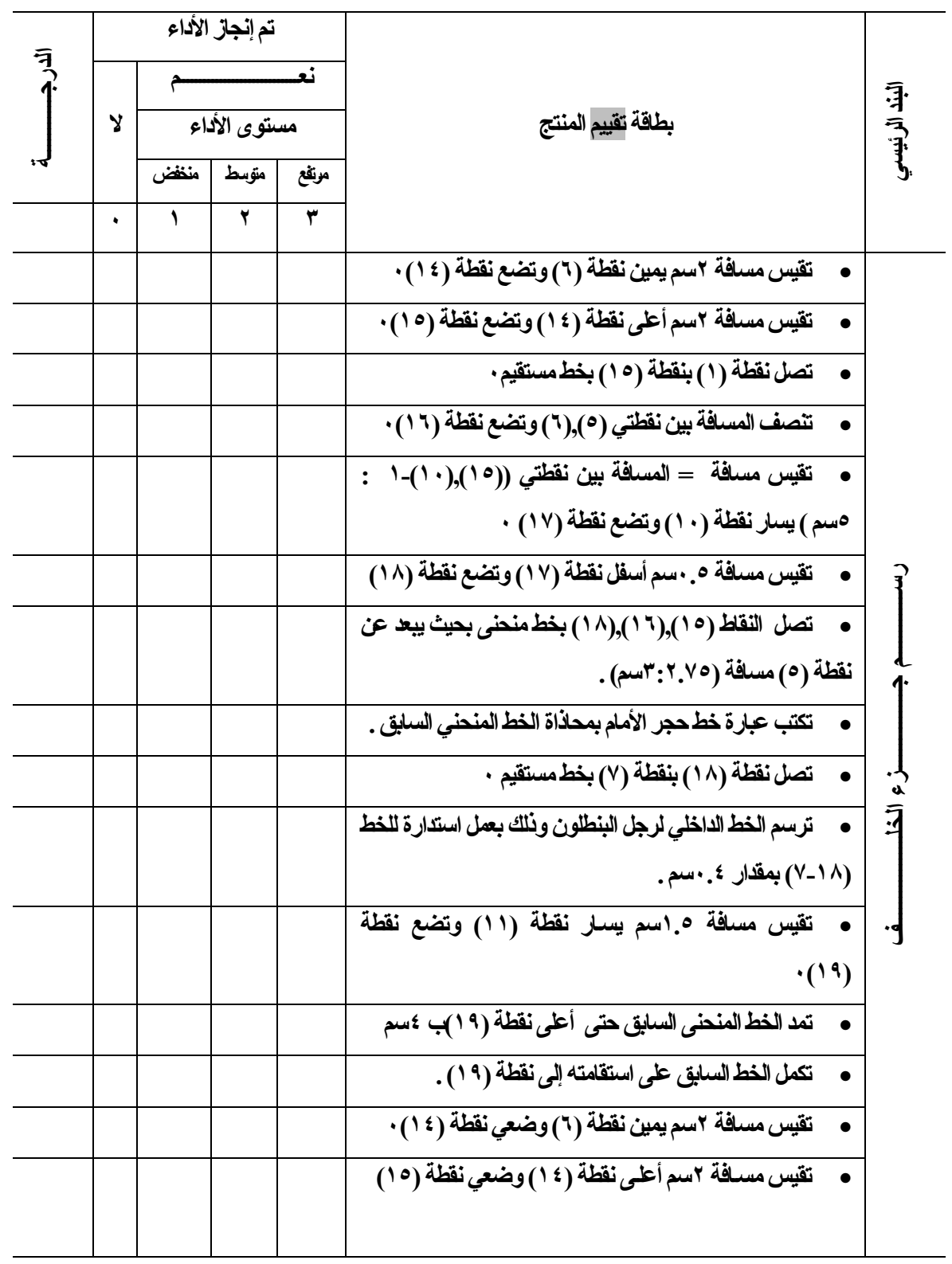




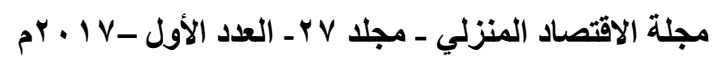

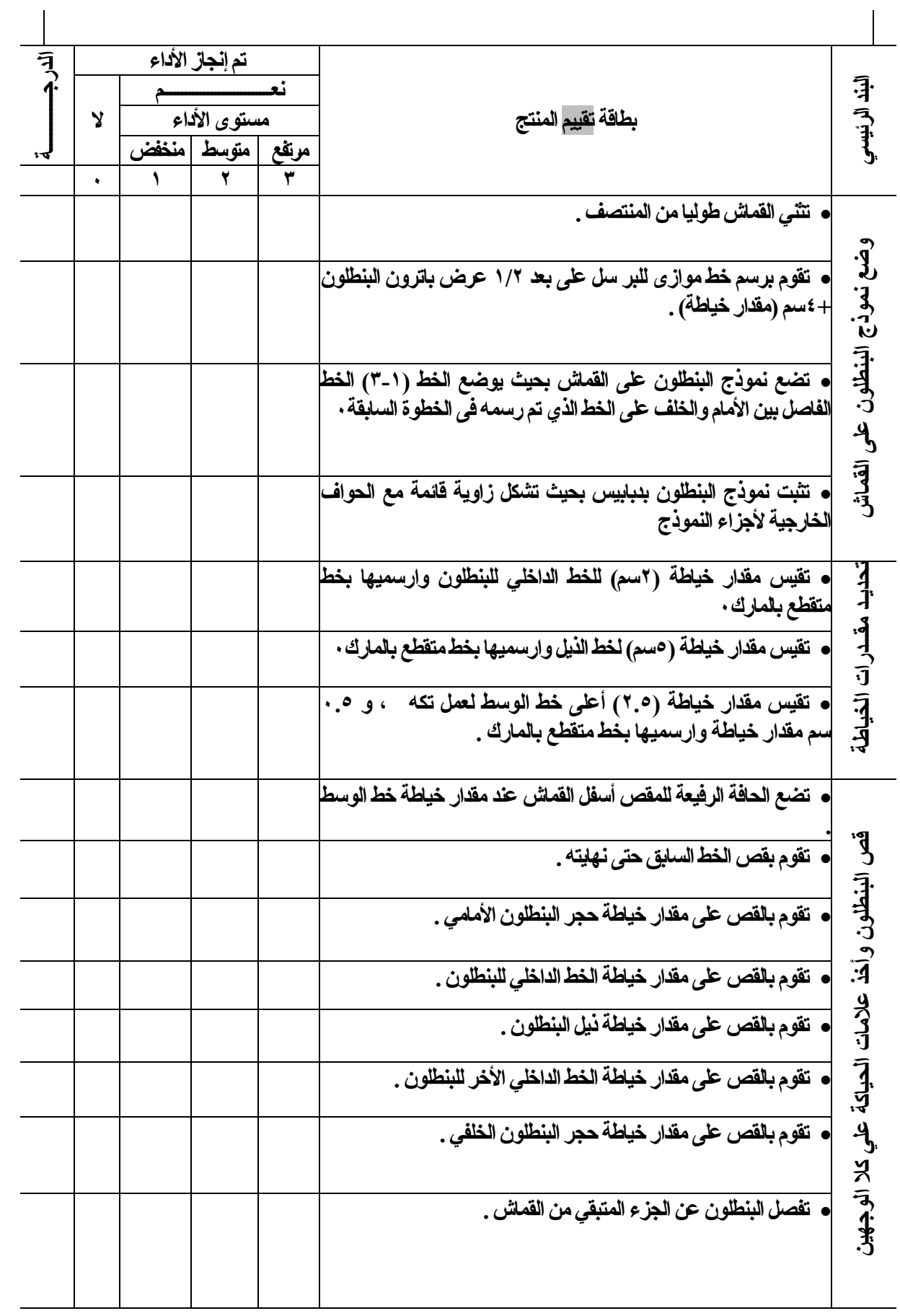




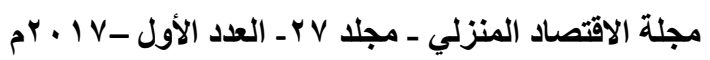

\begin{tabular}{|c|c|c|c|c|c|c|}
\hline \multirow{4}{*}{$\sqrt[7]{7}$} & \multicolumn{4}{|c|}{ تم إنجاز الأداء } & \multirow{5}{*}{ بطقة تقييم المنتج } & \\
\hline & \multirow{3}{*}{ لا } & \multirow{2}{*}{\multicolumn{3}{|c|}{ مستوى الأداء }} & & \\
\hline & & & & & & \\
\hline & & 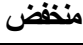 & 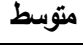 & 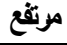 & & \\
\hline & $\cdot$ & 1 & $r$ & $r$ & & \\
\hline & & & & & • تطم بلمارك على جميع حلود نموذج البنطون . & \\
\hline & & & & & • تضكِع ويق كريون على منضدة العل بحيث يكون الوجه الثمعي & i) $\frac{9}{3}$ \\
\hline & & & & & • تضع القماش المثبت عليه نموذج البنطلون على وق الكريون . & 8 \\
\hline & & & & & •عمي بالروليت على حلود النموذج حتى نهاية مقار الخياطة. & 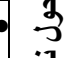 \\
\hline & & & & & 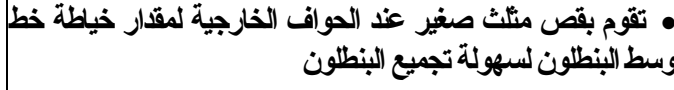 & 管. \\
\hline & & & & & • • نرفع النموذج الورقي من على القماث . & \\
\hline & & & & & 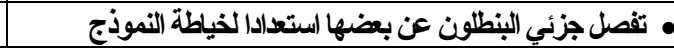 & \\
\hline
\end{tabular}

ثانيا : خطوات رسم النموذج الأساسى المسطح للبنطلون ذي القطعتين بطريقة ألدرش:

\begin{tabular}{|c|c|c|c|c|c|c|}
\hline \multirow{4}{*}{$\sqrt{\overline{7}}$} & \multicolumn{4}{|c|}{ تم إتجاز الأداء } & \multirow{5}{*}{ بطاقة تقييم المنتج } & \\
\hline & \multirow{3}{*}{ لا } & & 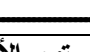 & & & \\
\hline & & \multicolumn{3}{|c|}{ مستوى الأذاء } & & \\
\hline & & 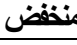 & 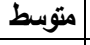 & 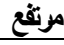 & & \\
\hline & - & 1 & r & r & & \\
\hline & & & & & هـ تضع نقطة (1) على يمين صفحة رسم نموذج البنطلون. & \\
\hline & & & & & 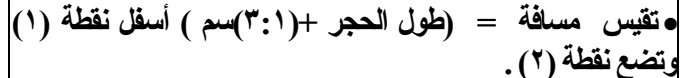 & \\
\hline & & & & & متصل نقطة (1) بنقطة (r) بخط مستقيم & \\
\hline & & & & & 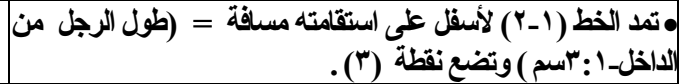 & \\
\hline & & & & & متتصف المسافة بين نقطتي (r, r (r) وضعي نقطة (؟) . & \\
\hline & & & & & وتضع نقطة (॰). & \\
\hline & & & & & (1) تقيس مسلفة = طول الخط (r،0) يسلر نقطة (1) وتضع نقطة & 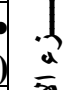 \\
\hline & & & & & | ه تصل نقطة (1) بنقطة (1) بخطمستقيم. & \\
\hline & & & & & ه تقيس مسافة اسم يمين نقطة (†) وتضع نقطة (V). & \\
\hline & & & & & ـ تكتب عبارة خطوسط الأمام بمحاذاة الخط (1، V) . & \\
\hline & & & & & | من نقطة (צ) تمد خط أفقي جهة اليسار لمسلفة تسلوى طول الخط & \\
\hline & & & & & مو من نقطة (r) تمد خط أفقي جهة اليسار لمسافة تسلوى طول الخط & \\
\hline
\end{tabular}




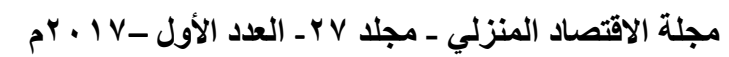

\begin{tabular}{|c|c|c|c|c|c|}
\hline \multirow{4}{*}{$\int_{1}^{\overline{7}}$} & \multicolumn{4}{|c|}{ تم إنجاز الأداء } & \multirow{5}{*}{ بطاقة تقييم المنتج } \\
\hline & \multirow{3}{*}{ ل } & \multirow{2}{*}{\multicolumn{3}{|c|}{ نعستوى الأداء }} & \\
\hline & & & & & \\
\hline & & منغقضض & متوسط & مرنفع & \\
\hline & $\cdot$ & 1 & $r$ & $r$ & \\
\hline & & & & & • تصل نقطة (ך) بنقطة (0) بخط مستقيم. \\
\hline & & & & & 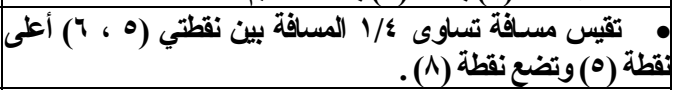 \\
\hline & & & & & 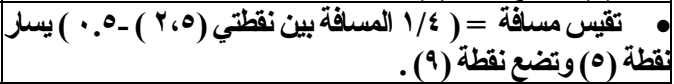 \\
\hline & & & & & 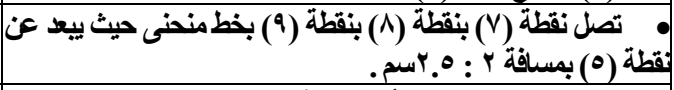 \\
\hline & & & & & • تكتب عبارة خطحجر الأمام بمحاذاة الخط المنحني السليق. . \\
\hline & & & & & 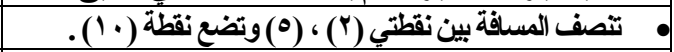 \\
\hline & & & & & 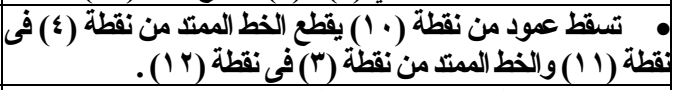 \\
\hline & & & & & 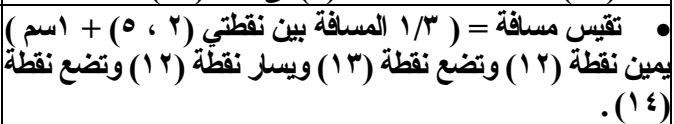 \\
\hline & & & & & 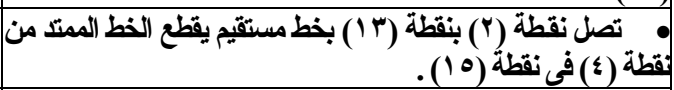 \\
\hline
\end{tabular}

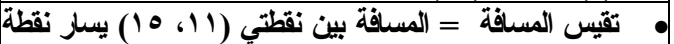

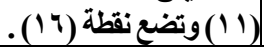

\begin{tabular}{|c|c|c|c|c|c|c|}
\hline \multirow{4}{*}{$\int_{1}^{\overline{7}}$} & \multicolumn{4}{|c|}{ تم إنجاز الأداء } & \multirow{5}{*}{ بطاقة تقيميم المنتج } & \multirow{5}{*}{$\begin{array}{l}\text { 䒠 } \\
\overline{3} \\
3\end{array}$} \\
\hline & \multirow{3}{*}{ ע } & 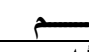 & 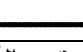 & & & \\
\hline & & \multicolumn{3}{|c|}{ مستوى الأداء } & & \\
\hline & & منغقضض & متوسط & مرنقع & & \\
\hline & . & 1 & $r$ & $r$ & & \\
\hline & & & & & • تصل نقطة (9) بنقطة (9 (1) بخطمستقيم. & \\
\hline & & & & & 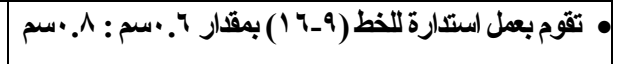 & \\
\hline & & & & & • تصل نقطة (7 (1) بنقطة (ع (1) بخط مستقيم. & \\
\hline & & & & & • تقيس مسافة r: ه. "rسم يمين نقطة (V) وتضع نقطة (IV) & \\
\hline & & & & & 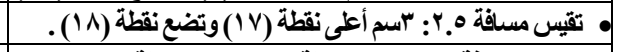 & \\
\hline & & & & & • تقيس مسلفة بسم يمين نقطة (1) وتضع نقطة (9 (1) ). & $\overrightarrow{3}$ \\
\hline & & & & & • تصل نقطة (9 (1) بنقطة (1 (1) بخطمستقيم. & \\
\hline & & & & & • ت تكتب عبارة خطوسط الخلف بمحذاة الخط (1)، 9 ( ) ). & \\
\hline & & & & & 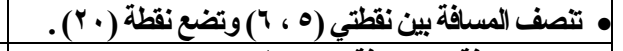 & \\
\hline & & & & & 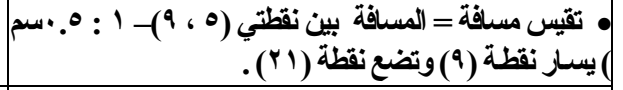 & $\overline{7}$ \\
\hline & & & & & 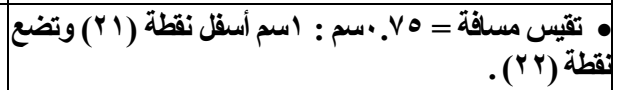 & \\
\hline
\end{tabular}




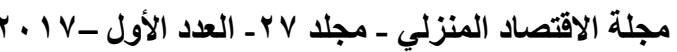

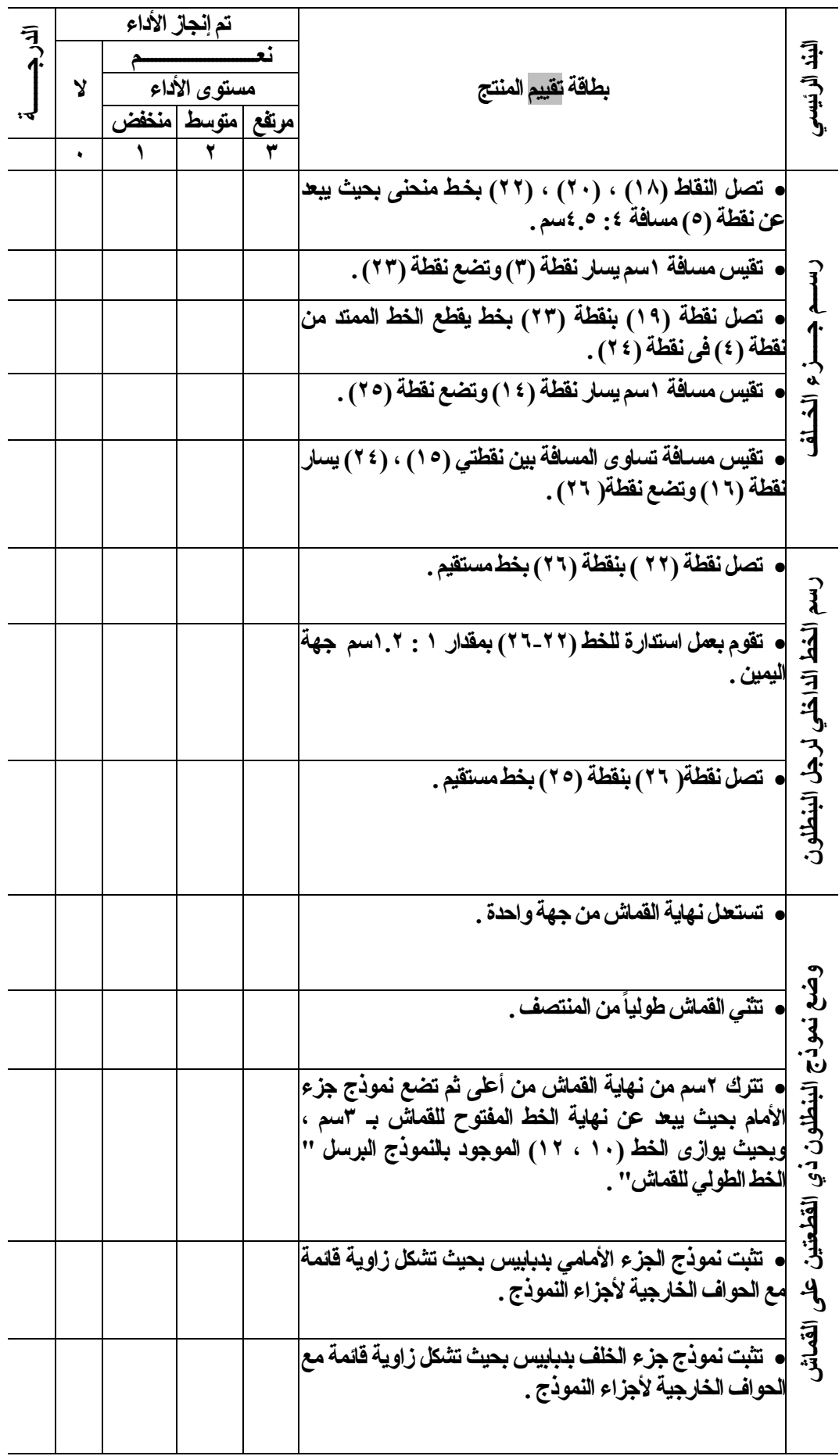


مجلة الاقتصاد المنزلي - مجلد V V - العدد الأول _ V • r م

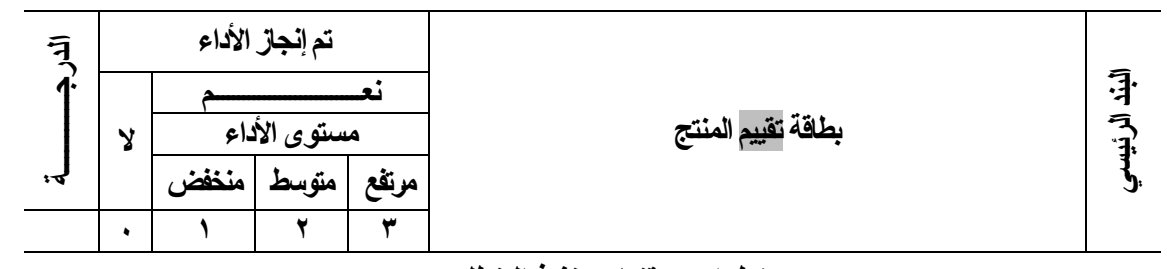

خطوات وتقنيات تنفيذ البنطلون :

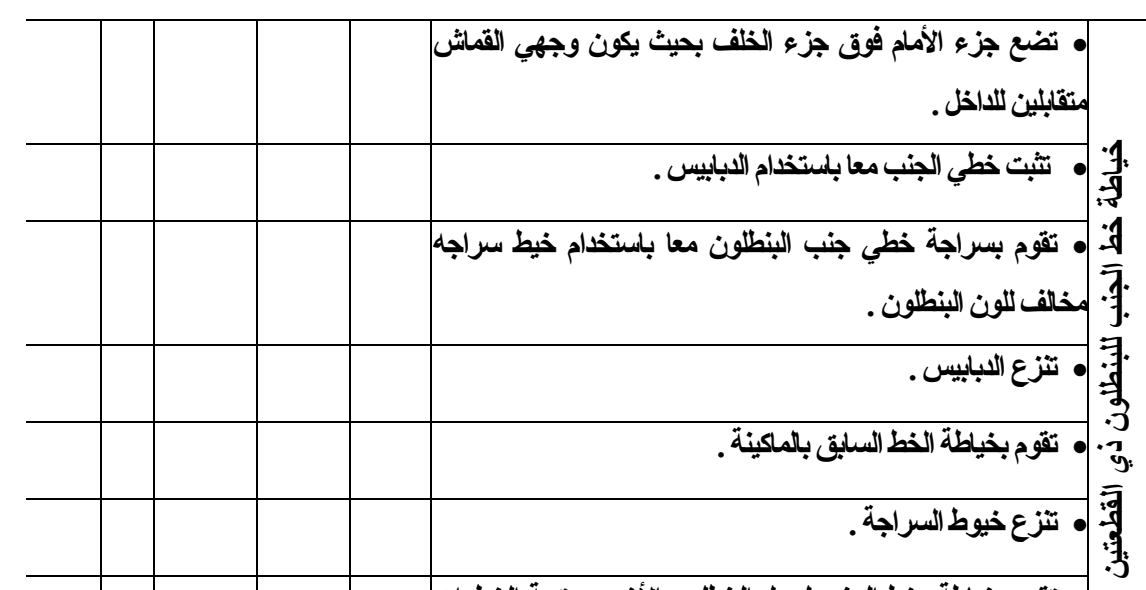

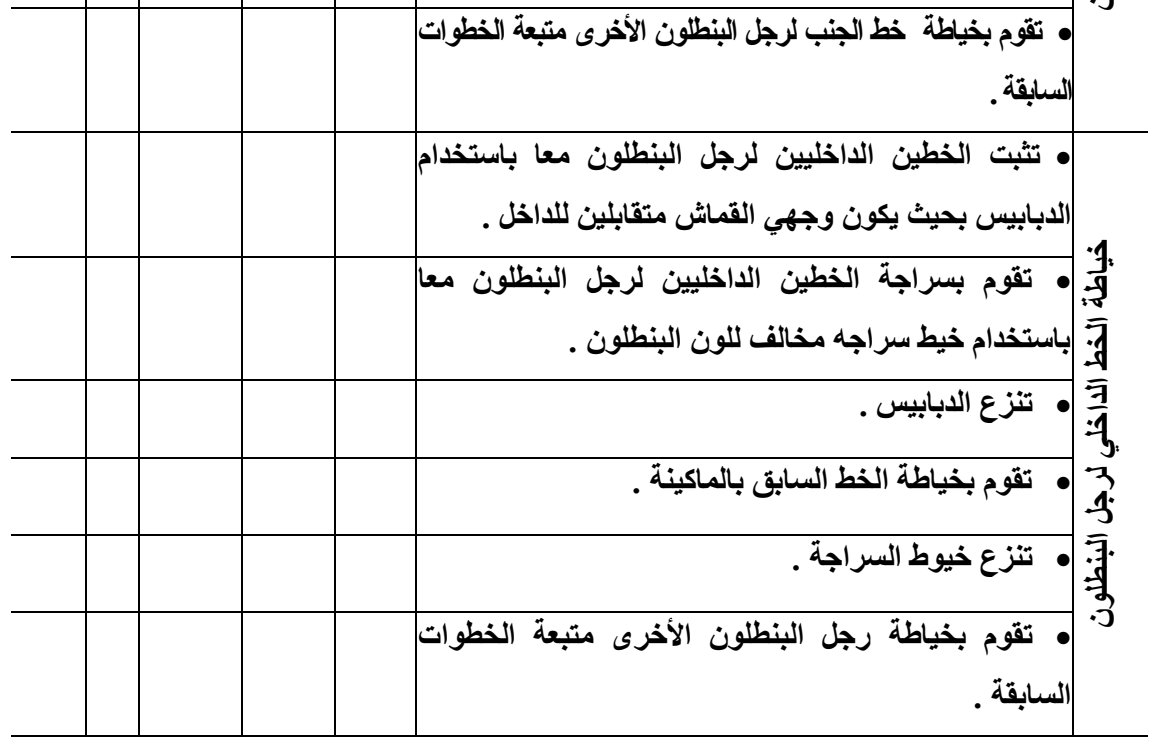




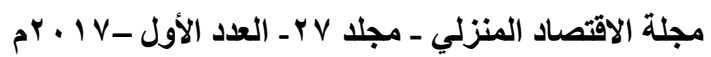

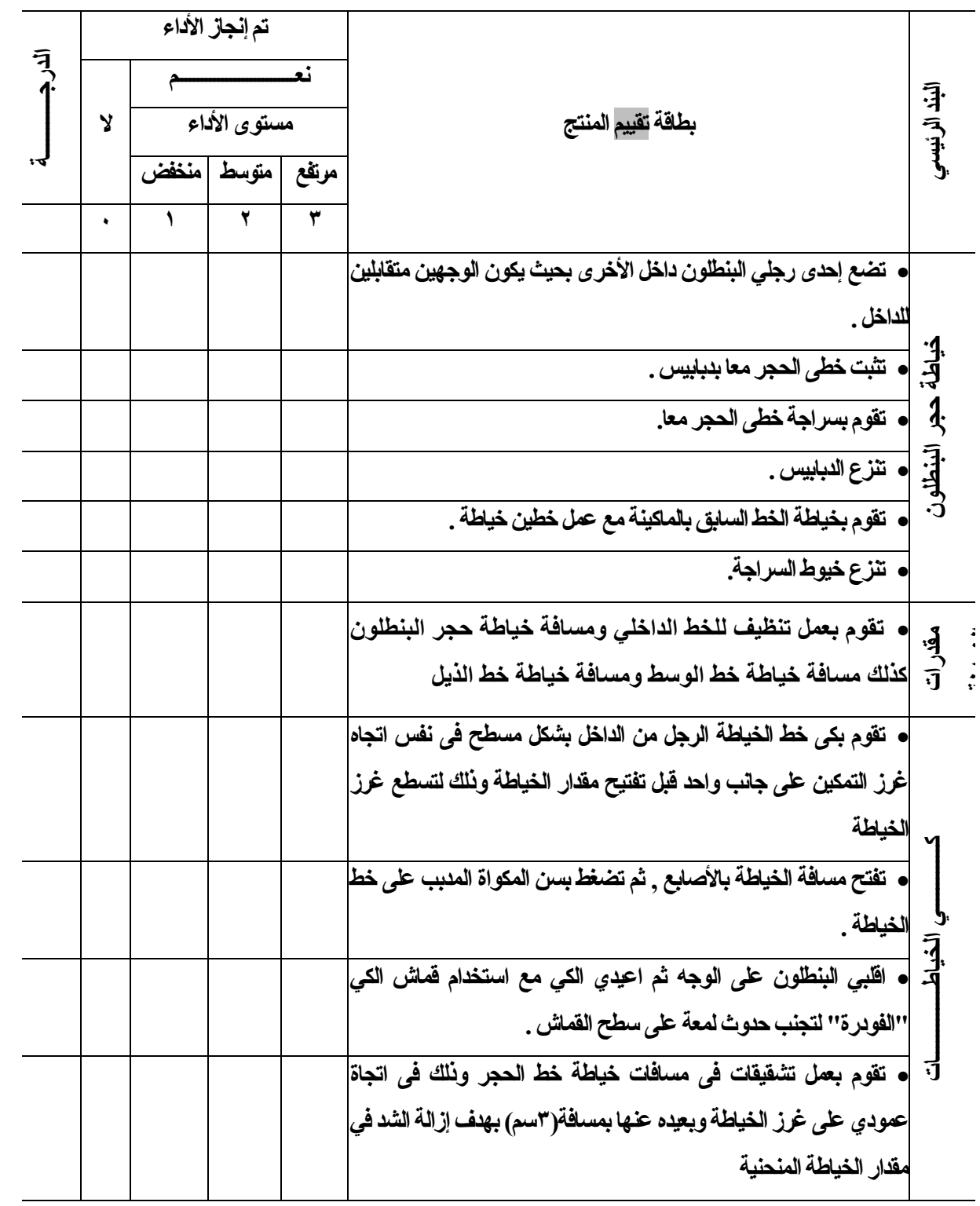




$$
\text { مجلة الاقتصاد المنزلي ـ مجلد V V - العدد الأول _ V • P م }
$$

\begin{tabular}{|c|c|c|c|c|c|c|}
\hline & \multicolumn{4}{|c|}{ تم إنجاز الأداء } & \multirow{4}{*}{ بطاقة تقييم المنتج } & \\
\hline & \multirow[t]{2}{*}{ ע } & \multicolumn{3}{|c|}{ مستوى الأداء } & & \\
\hline 8 & & | منفضض & | متوسط & مرتقع & & \\
\hline & $\cdot$ & 1 & r & $r$ & & \\
\hline & & & & & • تقوم بكى خط الحجر بشكل مسطح. & \\
\hline & & & & & • تضع خط الحجر فوق وسادة الكي ذات الثكل المنتفخ ثُم تقوم بالكي & \\
\hline & & & & & "القوبرة . تقب البنطلن على الوجة وتعيد الكي مع استخدام قملش الكي & - \\
\hline & & & & & • تشي •. • سم من مسافة خياطة خط الوسط للاخل ثم تقوم بلكي & \\
\hline & & & & & • تثني ๑. اسم مرة أخرى للاخل بحيث تكون ثية داخل شية & \\
\hline & & & & & • • تقوم بسراجة التكة على خط ه. اسم & \\
\hline & & & & & • تقوم بخياطة الخط السابق بلماكينة مع ترك ه. بسم لإنخال الأستيك & \\
\hline & & & & & • تقوم بالخال الأستك داخل التكة. & $\cdot 1$ \\
\hline & & & & & • ت تقوم بخياطة طرفي الأستك معا يصبحوا على شكل دائرة. & \\
\hline & & & & & • تقوم بخياطة الجزء المتروك ه. بسم مرة اخرى بالماكينة. & \\
\hline & & & & & 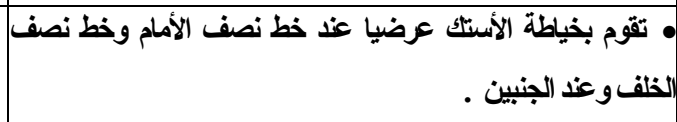 & \\
\hline & & & & & • تثي 1 سم من مقار خياطة خط النيل للاخل . & \\
\hline & & & & & • تثي ؛ سم المتبقية للاخل بحيث تكون شية داخل ثية. & \\
\hline & & & & & • تقوم بسراجة تشية النيل . & \\
\hline & & & & & 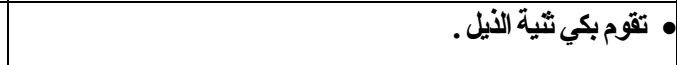 & • 呞 \\
\hline & & & & & • تقوم بخياطة شية النيل بالمكينة. & \\
\hline & & & & & • تقوم بكي البنطلون جيدا باستخدام فوبرة مبللة . & \\
\hline
\end{tabular}




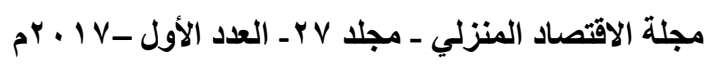

\begin{abstract}
:
The current research aims at detecting the impact of the use of support levels in ubiquitous learning in the development of atrainment and the trouser-product assessment card of students in the home economy. Which included the problem, objectives, approach, procedures and terms of the research, as well as a brief presentation of the results and its interpretation and recommendations and proposals of the current research, and The researcher relied on the descriptive approach in the preparation of research tools, and the experimental approach in the implementation of all the procedures of the research experiment and to verify the validity or incorrectness of the research hypotheses by the researcher, the model Mohammed Khamis (2015 And the search sample consisted of 128 students, a random sample of 48 students was selected in the pilot experiment, and the basic experiment was carried out on 80 students, divided into two groups of 40 students each, and the search tool was made for students consisting of A atrainment test, a card to evaluate the product, the researcher applied the appropriate statistical processing methods using the program (SPSS), and The researcher reached results that proved the effect of support levels (brief-medium) on the remote measurement of the achievement test in students of home economics, and this effect was in favor of the experimental group for the level of support medium and then the experimental group for the level of support brief, as The results demonstrated an effect on the dimension measurement of the product evaluation card for home economics students, which was in favour of the intermediate support level pilot group and then for the brief support level trial group.
\end{abstract}

Keywords: Ubiquitous e-learning, Support, Atrainment, Product assessment card. 